\title{
Climate engineering by mimicking natural dust climate control: the iron salt aerosol method
}

\author{
Franz Dietrich Oeste ${ }^{1}$, Renaud de Richter ${ }^{2}$, Tingzhen Ming ${ }^{3}$, and Sylvain Caillol ${ }^{2}$ \\ ${ }^{1} \mathrm{gM}$-Ingenieurbüro, Tannenweg 2, 35274 Kirchhain, Germany \\ ${ }^{2}$ Institut Charles Gerhardt Montpellier - UMR5253 CNRS-UM2 - ENSCM-UM1 - Ecole Nationale \\ Supérieure de Chimie de Montpellier, 8 rue de l'Ecole Normale, 34296 Montpellier CEDEX 5, France \\ ${ }^{3}$ School of Civil Engineering and Architecture, Wuhan University of Technology, No. 122, Luoshi Road, \\ Hongshan District, Wuhan, 430070, China \\ Correspondence to: Franz Dietrich Oeste (oeste@gm-ingenieurbuero.com)
}

\begin{abstract}
Received: 8 August 2016 - Published in Earth Syst. Dynam. Discuss.: 10 August 2016
Revised: 10 December 2016 - Accepted: 12 December 2016 - Published: 13 January 2017
\end{abstract}

\begin{abstract}
Power stations, ships and air traffic are among the most potent greenhouse gas emitters and are primarily responsible for global warming. Iron salt aerosols (ISAs), composed partly of iron and chloride, exert a cooling effect on climate in several ways. This article aims firstly to examine all direct and indirect natural climate cooling mechanisms driven by ISA tropospheric aerosol particles, showing their cooperation and interaction within the different environmental compartments. Secondly, it looks at a proposal to enhance the cooling effects of ISA in order to reach the optimistic target of the Paris climate agreement to limit the global temperature increase between 1.5 and $2{ }^{\circ} \mathrm{C}$.

Mineral dust played an important role during the glacial periods; by using mineral dust as a natural analogue tool and by mimicking the same method used in nature, the proposed ISA method might be able to reduce and stop climate warming. The first estimations made in this article show that by doubling the current natural iron

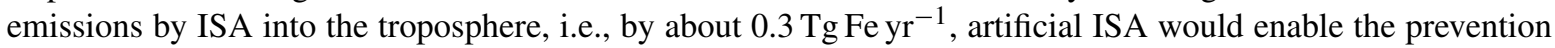
or even reversal of global warming. The ISA method proposed integrates technical and economically feasible tools.
\end{abstract}

\section{Introduction}

The 5th Assessment Report of the Intergovernmental Panel on Climate Change (IPPC), released in November 2014, states that global warming (GW) has already begun to dramatically change continental and marine ecosystems.

A recently noticed effect is that the vertical mixing in oceans decreases and even reaches a stagnation point (de Lavergne et al., 2014), thus weakening the net oceanic cumulative intake of atmospheric $\mathrm{CO}_{2}$ (Bernardello et al., 2014a, b).

A consequence of decreasing vertical ocean mixing is a reduced or interrupted oxygen supply to the depths of the ocean. Currently, the formation of low-oxygen areas in the oceans is increasing (Capone and Hutchins, 2013; Kalvelage et al., 2013). Furthermore, climate warming entails stratifica- tion of the water column and blocks vertical flows. Stratification may develop by warming the upper water layer as well as by evaporation and precipitation. Generation of a freshwater layer on top of the water column by precipitation, surface water runoff and meltwater inflow induces stratification (Hansen et al., 2016; van Helmond et al., 2015). Even the opposite, brine generation by evaporation may, induce stratification (Friedrich et al., 2008). Stratification blocks the oxygen transfer through the water column and triggers the formation of oxygen-depleted zones (Voss et al., 2013) that also emit nitrous oxide $\left(\mathrm{N}_{2} \mathrm{O}\right)$, a potent greenhouse gas $(\mathrm{GHG})$ and a powerful ozone-depleting agent.

As iron is part of many enzymes directing the bioenergetic transformation of nitrogen in the ocean, it has an additional direct influence on the cycling of these elements through 
the oceanic environment (Klotz and Stein, 2008; Simon and Klotz, 2013).

The severest consequence for oceanic ecosystems of such stratification is the development of anoxic milieus within stratified ocean basins. An example of the development of halocline and chemocline stratification is the Black Sea (Eckert et al., 2013). This ocean basin has a stable halocline which coincides with a chemocline, dividing an oxic salt-poor surface water layer from a saline anoxic sulfidic deep layer with a black sapropel sediment rich in organic $\mathrm{C}$ at the basin bottom (Eckert et al., 2013).

Geological past episodes with stratified ocean basins are regularly marked by black shale or black limestone as remnants of sapropel sediments. Stratified ocean basins during the Phanerozoic epoch occurred as a consequence of elevated $\mathrm{CO}_{2}$ levels in the atmosphere. This caused high sea surface temperatures (Meyers, 2014) and, as a global consequence, a global increase in evaporation, precipitation and production of brines of higher concentrations.

It has been pointed out that the increasing meltwater runoff from past polar and subpolar ice layers may have induced the cover of denser ocean water by a meltwater layer (Hansen et al., 2016). According to Praetorius et al. (2015), climate warming events during the last deglacial transition induced subsurface oxygen minimum zones accompanied by sea floor anoxia in the northern Pacific. This meltwater-induced stratification was accompanied by meltwater iron-induced phytoplankton blooms. The generation of increasing precipitation and surface water runoff accompanied by increasing brine production plus elevated surface water temperatures during hot high- $\mathrm{CO}_{2}$ climate episodes had similar consequences in past geological epochs (Meyers, 2014).

Ocean basin stratifications may be induced by increasing precipitation with increased surface water runoff (van Helmond et al., 2015) or by increased brine production (Friedrich et al., 2008). Such an ocean stratification event is characterized by regional to global ocean anoxia, black sediments with elevated organic $\mathrm{C}$ and a hot greenhouse climate, as we can see from the whole Phanerozoic past (Meyers, 2014), and was often accompanied by mass extinctions.

Even the largest mass extinction of ocean biota within the Phanerozoic epoch, during the Permian-Triassic transition, was induced by high temperatures as a consequence of elevated $\mathrm{CO}_{2}$ levels, which induced the change from a wellmixed oxic to a stratified euxinic-anoxic ocean (Kaiho et al., 2016).

What we have to face now is the extraordinary process developing from the recent situation: the combination of the $\mathrm{CO}_{2}$-dependent temperature-rise-generated precipitation increase, plus a meltwater increase. Mankind has to now find the appropriate tool to stop this dangerous stratification process.

Warming surface waters and a decreasing input of cold, oxygenated surface water trigger a temperature rise in sediments, transforming solid methane hydrate into gaseous methane $\left(\mathrm{CH}_{4}\right)$ emissions in seawater (Phrampus et al., 2014). $\mathrm{CH}_{4}$ oxidation consumes additional oxygen, decreasing the oxygen content above those areas (Yamamoto et al., 2014).

The same effects are expected with an anticipated increase in spring and summer coastal upwelling intensity, associated with increases in the rate of offshore advection, decreasing the nutrient supply while producing a spatial or temporal (phenological) mismatch between production and consumption in the world's most productive marine ecosystems (Bakun et al., 2015).

These events have the threatening consequence of a widespread lack of oxygen in the oceans. In such low-oxygen areas (sub-oxic to anoxic) only bacterial life is possible: higher life forms cannot exist there. Accordingly, an early result of the progression of climate warming could lead to a dramatic limitation of the oceanic food sources that will be needed for the projected 9-10 billion people by 2050 . The same deleterious consequences for seafood supply can also result from ocean surface acidification through increased $\mathrm{CO}_{2}$ dissolution in seawater and a decreased flow of surface water currents to ocean basin bottoms, limiting reef fish and shelled mollusk survival (Branch et al., 2013).

Any decrease in the thermohaline circulation (THC) has severe consequences for all kinds of ecosystems as it further triggers climate warming by different interactions. THC decrease induces a reduction in or eventual disappearance of the phytoplankton fertilizers $\mathrm{Si}, \mathrm{P}, \mathrm{N}$ and Fe extracted on the ocean surface from their sources at the bottom of the ocean basins. Hydrothermal fluid cycling by mid-ocean ridges, offaxis hydrothermal fluid fluxes, subduction-dependent hydrothermal convection fluids, hydrothermal fluxes at hot spot sea mounts and fluid emissions from anaerobic sediments contain said elements as dissolved or colloidal phase (Dick et al., 2013; Hawkes et al., 2013; Holm and Neubeck, 2009; Martin and Russell, 2007; Orcutt et al., 2011; Postec et al., 2015; Resing et al., 2015; Sousa et al., 2013). The deeper water of all ocean basins is enriched by these fertilizers. A THC decrease within the ocean basins will result in a decrease in the assimilative transformation of $\mathrm{CO}_{2}$ into organic carbon.

Moreover, any THC decrease would further trigger the acidification of the ocean surface by lowering or preventing the neutralization of dissolved $\mathrm{CO}_{2}$ and $\mathrm{HCO}_{3}^{-}$due to the alkalinity decrease from hydrothermal sources (Monnin et al., 2014; Orcutt et al., 2011).

During the convective water flow through the huge alkaline ocean crust volume, estimated to be about 20$540 \times 10^{3} \mathrm{~km}^{3} \mathrm{yr}^{-1}$ (Nielsen et al., 2006), ocean water is depleted in $\mathrm{O}_{2}$ but enriched in its reductant content such as $\mathrm{CH}_{4}$ (Kawagucci et al., 2011; Orcutt et al., 2011). Other elements are enriched in this convective water flow through the Earth crust, essential for the existence of life. The reoxygenation of this huge water volume is retarded or even impossible with a minimized THC. 
According to model calculations (Watson et al., 2015), the THC might have significantly changed between the last glacial and interglacial periods. During the Cenozoic epoch, ice-covered pole caps limited the incorporation of carbon in the form of carbonate into the oceanic crust compared to the warm late Mesozoic period (Coogan and Gillis, 2013). The findings of Coogan and Gillis (2013) show that during ice-free periods, THCs were possible with much higher effectiveness than in modern times. Even during those warm periods with low temperature gradients between polar and equatorial oceans, an effective production of brines leading to buoyancy differences necessary for the development of effective THC may have ben generated (Otto-Bliesner et al., 2002). However, increased inflow rates of high-density brines coming from shallow shelf regions with high evaporation rates induced several collapses or vertical reductions of the strong Cretaceous THC. From here and for more than a million years, the lower parts of ocean basins have been filled with anoxic brines (Friedrich et al., 2008). Further aspects of ocean stratification are discussed in Sect. 4.1.

Remnants of these anoxic events are black shale sediments (Takashima et al., 2006). During such THC collapses, the uptake of $\mathrm{CO}_{2}$ into the oceanic crust stayed restricted to organic carbon sediments. Additionally, the organic carbon productivity of the remaining oxic zone was decreased, as was eolic dust input, due to phytoplankton fertilizer production being limited to continental weathering.

These examples point out the sensitivity of the THC to disturbances. Without action, the weakness of our recent THC may worsen. Any THC collapse would not only result in severe damages to ecosystems, food chains and food resources of the oceans but would also lead to an acceleration of the increase in atmospheric $\mathrm{CO}_{2}$ concentration, resulting in faster climate warming than forecasted.

The best way to prevent such worrying situations and consequences is to stop GW.

A realistic chance of averting this development is the controlled application of a climate cooling process, used several times by nature throughout the last ice ages with high efficiency and based on loess dust. Loess is a windblown dust sediment formed by progressive accumulation and composed generally of clay, sand and silt (approximately at a ratio of $20: 40: 40$, respectively), loosely cemented by calcium carbonate.

The dust concentration in the troposphere increased during every cold period in ice ages and reached a multiple of today's levels (Martínez-Garcia et al., 2011). Dust deposition in the Southern Ocean during glacial periods was 3 to 10 times greater than during interglacial periods, and its major source region was probably Australia or New Zealand (Lamy et al., 2014). The windblown dust and its iron content effect on marine productivity in the Southern Ocean is thought to be a key determinant of atmospheric $\mathrm{CO}_{2}$ concentrations (Maher and Dennis, 2001). During high dust level periods, the global average temperature fell to $10^{\circ} \mathrm{C}$ (Lamy et al., 2014; Martin, 1990; Martínez-Garcia et al., 2011), which is $4.5^{\circ} \mathrm{C}$ lower than the current global average temperature. Loess sediments in the Northern and Southern Hemisphere on continents and ocean floors originate from these cold dusty periods.

Former geoscientists had the predominant conception that the cold glacial temperatures had caused dustiness, and not the reverse (Maher et al., 2010). Meanwhile, more evidence has accumulated that mineral dust was a main factor in the cause of the cold periods and that the iron $(\mathrm{Fe})$ fraction of windblown dust aerosol fertilized the oceans' phytoplankton, activating the assimilative conversion of $\mathrm{CO}_{2}$ into organic carbon (Anderson et al., 2014; Lamy et al., 2014; Maher et al., 2010; Martin, 1990; Martínez-García et al., 2014; Ziegler et al., 2013) and carbonate, which composes the main dry-body substance of phytoplankton, together with silica, another component of dust (Tréguer and Pondaven, 2000).

Evidence regarding the role of iron-containing dust in triggering ice ages during the late Paleozoic epoch is currently being discussed (Sur et al., 2015).

The biogeochemical cycles of carbon, nitrogen, oxygen, phosphorus, sulfur and water are well described in the literature, but the biogeochemical cycle of the Earth's iron is often overlooked. An overview of the progress made in the understanding of the iron cycle in the ocean is given by several authors (Breitbarth et al., 2010; Raiswell and Canfield, 2012).

The current state of knowledge of iron in the oceans is lower than that of carbon, although numerous scientific publications deal with this topic (Archer and Johnson, 2000; Boyd and Ellwood, 2010; Johnson et al., 2002a, b; Misumi et al., 2014; Moore and Braucher, 2008; Moore et al., 2013; Tagliabue et al., 2015; Turner and Hunter, 2001); however, the iron biogeochemical cycle in the atmosphere is described by fewer authors (Mahowald et al., 2005, 2009, 2010). This is in contrast to the iron biogeochemical cycle in soil and land, as almost no recent publications details the current knowledge about iron in soils and over the landscape (Anderson, 1982; Lindsay and Schwab, 1982; Mengel and Geurtzen, 1986), a task we attempt in this review.

The process of iron fertilization by the injection of an iron salt solution into the ocean surface has already been discussed as an engineering scheme proposed to mitigate global warming (Smetacek and Naqvi, 2008). But iron fertilization experiments with $\mathrm{FeSO}_{4}$ conducted over $300 \mathrm{~km}^{2}$ in the subantarctic Atlantic Ocean, although doubling primary productivity of chlorophyll a, did not enhance downdraft particles' flux into the deep ocean (Martin et al., 2013). The researchers who carried out this work attribute the lack of fertilizationinduced export into the deep ocean to the limitation of silicon needed for diatoms. Thus, ocean fertilization using only iron can increase the uptake of $\mathrm{CO}_{2}$ across the sea surface, but most of this uptake is transient and will probably not lead to long-term sequestration (Williamson et al., 2012). In other experiments, the authors (Smetacek et al., 2012) find 
that iron-fertilized diatom blooms may sequester carbon for centuries in ocean bottom water, and for longer in the sediments, as up to half the diatom bloom biomass sank below $1 \mathrm{~km}$ depth and reached the sea floor. Meanwhile, dissolution of olivine, a magnesium-iron-silicate-containing silica, with a $\mathrm{Mg}:$ Fe ratio of nearly $9: 1$, resulted in $35 \%$ marine carbon uptake (with the hypothesis of $1 \%$ of the iron dissolved and biologically available), with communities of diatoms being one of the phytoplankton winners (Köhler et al., 2015).

The idea of climate cooling by $\mathrm{CO}_{2}$ carbon conversion into organic sediment carbon by the addition and mixture of an iron salt solution into the ocean with a marine screw propeller has been the subject of controversial debates (Boyd and Bressac, 2016; Chisholm et al., 2002; Johnson and Karl, 2002). The eolic iron input per square meter of ocean surface by natural iron salt aerosol (ISA) is on the order of tens of milligrams of Fe per square meter per year. In comparison, the artificial Fe input by ship screws is several orders of magnitude above the natural fertilization with ISA.

The small content of water-soluble iron salts (ISs) in the dust particles triggers this fertilization effect (Duggen et al., 2007), and the soluble-iron deposition during glaciations had been up to 10 times the modern deposition (Conway et al., 2015). According to Spolaor et al. (2013), most of the bioavailable water-soluble Fe(II) has been linked, during the last 55000 years, to the fine dust fraction, as has been demonstrated from ice cores from Antarctica. Glacialstage dust fluxes of $\sim 400$ to 4000 times those of interglacial times have been found from late Paleozoic epochs (Soreghan et al., 2014), which gives an estimated carbon fixation $\sim 2-$ 20 times that of modern carbon fixation due to dust fertilization. Photochemistry by sunshine is the main trigger of the transformation of the primary insoluble-iron fraction of dust aerosols into soluble iron salts (Johnson and Meskhidze, 2013), and the understanding of how the different iron content and speciation in aerosols affect the climate is growing (Al-Abadleh, 2015). Currently, increased subglacial meltwater and icebergs may supply large amounts of bioavailable iron to the Southern Ocean (Death et al., 2014). The flux of bioavailable iron associated with glacial runoff is estimated at $0.40-2.54 \mathrm{Tg} \mathrm{yr}^{-1}$ in Greenland and 0.06-0.17 $\mathrm{Tg} \mathrm{yr}^{-1}$ in Antarctica (Hawkings et al., 2014), values which are comparable with eolian dust fluxes to the oceans surrounding Antarctica and Greenland and will increase by enhanced melting in a warming climate.

However, $\mathrm{CO}_{2}$ uptake by the oceans is not the only effect of iron dust. The full carbon cycle is well described in the literature; at the same time, we know less about the iron biogeochemical cycle. Recently, the major role of soluble-iron emissions from combustion sources has become more evident. Today, the anthropogenic combustion emissions play a significant role in the atmospheric input of soluble iron to the ocean surface (Sedwick et al., 2007). Combustion processes currently contribute from 20 to $100 \%$ of the soluble-iron deposition over many ocean regions (Luo et al., 2008). Model results suggest that human activities contribute to about half of the soluble-Fe supply to a significant portion of the oceans in the Northern Hemisphere (Ito and Shi, 2016) and that deposition of soluble iron from combustion sources contributes more than $40 \%$ of the total soluble-iron deposition over significant portions of the open ocean in the Southern Hemisphere (Ito, 2015). Anthropogenic aerosol associated with coal burning is maybe the major bioavailable iron source in the surface water of the oceanic regions (Lin et al., 2015). The Fe emission from coal combustion, higher than previously estimated, implies a larger atmospheric anthropogenic input of soluble Fe to the northern Atlantic and northern $\mathrm{Pa}$ cific Oceans, which is expected to enhance the biological carbon pump in those regions (Wang et al., 2015b).

The limited knowledge about dissolved or even dispersed iron distributions in the ocean confirms the work of Tagliabue et al. (2015): their calculation results of the residence time of iron in the ocean differ by up to 3 orders of magnitude from the different published models.

The precipitation of any iron salt results from the $\mathrm{pH}$ and $\mathrm{O}_{2}$ content of the ocean water milieu. But the presence of organic Fe chelators such as humic or fulvic acids (Misumi et al., 2014) as well as complexing agents produced by microbes (Boyd and Ellwood, 2010) and phytoplankton (Shaked and Lis, 2012) life forms prevents iron from precipitation. In principle, this allow the transport of iron, from its sources, to any place within the ocean across huge distances with the ocean currents (Resing et al., 2015). But organic material and humic acids have a limited lifetime in oxic environments due to their depletion to $\mathrm{CO}_{2}$. But within stratified anoxic ocean basins, their lifetime is unlimited.

The iron inputs into the ocean regions occur by atmospheric dust, coastal and shallow sediments, sea ice, icebergs, and hydrothermal fluids and deep-ocean sediments (Boyd and Ellwood, 2010; Elrod et al., 2004; Johnson et al., 1999; Mahowald et al., 2005, 2009; Moore and Braucher, 2008; Raiswell et al., 2016; Wang et al., 2015b).

Microbial life within the gradient of chemoclines dividing anoxic from oxic conditions generates organic carbon from $\mathrm{CO}_{2}$ or $\mathrm{HCO}_{3}^{-}$carbon (Borch et al., 2009; Schmidt et al., 2008; Sylvan et al., 2012). The activity at these chemoclines is the source of dissolved Fe(II). Humic acid is a main product of the food chain within any life habitat. Coastal, shelf and ocean bottom sediments, as well as hydrothermal vents and methane seeps, are such habitats and are known as iron sources (Boyd and Ellwood, 2010). Insoluble Fe oxides are part of the lithogenic particles suspended at the surface of the Southern Ocean. Along with organic phytoplankton substance, the suspended inorganics complete the gut passage of krill. During the gut passage of these animals, iron is reduced and leaves the gut in a dissolved state (Schmidt et al., 2016). There is no doubt that gut-microbial attack on ingested organics and inorganics produces faeces containing humic acids. This metabolic humic acid production is known from earth worm faeces (Muscolo et al., 2009) and human 
faeces (Reck et al., 2015; Wagner Mackenzie et al., 2015). The effect of iron mobilization from lithogenic particles by reduction during gut passage has been found in termites, too (Vu et al., 2004). The parallel generation of Fe-chelating humic acids during gut passage guarantees that the $\mathrm{Fe}$ is kept in solution after leaving the gut and entering the ocean. The examples demonstrate that every link of the ocean food chain may act as a source of dissolved iron.

The cogeneration of $\mathrm{Fe}(\mathrm{II})$ and Fe-chelating agents at any $\mathrm{Fe}$ sources at the bottom, surface and shelves of the oceans is the precondition of iron transport between source and phytoplankton at the ocean surface. But the transport between sources and the phytoplankton depends on the vertical and horizontal movement in the ocean basins (Misumi et al., 2014; Moore et al., 2013). Any movement between iron sources and the phytoplankton-rich surface in stratified ocean basins remains restricted to the surface, near $\mathrm{Fe}$ input from its sources (shelf sediments, meltwater, icebergs, rivers, surface water runoff and dust input).

During the glacial maxima the vertical movement reached an optimum. According to this, Fe transport from basin bottom sources and dust sources to the phytoplankton was at its maximum and produced a maximum primary productivity at the ocean surface, but carbon burial became lowest during that time (Lopes et al., 2015) although GHGs were at their lowest levels during the glacial maximum. The cause of this seeming contradiction are the changing burial ratios of organic $\mathrm{C}$ / carbonate $\mathrm{C}$ at the basin bottom(s). The burial ratio is high during episodes with a stratified water column, and it is very low during episodes with a vertically mixed water column, as we demonstrate in Sect. 4 in detail.

This review aims to describe the multistage chemistry of the iron cycle in the atmosphere, oceans, lands, sediments and ocean crust. This article is a comprehensive review of the evidence for connections between the carbon cycle and the iron cycle and their direct and indirect planetary cooling effects. Numerous factors influence the Fe cycle and the iron dissolution: iron speciation, photochemistry, biochemistry, redox chemistry, mineralogy and geology. In order to perform an accurate prediction of the impact of Fe-containing dusts, sea salt and acidic components, atmospheric chemistry models need to incorporate all relevant interaction compartments of the Fe cycle with sun radiation, chlorine, sulfur, nitrogen and water. This review advocates a balanced approach to benefit from the Fe cycle in order to fight global warming by enhancing natural processes of GHG depletion, albedo increase, carbon burial increase and de-stratification of the ocean basins.

\subsection{Breakdown of sections}

The next four sections describe nearly a dozen different climate cooling processes induced by ISAs and their interaction for modeling parameter development (Sects. 2-5). Then estimation of the requirements in terms of ISA to stop global warming will be given in Sect. 6 , followed by the description of a suggested ISA-enhanced method to fight global warming and induce planetary cooling in Sect. 7, and the possible risks of reducing acids and iron emissions in the future in Sect. 8. This is in turn followed by a general discussion and concluding remarks in Sects. 9 and 10. To our knowledge, this review completes, with atmosphere, solid and liquid surfaces at the surface of the globe, oceans, sediments and oceanic crust (Pérez-Guzmán et al., 2010), the previous ocean global iron cycle vision of Parekh (Parekh et al., 2004), Archer and Johnson (2000), Boyd and Ellwood (2010) and of many others. It advocates a balanced approach to make use of the iron cycle to fight global warming by enhancing natural processes.

\subsection{Components of the different natural cooling mechanisms by ISA}

The best known cooling process induced by ISA is the phytoplankton fertilizing stage described in the introduction. But this process is only part of a cascade of at least 12 climate cooling stages presented in this review. These stages are embedded within the coexisting multi-component complex networks of different reciprocal iron-induced interactions across the borders of atmosphere, surface ocean, sediment and igneous bedrock as well as across the borders of chemistry, biology and physics and across and along the borders of illuminated, dark, gaseous, liquid, solid, semi-solid, animated, unanimated, dead and different mix phase systems. Some impressions of the complexity of iron acting in the atmospheric environment have been presented by Al-Abadleh (2015).

The ISA-induced cooling effect begins in the atmosphere. Each of the negative forcing stages unfolds a climate-cooling potential for itself. Process stages 1-6 occur in the troposphere (Sect. 2), stage 6 at sunlit solid surfaces, stages 7-8 in the ocean (Sect. 3), and stages 9-12 in the oceanic sediment and ocean crust (Sect. 4). Other possible cooling stages over terrestrial landscapes and wetlands are described in Sect. 5. At least 12 stages of this cooling process cascade operate as described below.

\section{Tropospheric natural cooling effects of the iron cycle}

\subsection{ISA-induced cloud albedo increase}

ISA consists of iron-containing particles or droplets with a chloride content. Aerosols have significant effects on the climate (Forster et al., 2007). First, by direct scattering of radiation, and second, by inducing a cloud albedo increase. The latter effect is induced by cloud whitening and cloud lifetime elongation. Both effects induce a climate cooling effect by negative radiative forcing of more than $-1 \mathrm{~W} \mathrm{~m}^{-2}$.

Aerosols have a climate impact through aerosol-cloud interactions and aerosol-radiation interactions (Boucher, 2015). By reflecting sunlight radiation back to space, some 
types of aerosols increase the local albedo (which is the fraction of solar energy that is reflected back to space), producing a cooling effect (Bauer and Menon, 2012). If the top of clouds reflect back a part of the incident solar radiation received, the base of clouds receives the long-wave radiation emitted from the Earth surface and reemits part of it downward. Usually, the higher a cloud is in the atmosphere, the greater its effect on enhancing atmospheric greenhouse warming, and therefore the overall effect of high-altitude clouds, such as cirrus, is a positive forcing. Meanwhile, the net effect of low-altitude clouds (stratocumulus) is to cool the surface, as they are thicker and prevent more sunlight from reaching the surface. The overall effect of other types of clouds such as cumulonimbus is neutral: neither cooling nor warming.

More outgoing long-wave radiation is possible when the cirrus cover is reduced. Efficient ice nuclei (such as bismuth triiodide) seeding of cirrus cloud might artificially reduce their cover (Mitchell and Finnegan, 2009; Storelvmo et al., 2013).

In order to enhance the cooling effects of low-altitude clouds, marine cloud brightening has been proposed (Latham et al., 2012a), for instance by injecting sea-salt aerosols over the oceans. The effect depends on both particle size and injection amount, but a warming effect is possible (Alterskjær and Kristjánsson, 2013).

Aerosol effects on climate are complex because aerosols both reflect solar radiation to space and absorb solar radiation. In addition, atmospheric aerosols alter cloud properties and cloud cover depending on cloud type and geographical region (Koch and Del Genio, 2010). The overall effect of aerosols on solar radiation and clouds is negative (a cooling effect), which masks some of the GHG-induced warming. But some individual feedbacks and forcing agents (black carbon, organic carbon and dust) have positive forcing effects (a warming effect). For instance, brown clouds are formed over large Asian urban areas (Ramanathan et al., 2007) and have a warming effect. The forcing and feedback effects of aerosols have been clarified (Bauer and Menon, 2012) by separating direct, indirect, semi-direct and surface albedo effects due to aerosols.

Differing from any natural dust iron-containing mineral aerosol, the ISA aerosol does not contain any residual mineral components such as $\mathrm{Fe}_{2} \mathrm{O}_{3}$ minerals, known as strong radiation absorbers. Previous studies have shown that iron oxides are strong absorbers at visible wavelengths and that they can play a critical role in climate perturbation caused by dust aerosols (Sokolik and Toon, 1999; X. L. Zhang et al., 2015). As the primary ochre-colored aerosol particles emitted by the ISA (method I, see Sect. 7) have small diameters of $<0.05 \mu \mathrm{m}$ and are made of pure $\mathrm{FeOOH}$, they become easily and rapidly dissolved within the plume of acidic flue gas. The ISA FeOOH aerosol is emitted with the flue gas plumes generated in parallel and containing $\mathrm{SO}_{2}$ and $\mathrm{NO}_{x}$ as sulfuric and nitric acid generators. ISA stays within the troposphere for weeks before precipitating on the ocean or land surfaces. Due to their small diameter and high surface area, the aerosol particles will immediately react with $\mathrm{HCl}$, generated as a reaction product between sea-salt aerosol and the flue-gas-borne acids. The reaction product is an orangecolored $\mathrm{FeCl}_{3}$ aerosol: ISA. During daytime the sunlight radiation bleaches ISA into $\mathrm{FeCl}_{2}$ and $\cdot \mathrm{Cl}$; at night the reoxidation of ISA plus $\mathrm{HCl}$ absorption generates ISA again. The $\mathrm{FeCl}_{2}$ aerosol particles are colorless at low humidity and pale green during high-humidity episodes. The daytime bleaching effect reduces the radiation absorption of ISA to much lower levels compared to oxides such as $\mathrm{Fe}_{2} \mathrm{O}_{3}$.

Hygroscopic salt aerosols act as cloud condensation nuclei (CCN; Karydis et al., 2013; Levin et al., 2005). ISA particles are hygroscopic. High $\mathrm{CCN}$ particle concentrations have at least three different cooling effects (Rosenfeld and Freud, 2011; Rosenfeld et al., 2008). Each effect triggers the atmospheric cooling by a separate increase of earth reflectance (albedo) (Rosenfeld et al., 2014):

- cloud formation (even at low supersaturation);

- formation of very small cloud droplets, with an elevated number of droplets per volume, which causes elevated cloud whiteness;

- extending the lifetime of clouds, as the small cloud droplets cannot coagulate with each other to induce precipitation fall.

Figure 1 illustrates this albedo change due to ISA CCN particles.

Additional to climate cooling effects, $\mathrm{CCN}$-active aerosols might induce a weakening of tropical cyclones. The cooling potential of the ocean surface in regions of hurricane genesis and early development potential (Latham et al., 2012b) may be possible by cloud brightening. Further effects such as delayed development, weakened intensity, early dissipation and increased precipitation have been found (Y. Wang et al., 2014; H. Zhang et al., 2009).

\subsection{Oxidation of methane and other GHGs}

Currently, methane $\left(\mathrm{CH}_{4}\right)$ in the troposphere is destroyed mainly by the hydroxyl radical $\cdot \mathrm{OH}$.

Around 3 to $4 \% \mathrm{CH}_{4}\left(25 \mathrm{Tg} \mathrm{yr}^{-1}\right)$ (Allan et al., 2007; Graedel and Keene, 1996) are oxidized by $\cdot \mathrm{Cl}$ in the troposphere, and larger regional effects are predicted: up to 5.4 to $11.6 \% \mathrm{CH}_{4}$ (up to $75 \mathrm{Tg} \mathrm{yr}^{-1}$ ) in the Cape Verde region (Sommariva and von Glasow, 2012) and $\sim 10$ to $>20 \%$ of total boundary layer $\mathrm{CH}_{4}$ oxidation in other locations (Hossaini et al., 2016).

According to Blasing (Blasing, 2010, 2016; Forster et al., 2007), the increase in the $\mathrm{GHG} \mathrm{CH}_{4}$ since 1750 has induced a radiative forcing of about $+0.5 \mathrm{~W} \mathrm{~m}^{-2}$. The research results of Wittmer et al. (2015a, b, 2016) and Wittmer and 


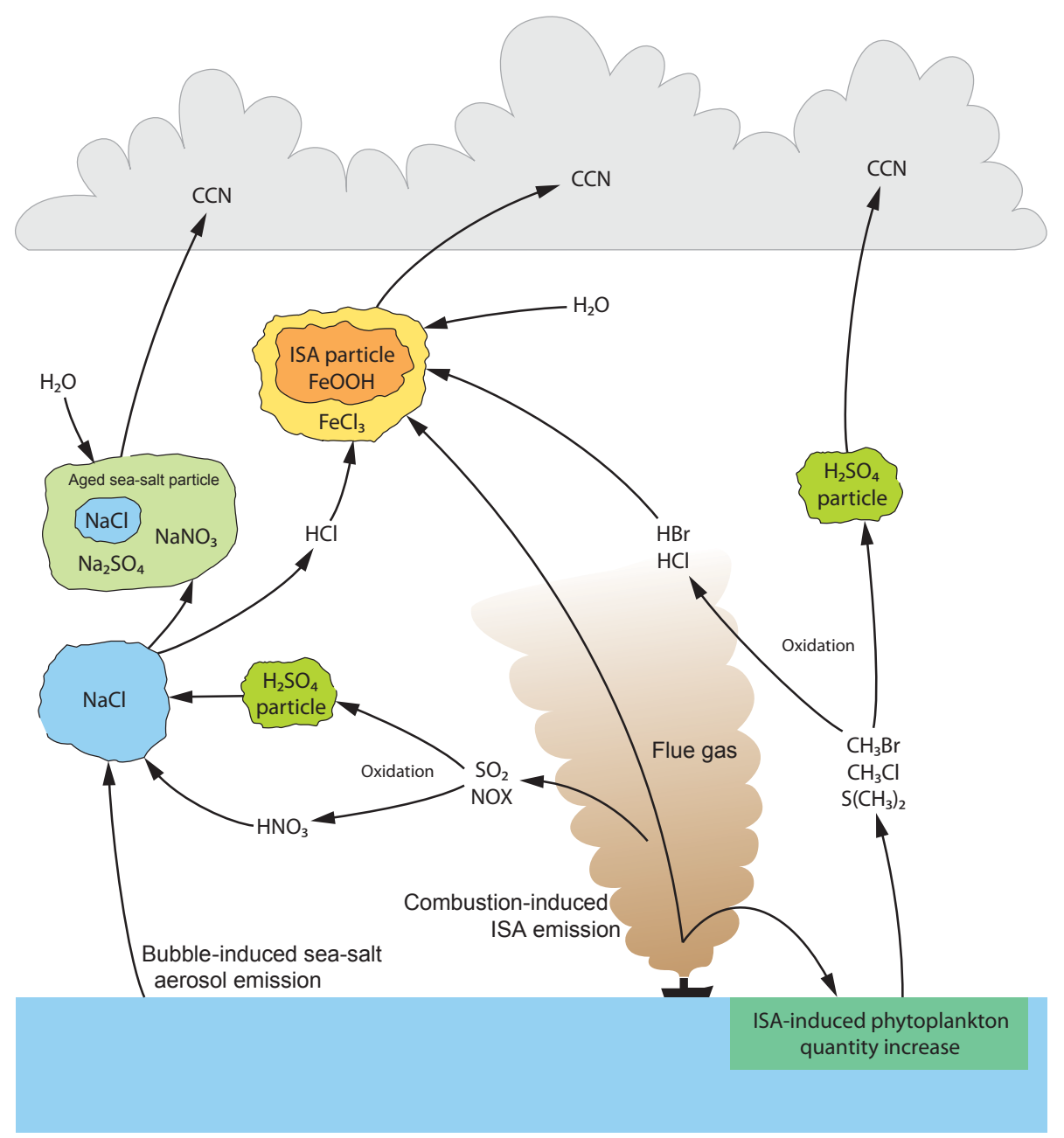

Figure 1. Process of tropospheric cooling by direct and indirect increasing of the quantity of different cloud condensation nuclei (CCN) inducing albedo increase by cloud formation at low supersaturation, cloud whitening and cloud life elongation.

Zetzsch (2016) demonstrated the possibility of significantly reducing the $\mathrm{CH}_{4}$ lifetime by the ISA method significantly. According to Anenberg et al. (2012) the health effects of the combination of increased $\mathrm{CH}_{4}$ and $\mathrm{NO}_{x}$-induced $\mathrm{O}_{3}$ levels with an increase in black carbon are responsible for tens of thousands of deaths worldwide.

Any increase in the $\cdot \mathrm{Cl}$ level will significant elevate the depletion rate of $\mathrm{CH}_{4}$ and volatile organic compounds (VOCs) as well as ozone $\left(\mathrm{O}_{3}\right)$ and dark carbon aerosol as described in Sects. 2.3 and 2.4.

Absorption of photons by semiconductor metal oxides can provide the energy to produce an electron-hole pair able to produce either a reduced or an oxidized compound. In suitable conditions, UV and visible light can reduce a variety of metal ions in different environments (Monico et al., 2015; Oster and Oster, 1959; Thakur et al., 2015). Photoreduced metal compounds may further act as effective chemical reductants (Ola and Maroto-Valer, 2015; Xu et al., 2015), and the oxidized compounds such as hydroxyl radicals or chlorine atoms can further act as effective oxidants. Zamaraev et al. (1994) proposed the decomposition of reducing atmospheric components such as $\mathrm{CH}_{4}$ by the photolytically induced oxidation power of the oxides of iron, titanium and some other metal oxide containing mineral dust components. Accordingly, Zamaraev designated the dustgenerating deserts of the globe as "kidneys of the earth" (Zamaraev, 1997) and the atmosphere as a "giant photocatalytic reactor" where numerous physicochemical and photochemical processes occur (Zamaraev et al., 1994). Researchers have proposed giant photocatalytic reactors to clean the atmosphere of several GHGs, such as $\mathrm{N}_{2} \mathrm{O}$ (de Richter et al., 2016b), CFCs and HCFCs (de Richter et al., 2016a) and even $\mathrm{CO}_{2}$ after direct air capture (Kiesgen de Richter et al., 2013), as almost all GHGs can be transformed or destroyed by photocatalysis (de Richter and Caillol, 2011; de Richter et al., 2017).

Oeste (2004) suggested and Wittmer et al. (2015a, b, 2016) and Wittmer and Zetzsch (2016) confirmed the emis- 


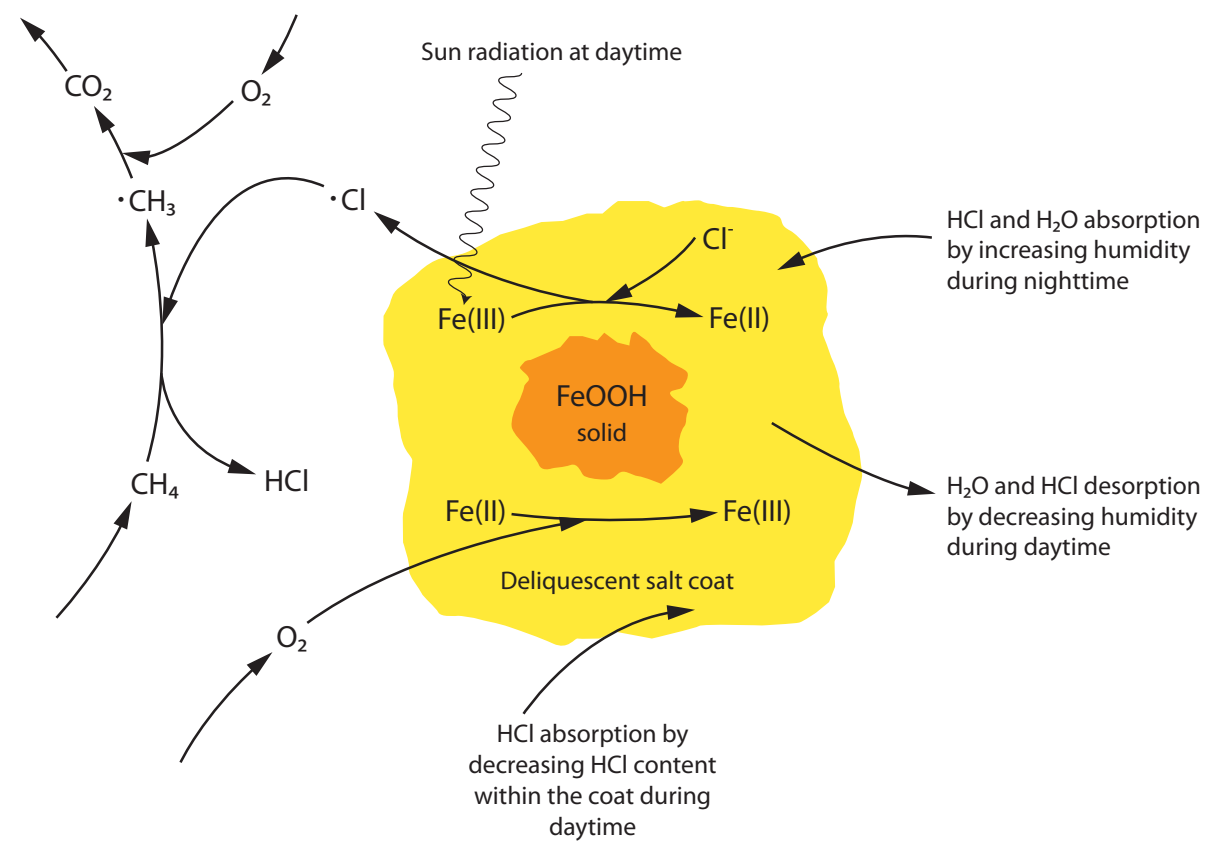

Figure 2. Simplified chemical reaction scheme of the generation of chlorine radicals by iron salt aerosols under sunlight radiation and the reaction of the chlorine radicals with atmospheric methane.

sion of $\mathrm{CH}_{4}$-depleting chlorine atoms. This can be induced in three ways: sunlight photoreduction of $\mathrm{Fe}(\mathrm{III})$ to $\mathrm{Fe}(\mathrm{II})$ from $\mathrm{FeCl}_{3}$ - or $\mathrm{FeOOH}$-containing salt pans, from $\mathrm{FeCl}_{3}$ - or $\mathrm{FeOOH}$-containing sea spray aerosols and from pure $\mathrm{FeOOH}$ aerosol in contact with air containing parts per billion by volume amounts of $\mathrm{HCl}$. Because the $\mathrm{H}$ abstraction from the $\mathrm{GHG} \mathrm{CH}_{4}$ as the first oxidation step by $\cdot \mathrm{Cl}$ is at least 16 times faster compared to the oxidation by $\cdot \mathrm{OH}$, which is the main $\mathrm{CH}_{4}$ oxidant acting in the ISA-free atmosphere, the concentration of $\mathrm{CH}_{4}$ can be significantly reduced by ISA emission. Figure 2 illustrates this climate cooling mechanism by the ISA method with a simplified chemical reaction scheme: a direct cooling of the troposphere by $\mathrm{CH}_{4}$ oxidation induced by ISA particles.

At droplet or particle diameters below $1 \mu \mathrm{m}$ (between 1 and $0.1 \mu \mathrm{m}$ ), contact or coagulation actions between the particles within aerosol clouds are retarded (Ardon-Dryer et al., 2015; Rosenfeld and Freud, 2011; Santachiara et al., 2012; Wang et al., 1978). Otherwise the aerosol lifetime would be too short to bridge any intercontinental distance or arrive in polar regions. This reduces the possible $\mathrm{Cl}^{-}$exchange by particle contact. But absorption of gaseous $\mathrm{HCl}$ by reactive iron oxide aerosols resulting in $\mathrm{Fe}(\mathrm{III})$ chloride formation at the particle surfaces is possible (Wittmer and Zetzsch, 2016). Gaseous $\mathrm{HCl}$ and other gaseous chloro-compounds are available in the troposphere: $\mathrm{HCl}$ (300 pptv above the oceans and 100 pptv above the continents) (Graedel and Keene, 1996), $\mathrm{ClNO}_{2}$ (up to $1500 \mathrm{pptv}$ near flue gas emitters) (Osthoff et al., 2008; Riedel et al., 2014) and $\mathrm{CH}_{3} \mathrm{Cl}$ (550 pptv, far from urban sources) (Khalil and Rasmussen, 1999; Yokouchi et al., 2000). By or after sorption and reactions such as photolysis, oxidation and reduction, any kind of these chlorine species can induce chloride condensation at the ISA particle surface. Acid tropospheric aerosols and gases such as $\mathrm{H}_{2} \mathrm{SO}_{4}, \mathrm{HNO}_{3}$, oxalic acid and weaker organic acids further induce the formation of gaseous $\mathrm{HCl}$ from sea-salt aerosol (Drozd et al., 2014; Kim and Park, 2012; Pechtl and von Glasow, 2007). Since 2004, evidence and proposals for possible catalyst-like sunshineinduced cooperative heterogeneous reaction between $\mathrm{Fe}(\mathrm{II})$, $\mathrm{Fe}(\mathrm{III}), \mathrm{Cl}^{-}, \cdot \mathrm{Cl}$ and $\mathrm{HCl}$ fixed on mineral dust particles and in the gaseous phase on the $\mathrm{CH}_{4}$ oxidation have been known (Oeste, 2004; Wittmer and Zetzsch, 2016). Further evidence of sunshine-induced catalytic cooperation of $\mathrm{Fe}$ and $\mathrm{Cl}$ came from the discovery of $\cdot \mathrm{Cl}$ production and $\mathrm{CH}_{4}$ depletion in volcanic eruption plumes (Baker et al., 2011; Rose et al., 2006). Wittmer and Zetzsch (2016) presented sunshineinduced $\cdot \mathrm{Cl}$ production by iron oxide aerosols in contact with gaseous $\mathrm{HCl}$ (Wittmer and Zetzsch, 2016). Further evidence comes from $\cdot \mathrm{Cl}$ found in tropospheric air masses above the South China Sea (Baker et al., 2015). It is known that the troposphere above the South China Sea is often in contact with Fe-containing mineral dust aerosols $\left(\sim 18 \mathrm{~g} \mathrm{~m}^{-2} \mathrm{yr}^{-1}\right)$ (Wang et al., 2012), which is further evidence that the Feoxide-containing mineral dust aerosol might be a source for the $\cdot \mathrm{Cl}$ content within this area.

$\mathrm{HCl}$, water content and $\mathrm{pH}$ within the surface layer of the aerosol particles depend on relative humidity. Both liquid contents, $\mathrm{H}_{2} \mathrm{O}$ and $\mathrm{HCl}$, grow with increasing humidity (von Glasow and Sander, 2001). In spite of growing $\mathrm{HCl}$ 
quantity with increasing humidity, $\mathrm{pH}$ increases, due to decreasing $\mathrm{HCl}$ concentration within the surface layer. Hence, since the radiation-induced $\cdot \mathrm{Cl}$ production decreases with decreasing $\mathrm{pH}$, the $\cdot \mathrm{Cl}$ emission decreases in humid conditions (Wittmer and Zetzsch, 2016). Under dry conditions, even sulfate may be fixed as solid Na-sulfate hydrates. Solubilized sulfate slightly inhibits the iron-induced $\cdot \mathrm{Cl}$ production (Bleicher et al., 2014).

Night or early morning humidity similarly produces the maximum chloride content on the liquid aerosol particle surface. During daytime, the humidity decrease induces ISA photolysis and $\mathrm{Cl}^{-}$conversion to $\cdot \mathrm{Cl}$ production by decreasing water content and $\mathrm{pH}$. The ISA particle surface layer reaches $\mathrm{Cl}^{-}$minima levels during afternoon hours. In the continental troposphere with a low sea-salt aerosol level, these effects enable the pure ISA iron oxide aerosol particles to coat their surface with chloride solution at night and to emit chlorine atoms in the daytime.

Freezing has different effects on the primary wet ISA particles. The frozen ice, which is changed to cloud droplets with solubilized chloride and iron content by CCN action, is covered by a mother liquor layer with an elevated concentration of both iron and chlorine when it arrives in freezing conditions. Some acids such as $\mathrm{HCl}$ do not decrease the mother liquor $\mathrm{pH}$ proportional to concentration, and the behavior of the ice surfaces, grown from low salt content water, is different from high salt content water; thus, the different kinds of ISA behave differently (Bartels-Rausch et al., 2014; Kahan et al., 2014; Wren and Donaldson, 2012). Direct measurements of molecular chlorine levels in the Arctic marine boundary layer in Barrow, Alaska, showed up to $400 \mathrm{pptv}$ levels of molecular chlorine (Liao et al., 2014). The $\mathrm{Cl}$ concentrations fell to near-zero levels at night but peaked in the early morning and late afternoon. Liao et al. (2014) estimated that the $\mathrm{Cl}$ radicals oxidized on average more $\mathrm{CH}_{4}$ than hydroxyl radicals and enhanced the abundance of short-lived peroxy radicals.

Further investigations have to prove how the different types of ISA particles behave at different temperatures in clouds below the freezing point or in the snow layer; these different types are the primary salt-poor Fe oxide, the poor hydrolyzed $\mathrm{FeCl}_{3}$ and the $\mathrm{FeCl}_{3}-\mathrm{NaCl}$ mixture because the - $\mathrm{Cl}$ emission depends on $\mathrm{pH}, \mathrm{Fe}$ and $\mathrm{Cl}$ concentration.

Additional to iron photolysis, in a different and daytimeindependent chemical reaction, iron catalyzes the formation of $\cdot \mathrm{Cl}$ or $\mathrm{Cl}_{2}$ from chloride by tropospheric ozone (Sadanaga et al., 2001). Triggering the $\mathrm{CH}_{4}$ decomposition, both kinds of iron and chlorine have a cooperative cooling effect on the

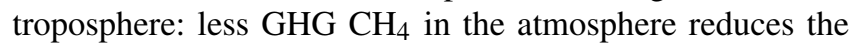
greenhouse $(\mathrm{GH})$ effect and allows more outgoing infrared (IR) heat to the outer space (Ming et al., 2014).

These reactions were active during the glacial period: Levine et al. (2011) found elevated ${ }^{13} \mathrm{CH}_{4} /{ }^{12} \mathrm{CH}_{4}$ isotope ratios in Antarctic ice core segments representing the coldest glacial periods. The unusual isotope ratio is explained by the
Table 1. The Henry's law constants (Sander, 2015) and daylight stability for different gaseous or vaporous components reacting with or produced by ISA in the troposphere.

\begin{tabular}{lrc}
\hline Substance & $\begin{array}{r}\text { Henry's law } \\
\text { constant } \\
\left(\mathrm{mol} \mathrm{m}^{-3} \mathrm{~Pa}^{-1}\right)\end{array}$ & $\begin{array}{r}\text { Stability against } \\
\text { tropospheric day- } \\
\text { light }(+ \text { stable; } \\
- \text { unstable })\end{array}$ \\
\hline $\mathrm{CH}_{4}$ & $1.4 \times 10^{-5}$ & + \\
$\cdot \mathrm{Cl}$ & $2.3 \times 10^{-2}$ & + \\
$\mathrm{Cl}_{2}$ & $9.2 \times 10^{-4}$ & - \\
$\mathrm{HCl}$ & $1.5 \times 10^{1}$ & + \\
$\mathrm{HOCl}$ & 6.5 & - \\
$\cdot \mathrm{OH}$ & $3.8 \times 10^{-1}$ & + \\
$\mathrm{H}_{2} \mathrm{O}_{2}$ & $8.3 \times 10^{2}$ & - \\
\hline
\end{tabular}

much greater $\cdot \mathrm{Cl}$ preference for ${ }^{12} \mathrm{CH}_{4}$ oxidation than ${ }^{13} \mathrm{CH}_{4}$ oxidation, which is greater than the preference of $\cdot \mathrm{OH}$. Additional evidence gives the decreased $\mathrm{CH}_{4}$ concentration during elevated loess dust emission epochs (Skinner, 2008).

As shown in more detail in Sect. 2.3, ISA produces $\cdot \mathrm{Cl}$ and much more hydrophilic $\cdot \mathrm{OH}$ and ferryl as other possible $\mathrm{CH}_{4}$ oxidants by Fenton and photo-Fenton processes (Al-Abadleh, 2015). To gain the optimal reaction conditions within the heterogeneous gaseous-liquid-solid phase ISA system in the troposphere, the $\mathrm{CH}_{4}$ reductant and the oxidant (Fenton and photo-Fenton oxidant) have to be directed in such a way that oxidant and reductant can act within the identical medium.

As seen in Table 1, according to the $\mathrm{CH}_{4}$ Henry's law constant the preference of the $1.8 \mathrm{ppm}$ tropospheric $\mathrm{CH}_{4}$ is undoubtedly the gaseous phase. $\cdot \mathrm{Cl}$ has also a preference for the gaseous phase.

Iron exists at least in part as $\mathrm{Fe}$ (III) during the nighttime and at least in part as $\mathrm{Fe}(\mathrm{II})$ during daytime. The $\mathrm{CH}_{4}$ oxidation by $\cdot \mathrm{Cl}$ and $\cdot \mathrm{OH}$ is restricted to the daytime as during night hours $\cdot \mathrm{Cl}$ and $\cdot \mathrm{OH}$ recombine fast to $\mathrm{Cl}_{2}, \mathrm{HOCl}$ and $\mathrm{H}_{2} \mathrm{O}_{2}$ in the dark (von Glasow, 2000). During daylight hours, these recombination products photolyze again by the regeneration of the radicals. But even during daytime these radicals and their recombination products coexist due to the cycling between $\cdot \mathrm{Cl}, \cdot \mathrm{OH}, \mathrm{Cl}_{2}, \mathrm{HOCl}$ and $\mathrm{H}_{2} \mathrm{O}_{2}$. This cycling is activated by sunlight photolysis and radical recombination reactions (Luna et al., 2006; von Glasow, 2000).

As we learn from the Henry's law constants in Table 1, the oxygen species $\cdot \mathrm{OH}$ and $\mathrm{H}_{2} \mathrm{O}_{2}$ have a much higher tendency to stay in the liquid phase than the chlorine species $\cdot \mathrm{Cl}$ and $\mathrm{Cl}_{2} \cdot \mathrm{Cl}_{2}$ has the tendency to react with water of neutral $\mathrm{pH}$ by producing $\mathrm{HOCl}$. But the $\mathrm{pH}$ values of ISA, especially if ISA is emitted as acid flue gas plumes, are lower than 3 . Within this acidic region the tendency of $\mathrm{HOCl}$ generation from $\mathrm{Cl}_{2}$ decreases to very low values, and even at those humidity levels at which the ISA particles become deliquescent, the ma- 
jority of the activated chlorine species will be localized in the gaseous phase containing $\mathrm{CH}_{4}$, not in the liquid phase.

But $\cdot \mathrm{OH}$ may leave the condensed phase in favorable circumstances and enter the gaseous phase (Nie et al., 2014) and may contribute there to the oxidation of $\mathrm{CH}_{4}$ during clear dry conditions without liquid phase at the $\mathrm{Fe}(\mathrm{III})$ surfaces.

Water-soluble ammonia $\left(5.9 \times 10^{-1}\right)$ has a similar Henry's law constant to $\cdot \mathrm{OH}$. Therefore, $\cdot \mathrm{OH}$ has the tendency to stay within hydrous phases during humid conditions. This tendency is 16 times lower for $\cdot \mathrm{Cl}$. This property is combined with the 16 times higher reactivity in comparison to $\cdot \mathrm{OH}$. At an equal production of $\cdot \mathrm{Cl}$ and $\cdot \mathrm{OH}$, the reaction of $\cdot \mathrm{Cl}$ with $\mathrm{CH}_{4}$ has a probability of up to 250 times $(16 \times 16)$ that of the reaction of $\cdot \mathrm{OH}$ with $\mathrm{CH}_{4}$ when the ISA particles are wet and 16 times that of $\cdot \mathrm{OH}$ with $\mathrm{CH}_{4}$ when the ISA particles are dry. The probability of $\mathrm{CH}_{4}$ oxidation by ISA-derived $\cdot \mathrm{Cl}$ against ISA-derived $\cdot \mathrm{OH}$ may be restricted by the $\mathrm{pH}$ increase tendency within ISA during humid episodes (decreased $\cdot \mathrm{Cl}$ generation on ISA with rising $\mathrm{pH})$ to values fluctuating between the extremes 1 and 250. Independently of the kind of oxidants produced by ISA - during dry, clear-sky and sunshine episodes - the ISA-derived oxidants produce maximum oxidant concentrations within the $\mathrm{CH}_{4}$-containing gaseous phase, producing optimum $\mathrm{CH}_{4}$ depletion rates.

The $\cdot \mathrm{Cl}$ reactivity on most VOCs other than $\mathrm{CH}_{4}$ is at least 1 order of magnitude higher than that of $\cdot \mathrm{OH}$ (Young et al., 2014). Halogen organics such as dichloromethane (Pena et al., 2014) as well as the environmentally persistent and bioaccumulating perfluoro organics such as perfluorooctane sulfonate may be depleted by sunlit ISA (Jin et al., 2014).

\subsection{Oxidation of organic aerosol particles containing black and brown carbon}

Black carbon in soot is the dominant absorber of visible solar radiation in the atmosphere (Ramanathan and Carmichael, 2008). Total global emission of black carbon is $7.5 \mathrm{Mt} \mathrm{yr}^{-1}$ (Bond et al., 2013). Direct atmospheric forcing of atmospheric black carbon is $+0.7 \mathrm{~W} \mathrm{~m}^{-2}$ (Bond et al., 2013). In addition to its climate relevance, black-carbon soot induces severe health effects (Anenberg et al., 2012).

Andreae and Gelencsér (2006) defined the differences between the carbons: black carbon contains insoluble elemental carbon; brown carbon contains at least partly soluble organic carbon. Black carbon also contains additional extractable organics of greater or lesser volatility and/or water solubility (Andreae and Gelencsér, 2006; Nguyen and Ball, 2006).

Black and brown carbonaceous aerosols have a positive radiative forcing (warming effect) on clouds (Ramana et al., 2010) as seen in Sect. 2.1 and also after deposition on snow, glaciers, sea ice or in the polar regions, as the albedo is reduced and the surface is darkened (Hadley and Kirchstetter, 2012). One of the most effective methods of slowing global warming rapidly in the short term is by reducing the emis- sions of fossil fuel particulate black carbon, organic matter and tropospheric ozone (Jacobson, 2002).

Both aerosol types have adverse effects on health (human, animal, livestock, vegetal), and reducing their levels will save lives and provide many benefits (Shindell et al., 2012). Thus, any tropospheric lifetime reduction in both dark carbons would lead to cooling effects and further positive effects.

Both carbons are characterized by aromatic functions. The black carbons contain graphene structures; the brown ones have low-molecular weight humic-like aromatic substances (HULISs). HULISs derive from tarry combustion smoke residues and/or from aged secondary organic aerosol (SOA). The sources of SOA are biogenic VOCs such as terpenes (Fry et al., 2014). HULISs contain polyphenolic redox mediators such as catechol and nitro-catechols (Claeys et al., 2012; Hoffer et al., 2004; Ofner et al., 2011; Pillar et al., 2014).

The polyphenolic HULIS compounds are ligands with a very strong bond with iron. Rainwater-dissolved HULISs prevent $\mathrm{Fe}$ (II) from oxidation and precipitation when mixing with seawater (Willey et al., 2008). Wood-smoke-derived HULIS nanoparticles penetrate into living cell walls of respiratory epithelia cells. After arrival in the cells the HULIS particles extract the cell iron from the mitochondria by formation of HULIS-iron complexes (Ghio et al., 2015).

Beside iron, other metals such as manganese and copper have oxygen transport properties which improve the oxidation power of $\mathrm{H}_{2} \mathrm{O}_{2}$ by Fenton reactions generating $\cdot \mathrm{OH}$ (Chemizmu and Fentona, 2009). $\mathrm{H}_{2} \mathrm{O}_{2}$ is a troposphereborne oxidant (Vione et al., 2003).

Polyphenolic and carboxylate ligands of HULIS enhance the dissolution of iron oxides. These ligands bind to undissolved iron oxides (Al-Abadleh, 2015).

Iron and catechols are both reversible electron shuttles:

$\mathrm{Fe}^{2+} \leftrightarrow \mathrm{Fe}^{3+}+e ;$

catechol $\leftrightarrow$ quinone $+2 e$.

The HULIS-iron connection enhances the oxidative degradation of organic compounds such as aromatic compounds (Al-Abadleh, 2015).

Oxidant generation by the reaction of oxidizable dissolved or undissolved metal cations such as $\mathrm{Fe}$ (II), $\mathrm{Cu}$ (I) and $\mathrm{Mn}$ (II) with $\mathrm{H}_{2} \mathrm{O}_{2}$ was first discovered for $\mathrm{Fe}$ (II) in 1894 (Fenton, 1894). Since then these reactions have been known as Fenton reactions. The mechanisms and generated oxidants of Fenton reactions are still under discussion.

Depending on the participating metal ligand oxidants such as $\cdot \mathrm{OH}, \mathrm{Fe}(\mathrm{IV}) \mathrm{O}^{2+}(=\mathrm{Ferryl}), \cdot \mathrm{Cl}, \cdot \mathrm{SO}_{4}^{-}$, organic peroxides and quinones may appear (Barbusiński, 2009).

According to Barbusinsky (2009) the primary reaction intermediate from $\mathrm{Fe}^{2+}$ and $\mathrm{H}_{2} \mathrm{O}_{2}$ is the adduct $\left\{\mathrm{Fe}(\mathrm{II}) \mathrm{H}_{2} \mathrm{O}_{2}\right\}^{2+}$, which is transformed into the ferryl complex $\left\{\mathrm{Fe}(\mathrm{IV})(\mathrm{OH})_{2}\right\}^{2+}$. The latter stabilizes as 


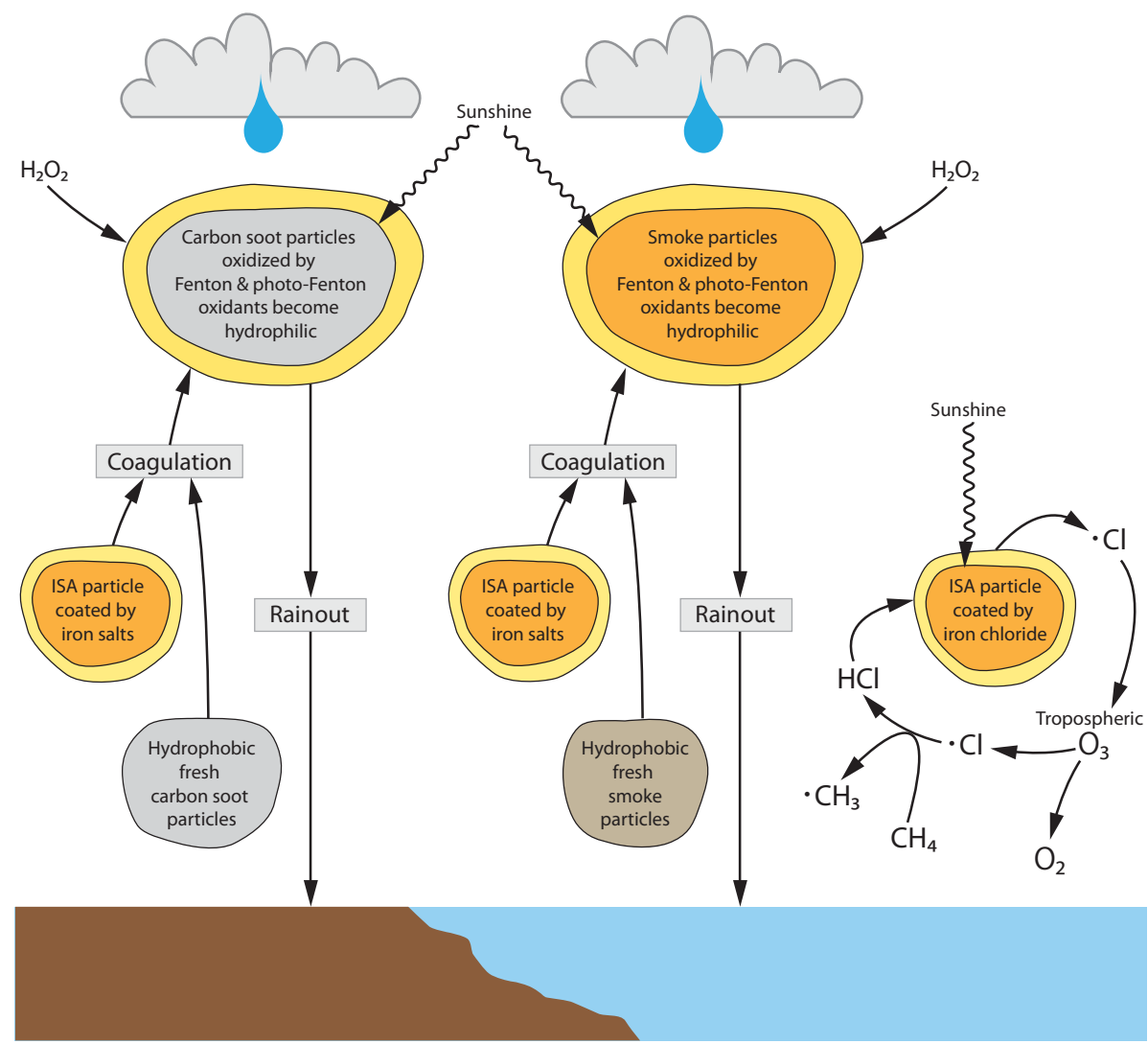

Figure 3. Schematic representation of the cooling of the troposphere by inducing the decrease in ozone and organic aerosol particles such as soot and smoke.

$\{\mathrm{Fe}(\mathrm{IV}) \mathrm{O}\}^{2+}+\mathrm{H}_{2} \mathrm{O}$. Reductants may also react directly with $\{\mathrm{Fe}(\mathrm{IV}) \mathrm{O}\}^{2+}$ or after its decomposition to $\mathrm{Fe}^{3+}+\cdot \mathrm{OH}+\mathrm{OH}-$ by $\cdot \mathrm{OH} . \mathrm{Fe}^{3+}$ reacts with $\mathrm{H}_{2} \mathrm{O}_{2}$ to $\mathrm{Fe}^{2+}$ via $\cdot \mathrm{O}_{2} \mathrm{H}$ development; the latter decays into $\mathrm{O}_{2}+\mathrm{H}_{2} \mathrm{O}$.

Light enhances the Fenton reaction effectiveness. It reduces $\mathrm{Fe}^{3+}$ to $\mathrm{Fe}^{2+}$ by photolysis inducing $\cdot \mathrm{OH}$ or $\cdot \mathrm{Cl}$ generation, the latter in the case of available $\mathrm{Cl}^{-}$, which reduces the $\mathrm{H}_{2} \mathrm{O}_{2}$ demand (Machulek Jr. et al., 2009; Southworth and Voelker, 2003).

This process is illustrated by Fig. 3 .

The Fenton reaction mechanism is dependent on $\mathrm{pH}$ and on the kinds of ligands bound to the Fenton metal. The reaction mechanism with oxidants of $\mathrm{SO}_{4}^{2-}, \mathrm{NO}_{3}^{-}, \mathrm{Cl}^{-}$and 1,2dihydroxy benzene ligands has been studied (De Laat et al., 2004).

In biological systems, 1,2-dihydroxy benzenes (catecholamines) regulate the Fenton reaction and orient it toward different reaction pathways (Salgado et al., 2013).

Additionally, the fractal reaction environments like surface-rich black and brown carbons and ISA have considerable influence on the Fenton reaction. By expanding the aqueous interface, accelerations of the reaction velocity up to 3 orders of magnitude has been measured (Enami et al., 2014). This may be one of the reasons why ironcontaining solid surfaces made of fractal iron oxides, pyrite, activated carbon, graphite, carbon nanotubes, vermiculite, pillared clays and zeolites have been tested as efficient Fenton reagents (Pignatello et al., 2006; Pinto et al., 2012; Teixeira et al., 2012).

Even the oxidation power of artificial Fenton and photoFenton systems is known to be high enough to hydroxylate aliphatic $\mathrm{C}-\mathrm{H}$ bonds, inclusing $\mathrm{CH}_{4}$ hydroxylation to methanol (Gopakumar et al., 2011; Hammond et al., 2012; Yoshizawa et al., 2000).

But the HULIS itself becomes depleted by the Fenton oxidation when it remains as the only reductant (Salgado et al., 2013).

Like HULIS or humic substances, the different kinds of black carbons act as redox mediators due to their oxygen functionalities bound to the aromatic hexagon network such as hydroxyl, carbonyl and ether (Klüpfel et al., 2014; Oh and Chiu, 2009). These functionalities similarly act as hydroquinone, quinone, aromatic ether, pyrylium and pyrone in the extended graphene planes as electron acceptors and donor moieties. Soot also possesses such redox mediator groups (Drushel and Hallum, 1958; Studebaker et al., 1956). Again these are ligands with well-known binding activity on iron 
compounds. The difference between them and the HULIS ligands is that the former are attached to stacks of aromatic graphene hexagon networks instead of mono- or oligo-cyclic aromatic hexagons of HULIS. As well as the HULIS redox mediator ligands these hydroxyl and ketone groups transfer electrons from oxidants to reductants and vice versa. Like the HULIS-iron pair, the black-carbon-iron pair enhances the redox mediation above the levels of every individual electron shuttle (Kim et al., 2013; Lima et al., 2013; L. Wang et al., 2014). Accordingly, any ISA doping of black carbons generates effective oxidation catalysts (Oeste, 1977; Song et al., 2015).

Lit by sunlight the ISA-doped soot represents an oxidation catalyst to adsorbed organics, producing its own oxidants by the photo-Fenton reaction. In spite of the higher chemical stability of the graphene network of soot compared to HULIS soot, by wet oxidation other oxygen groups are fixed to the soot graphene stacks (Moreno-Castilla et al., 2000) increasing soot's hydrophilic property, which is necessary to arrange its rainout. The hydroxyl radical attack resulting from the photo-Fenton reaction ultimately breaks the graphene network into parts (Bai et al., 2014; Zhou et al., 2012). PhotoFenton is much more efficient in $\cdot \mathrm{OH}$ generation than Fenton because $\mathrm{Fe}(\mathrm{III})$ reduction as a regeneration step occurs by $\mathrm{Fe}(\mathrm{III})$ photoreduction rather than consuming an organic reductant.

The oxidized hydrophilic carbon particles are more readily washed out of the atmosphere by precipitation (Zuberi et al., 2005). ISA accelerates this oxidation process as the iron-induced Fenton and photo-Fenton reaction cycles produce hydroxyl and chlorine radical oxidants, speeding up the soot oxidation.

$\mathrm{Fe}$ (III) forms colored complexes with hydroxyl and carboxylic hydroxyl groups too, particularly if two of them are in 1,2 or 1,3 position, such as in oxalic acid. The latter belong to the group of dicarboxylic acids known to be formed as oxidation products from all kind of volatile, dissolved or particular organic carbons in the atmosphere (Kawamura et al., 2003). Dicarboxylate complexes with iron are of outstanding sensitivity to destruction by photolyzation (Eder, 1880, 1906; Weller et al., 2014; Zhu et al., 1993): photolysis reduces $\mathrm{Fe}$ (III) to $\mathrm{Fe}(\mathrm{II})$ by producing $\mathrm{H}_{2} \mathrm{O}_{2}$ and oxidation of the organic complex compounds. Then Fe(II) is reoxidized to $\mathrm{Fe}$ (III) by $\mathrm{H}_{2} \mathrm{O}_{2}$ in the Fenton reaction by the generation of $\cdot \mathrm{OH}$ (Cunningham et al., 1988). Due to their elevated polarity, oxidation products containing hydroxyl and carboxyl groups have increased wettability, are more water soluble and are thus rapidly washed out from the atmosphere.

Due to their elevated reactivity compared to $\mathrm{CH}_{4}$, the gas phase oxidation of airborne organic compounds by ISAgenerated $\cdot \mathrm{OH}$ or $\cdot \mathrm{Cl}$ is enhanced. By eliminating black and brown carbon aerosols, ISA contributes to global warming reduction and to decreasing polar ice melting by surface albedo reduction caused by black-carbon snow contam- ination (Flanner et al., 2007; Ramanathan and Carmichael, 2008).

The generation of ISA by combusting fuel oil with ferrocene or other oil-soluble iron additives in ship engines or heating oil burners has additional positive effects because soot is catalytically flame-oxidized in the presence of flameborne ISA (detailed in Sect. 6) as a combustion product of the iron additive (Kasper et al., 1998; Weiser et al., 2007).

\subsection{Tropospheric ozone depletion by ISA}

An additional GHG is the tropospheric ozone (Jacobson, 2002). Carbon dioxide is the principal cause of GW and represents two-thirds of the global radiative forcing, but long-lived methane and short-lived tropospheric ozone are both GHGs and, respectively, responsible for the second and third most important positive radiative forcing.

According to Blasing (Blasing, 2010, 2016; Forster et al., 2007), tropospheric $\mathrm{O}_{3}$ has an atmospheric forcing of $+0.4 \mathrm{~W} \mathrm{~m}^{-2}$. Any direct depleting action of tropospheric $\mathrm{O}_{3}$ by the ISA-induced $\cdot \mathrm{Cl}$ is accompanied by an indirect emission decrease of $\mathrm{O}_{3}$ as the reduction of $\mathrm{CH}_{4}$ and other VOC by the ISA method decreases the $\mathrm{O}_{3}$ formation (Cooper et al., 2014).

Reactive halogen species (mainly $\mathrm{Cl}, \mathrm{Br}$ ) cause stratospheric ozone layer destruction and thus the "ozone layer hole". Tropospheric ozone destruction by reactive halogen species is also a reality (Sherwen et al., 2016). For a long time now, $\cdot \mathrm{Cl}$ and $\cdot \mathrm{Br}$ have been known as catalysts for $\mathrm{O}_{3}$ destruction in the stratosphere (Crutzen and Oppenheimer, 2008). Investigations both in the laboratory and in nature have shown that $\cdot \mathrm{Br}$ is a much more effective catalyst of ozone depletion within the troposphere than $\cdot \mathrm{Cl}$ (Le Bras and Platt, 1995; Liao et al., 2014; Wayne et al., 1995).

As discussed at the end of Sect. 2.6, clear evidence exists that the ozone-depleting "bromine explosions" known as regular phenomena developing from coastal snow layers at sunrise in the polar spring (Blechschmidt et al., 2016; Pratt et al., 2013) are likely to be induced by the photolyzed precipitation of iron-containing dust. According to Pratt, bromideenriched brines covering acidified snow particles are oxidized by photolyzation to $\cdot \mathrm{Br}$.

In coastal areas of both the northern and southern polar regions during springtime, inert halide salt ions (mainly $\mathrm{Br}^{-}$) are converted by photochemistry into reactive halogen species (mainly $\mathrm{Br}$ atoms and $\mathrm{BrO}$ ) that deplete ozone in the boundary layer to near-zero levels (Simpson et al., 2007). During these episodes, called "tropospheric ozone depletion events" or "polar tropospheric ozone hole events", $\mathrm{O}_{3}$ is completely destroyed in the lowest kilometer of the atmosphere in areas of several million square kilometers; this has a negative climate feedback or cooling effect (Roscoe et al., 2001).

In the tropics, halogen chemistry (mostly $\mathrm{Br}$ and I) is also responsible for a large fraction $(\sim 30 \%)$ of tropo- 
spheric ozone destruction (Read et al., 2008; Sommariva and von Glasow, 2012) and up to $7 \%$ of the global methane destruction is due to chlorine (Hossaini et al., 2016; Lawler et al., 2009). It has been estimated that $25 \%$ of the global oxidation of $\mathrm{CH}_{4}$ occurs in the tropical marine boundary layer (Bloss et al., 2005). A one-dimensional model has been used to simulate the chemical evolution of air masses in the tropical Atlantic Ocean (Sommariva and von Glasow, 2012) and to evaluate the impact of the measured halogens levels. In this model, halogens (mostly $\mathrm{Br}$ and I) accounted for $35-40 \%$ of total tropospheric $\mathrm{O}_{3}$ destruction while the $\mathrm{Cl}$ atoms accounted for $5.4-11.6 \%$ of total $\mathrm{CH}_{4}$ sinks. Sherwen et al. (2016) estimate the radiative forcing reduction due to $\mathrm{O}_{3}$ from the preindustrial to the present day as being $-0.066 \mathrm{~W} \mathrm{~m}^{-2}$.

The ISA-induced increase in $\cdot \mathrm{Br}$ concentration at seasalt-containing tropospheric conditions has been confirmed (Wittmer et al., 2015b). This establishes ISA as part of an ozone-depleting reaction cycle and additional cooling stage. This depletion effect of the GHG tropospheric ozone is worth noting.

\subsection{ISA-induced phytoplankton fertilization albedo increase (by enhancing dimethylsulfide (DMS) emissions) and $\mathrm{CH}_{4}$ oxidation efficiency (by increasing methyl chloride and DMS emissions)}

One of the largest reservoirs of gas phase chlorine is the ca. $5 \mathrm{Tg}$ of methyl chloride (MC) in the Earth's atmosphere (Khalil and Rasmussen, 1999). Methyl chloride is released from phytoplankton (Hu et al., 2013) and from coastal forests, terrestrial plants and fungi (Khalil et al., 1999).

Dimethylsulfide (DMS) is a volatile sulfur compound that plays an important role in the global sulfur cycle. Through the emission of atmospheric aerosols, DMS may control climate by influencing cloud albedo (Charlson et al., 1987).

Currently, researchers (Lana et al., 2011) estimate that $28.1(17.6-34.4) \mathrm{Tg}$ of sulfur in the form of DMS are transferred annually from the oceans into the atmosphere.

Ocean acidification has the potential to exacerbate anthropogenic warming through reduced DMS emissions (Six et al., 2013). By contrast, increased emissions of DMS and MC into the troposphere are a consequence of the ISA-induced phytoplankton growth and DMS + MC release into the troposphere. DMS is oxidized in the troposphere to sulfuric and sulfonic acid aerosols, which are highly active $\mathrm{CCN}$. This process enhances the direct ISA cooling effect as described in Sect. 2.1 (Charlson et al., 1987).

Upon contact of this acidic aerosol with sea spray aerosol, sulfate and sulfonate aerosols are formed and gaseous $\mathrm{HCl}$ is produced. Sulfate aerosols are known to have a negative radiative forcing (a cooling effect) (Crutzen, 2006).

Another $\mathrm{HCl}$ source is the oxidation of MC. Both effects induce the tropospheric $\mathrm{HCl}$ level to rise. Due to the cooling stage described in Sect. 2.2, with the increased $\mathrm{HCl}$ level, ad- ditional chlorine atoms are produced by reaction with ISA. This effect further accelerates the $\mathrm{CH}_{4}$ oxidation and its removal from the atmosphere, reducing its radiative forcing.

\subsection{Oxidation of $\mathrm{CH}_{4}$ and other GHGs by sunlit solid surfaces}

Mineral aerosol particles adhere strongly to sunlit, dry and solid surfaces of rocks and stones. A well-known remnant of the dust deposition in rock or stone deserts and rocky semiarid regions is the orange, brown, red or black "desert varnish" coat covering stones and rocks. The hard desert varnish is the residue, which is glued together and hardened, of the primary dust deposit. Daily sun radiation and humidity change, as well as microbe and fungi influence, builds up the varnish, changing the primary aerosol deposit (Perry et al., 2005) by photolytic Fe(III) and Mn(IV) reduction during daytime and nighttime oxidation of $\mathrm{Fe}$ (II) and $\mathrm{Mn}$ (II). The oxidation is triggered further by $\mathrm{Mn}$ - and $\mathrm{Fe}$-oxidizing microbes adapted to this habitat (Allen et al., 2001; Hungate et al., 1987). Desert varnish preserves the Fe and Mn photoreduction ability of the aerosol: lit by light the varnish can produce chlorine from chloride-containing solutions (Johnson and Eggleston, 2013). The photo-, humidity- and microbially induced permanent $\mathrm{Fe}$ and $\mathrm{Mn}$ valence change between night and day (Matsunaga et al., 1995); accompanied by adequate solubility, changes seem to trigger the physicochemical hardening of every new varnish layer.

The varnish is composed of microscopic laminations of $\mathrm{Fe}$ and $\mathrm{Mn}$ oxides. Fe plus Mn represent about one-fifth of the varnish. Meanwhile, four-fifths of the laminations are composed of $\mathrm{SiO}_{2}$, clay and former dust particles. The dominant mineral is $\mathrm{SiO}_{2}$ and/or clay (Dorn, 2009; Liu and Dorn, 1996). There is little doubt that desert varnish can build up even from pure iron oxides or iron chloride aerosol deposits such as ISA. The optimum $\mathrm{pH}$ to photo-generate the methane-oxidizing chlorine atoms from ISA is $\mathrm{pH} 2$ (Wittmer et al., 2015a). Established by the gaseous $\mathrm{HCl}$ content of the troposphere (Graedel and Keene, 1996), a pH drop to $\mathrm{pH} 2$ at the varnish surface is possible on neutral alkalinefree surfaces such as quartz, quartzite and sandstone. The humidity-controlled mechanism acting between gaseous $\mathrm{HCl}$ and $\mathrm{HCl}$ dissolved in the liquid water layer absorbed on the solid iron oxide surface of ISA particles, as explained in Sect. 2.2 , acts at the varnish surface in a similar manner to an ISA particle surface: an $\mathrm{FeCl}_{3}$ stock can pile up by $\mathrm{Fe}$ (II) oxidation and humidity-triggered $\mathrm{HCl}$ absorption during the nighttime. The $\mathrm{FeCl}_{3}$ stock at the varnish surface is consumed during daytime by photolytic Fe(II) and chlorine atom generation.

ISA aerosol particles emit $\mathrm{HCl}$ during dry conditions. Like oxidic ISA, desert varnish absorbs $\mathrm{H}_{2} \mathrm{O}$ and $\mathrm{HCl}$ from the atmosphere, gathering it during the nighttime as a surfacebound $\mathrm{H}_{2} \mathrm{O}, \mathrm{OH}^{-}$and $\mathrm{Cl}^{-}$coating. During sunlit daytime, chloride and water desorbs from $\mathrm{Fe}(\mathrm{III})$ as $\cdot \mathrm{Cl}, \cdot \mathrm{OH}$ and 


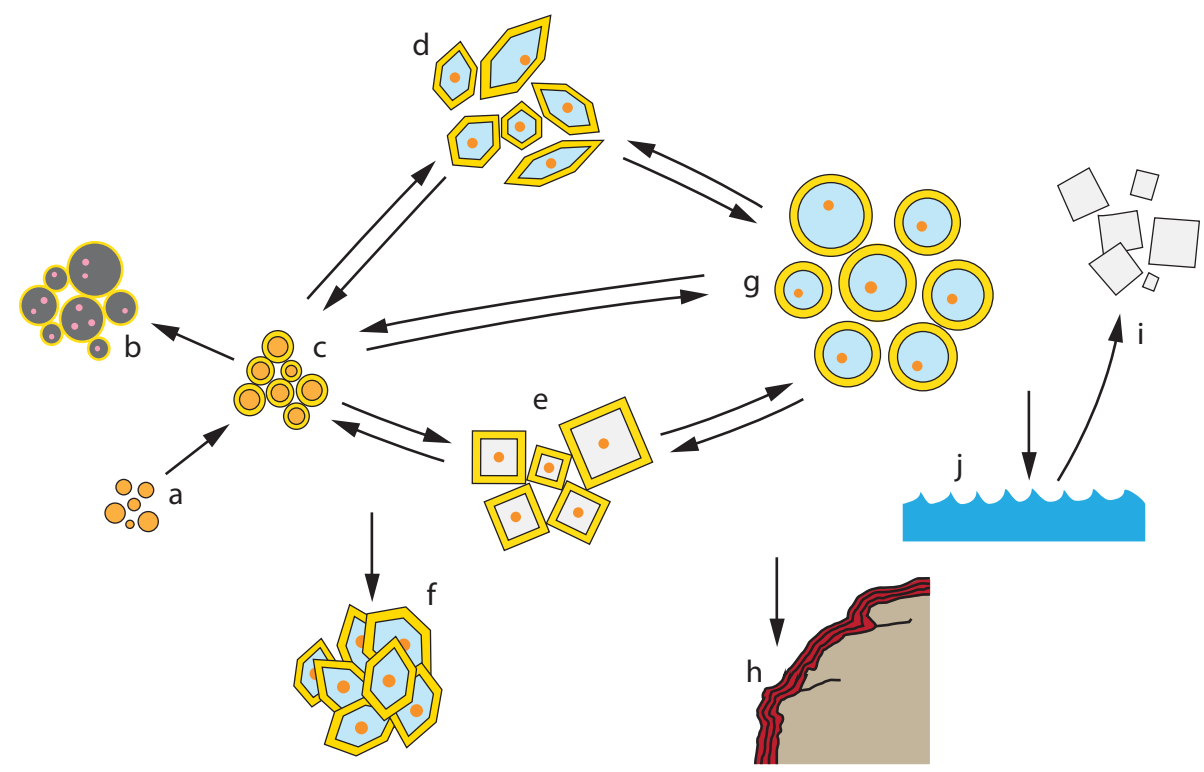

Figure 4. Schematic representation of iron salt aerosol interactions with different solid surfaces: primary ISA precursor FeOOH particles (a) react with gaseous $\mathrm{HCl}$ by generation of ISA as $\mathrm{FeCl}_{3}$ coated on $\mathrm{FeOOH}$ particles (c). Coagulation, condensation and chemical reaction with particles and vapors produce different kinds of liquid and/or solid ISA variants and sediments: (b) hydrolyzed $\mathrm{FeCl}_{3}$ coated on soot and/or HULIS particles; (d) hydrolyzed $\mathrm{FeCl}_{3}$ coated on ice crystals; (e) hydrolyzed $\mathrm{FeCl}_{3}$ coated on salt crystals; (f) hydrolyzed $\mathrm{FeCl}{ }_{3}$ coated on ice crystals of snow layers (ISA sediment); (g) hydrolyzed $\mathrm{FeCl}_{3}$ dissolved in cloud droplets; (h) $\mathrm{FeCl}_{3}$ hydrolysate residue on desert varnish (ISA sediment); (j) hydrolyzed $\mathrm{FeCl}_{3}$ as dissolved residue in ocean surface water fertilizes the phytoplankton growth and ultimately triggers the generation of sulfuric, sulfonic and dicarboxylic acids by emission of DMS, MC and other organics. This activates the tropospheric generation of vaporous $\mathrm{HCl}$ by reaction of sea-salt aerosol (i) with the acids. $\mathrm{HCl}$ again changes the ISA precursor FeOOH aerosol (a) to ISA (c).

$\mathrm{H}_{2} \mathrm{O}$, leaving $\mathrm{Fe}$ (II) in the varnish surface. The surface $\mathrm{Fe}$ (II) (and $\mathrm{Mn}(\mathrm{II})$ ) is bound by oxygen bridges to the varnish bulk of $\mathrm{Fe}(\mathrm{III})$ (and $\mathrm{Mn}(\mathrm{IV})$ ), perhaps like the combination of $\mathrm{Fe}$ (II) and $\mathrm{Fe}(\mathrm{III})$ within magnetite. During the nighttime the $\mathrm{Fe}(\mathrm{III})$ (and $\mathrm{Mn}(\mathrm{IV})$ ) surface coating is regenerated by microbial and/or abiotic oxidation with $\mathrm{O}_{2}$. It is worth mentioning that desert varnish can exist only within dry regions.

Figure 4 illustrates the interactions of ISA at the phase borders of tropospheric aerosols, ocean surface and dry solid surfaces.

Similar daytime-dependent microbially activated abiotic photoreduction and photooxidation reaction cycles are known from aquifer environments (Gammons et al., 2007). Thus, the $\mathrm{CH}_{4}$ depletion of the former ISA deposits will persist even after change into desert varnish. As explained in Sect. 2.2, continental $\mathrm{HCl}(300 \mathrm{pptv}$ above the oceans and $100 \mathrm{pptv}$ above the continents) (Graedel and Keene, 1996), $\mathrm{ClNO}_{2}$ (up to $1500 \mathrm{pptv}$ near flue gas emitters) (Osthoff et al., 2008; Riedel et al., 2014) and $\mathrm{CH}_{3} \mathrm{Cl}$ (550 pptv, far from urban sources) (Khalil and Rasmussen, 1999; Yokouchi et al., 2000) and, in deserts, chloride salt-containing dusts are direct and indirect sources of chloride which could provide desert varnishes with $\mathrm{Cl}^{-}$.

Furthermore, analogously to ISA deposited on solid desert surfaces, ISA depositions on dry snow, snow cover and ice occurring in permanently snow-covered mountain regions or within polar and neighboring regions preserve its $\mathrm{CH}_{4}$ destruction activity during sunlit days in spring and summer (Liao et al., 2014).

The global area of the desert varnish surface does not change with changing dust precipitation rates. It only depends on the precipitation frequency. It grows through desertification and shrinks with increasing wet climate. Until now, quantitative measurements about the specific amount of $\mathrm{CH}_{4}$ depletion per square meter of desert varnish are not known. Without these data, an estimation of its influence on the $\mathrm{CH}_{4}$ depletion and climate is impossible.

The photochemical actions inducing $\mathrm{CH}_{4}$ depletion of the desert varnish surfaces resulting from dust precipitation are concurrent with the surfaces of deserts and semideserts made of sand or laterite soils. Their surface is colored by ochre-tored iron oxide pigments. Their iron components should act in principle by the same $\mathrm{CH}_{4}$-depleting photochemistry as ISA and desert varnish.

As mentioned in Sect. 2.4, the $\mathrm{Cl}$ and $\mathrm{Br}$ activation by iron photolysis changes after the separation of the ingredients, by freezing or drying of the formerly homogeneous liquid, into solid salt-poor ice and a liquid brine coating or solid salt and a liquid brine coating. This inhomogeneous partitioning phenomenon of the predominant transformation of aerosol 
droplets into solid states, and vice versa, applies to snow or salt layers containing a proportion of ISA.

It has been shown that by cooling the precipitation of buffering salts (such as carbonates, sulfates and chlorides of bromide- and chloride-rich mother liquors) onto Arctic snow packs or ice particles can minimize their buffering capacity against $\mathrm{pH}$ change (Bartels-Rausch et al., 2014; Blechschmidt et al., 2016; Sander et al., 2006). Similar mechanisms may act when liquid aerosol particles become solid by drying.

Then, the uptake and contact over time of solid ironbearing particles and airborne organic and inorganic acids and acid precursors on, or with, ice crystal surfaces may lower the $\mathrm{pH}$ of the formerly alkaline particle surface, to the reaction conditions of bromide oxidation by iron(III) photoreduction.

According to Kim et al. (2010), the photogeneration of $\mathrm{Fe}$ (III) oxides, proceeding slowly at $\mathrm{pH} 3.5$ in bulk solution, becomes significantly accelerated in polycrystalline Arctic ice. This effect is accompanied by an acceleration of the physical dissolution of the $\mathrm{Fe}$ (III) oxides by freezing ice (Jeong et al., 2012; Kim et al., 2010).

The contact of Arctic snow layers with iron oxides is confirmed by Kim et al. (2010). Dorfman et al. (2015) found recent loess dust sedimentation rates in the Alaskan Arctic Burial Lake of $0.15 \mathrm{~mm} \mathrm{yr}^{-1}$. According to research results from artificial iron-doped salt pans (Wittmer et al., 2015b), iron-salt-doped sea-salt aerosols (Wittmer et al., 2015a) or sea-salt-doped iron oxide aerosols or pure iron oxide aerosols in contact with gaseous $\mathrm{HCl}$ (Wittmer and Zetzsch, 2016) chloride and bromide in sunlit surfaces are oxidized to $\cdot \mathrm{Cl}$ and $\cdot \mathrm{Br}$ by photoreduced $\mathrm{Fe}$ (III) if the $\mathrm{pH}$ of the reaction media is 3.5 or lower.

As known from the bromine explosions, they appear on acidified first-year tundra and first-year sea ice snow, lit by sunlight (Pratt et al., 2013). According to Kim et al. (2010) and Dorfman et al. (2015) the year-old snow layers contain iron(III). This confirms that sufficient reaction conditions exist to produce bromine explosions by the oxidation of iron(III) photoreduction.

Continents have considerable areas where the outflowing water is drained into "endorheic" water bodies and not into the oceans. Endorheic lakes have no outlets other than evaporation, and thus dissolved salts and nutrients concentrate over time. Large surfaces of these basins are covered by salt crusts, salt marshes, salty soils or salt lakes. Most of these areas are situated within desert or semidesert areas (Hammer, 1986). These salt environments gain iron from precipitating dust or from iron-containing brines they have precipitated from. As soon as these environments become acidic, they oxidize $\mathrm{CH}_{4}$ by iron photolysis-induced $\cdot \mathrm{Cl}$ (Wittmer et al., 2015b).

To summarize the climate-relevant action of ISA within the troposphere as described in Sects. 2.1-2.6: $\mathrm{CH}_{4}$, VOC, $\mathrm{O}_{3}$ and dark carbon aerosol plus cloud albedo, in sum, have a similar effect on the climate warming to $\mathrm{CO}_{2}$. With ISA method significant reductions in $\mathrm{CH}_{4}$, VOC, $\mathrm{O}_{3}$ are anticipated based on the test results from Wittmer et al. (2015a, b, 2016) and Wittmer and Zetzsch (2016), and significant reductions in dark carbon aerosol and a significant increase in cloud albedo are anticipated based on the literature cited. We found no arguments against these statements. This allows the conclusion that the ISA method should have significant climate cooling effects only within the troposphere.

\section{Oceanic natural cooling effects of the iron cycle}

\subsection{Biotic $\mathrm{CO}_{2}$ conversion into organic and carbonate carbon}

Vegetation uses the oxidative power of organic metal compounds induced by photon absorption, oxidizing water to oxygen and reducing $\mathrm{CO}_{2}$ by organic carbon generation (photosynthesis by chlorophyll, a green $\mathrm{Mg}$-porphyrin complex). This assimilation process is retarded by prevailing iron deficiency in the oceans, which slows phytoplankton growth.

However, there is no doubt that ISA-containing dust precipitation fertilizes the phytoplankton, which in turn affects the climate (Albani et al., 2016).

ISA triggers the phytoplankton reproduction and increases the formation of organic carbon from the GHG $\mathrm{CO}_{2}$ (Martínez-García et al., 2014). The vast majority of the oxygen thus formed, which is only slightly water soluble $\left(11 \mathrm{mg} \mathrm{O}_{2} \mathrm{~L}^{-1}\right)$, escapes into the atmosphere. In contrast, the organic carbon formed remains completely in the ocean, forming the basis of the marine food and debris chain.

Of the primary produced phytoplankton carbon, only a small fraction arrives at the ocean bottom as organic debris and becomes part of the sediment. Cartapanis et al. (2016) and Jaccard et al. (2016) found direct evidence that during the glacial maxima, the accumulation rate of organic carbon was consistently higher (50\%) than during interglacials. This resulted from the high dust concentrations during the glacial maxima, fertilizing the phytoplankton with ISA.

The buildup of $\mathrm{Ca}$ carbonate shell and frame substances by the calcification process at the ocean surface extracts additional $\mathrm{CO}_{2} \mathrm{C}$ from the troposphere. The bulk of calcification can be attributed to corals, foraminifera and coccolithophores; the latter are believed to contribute up to half of current oceanic $\mathrm{CaCO}_{3}$ production (Mackinder et al., 2010).

Both carbon fixation processes increase the removal of the GHG $\mathrm{CO}_{2}$ and thus contribute to cooling the troposphere. The Fe-fertilizing process was in progress during the ice ages, as the evaluations of Antarctic ice cores show: the minimum $\mathrm{CO}_{2}$ concentrations and temperatures in the troposphere are connected to the high dust phases (Skinner, 2008).

It has been discussed that the alkalinity loss by phytoplankton calcification and $\mathrm{CaCO}_{3}$ loss with phytoplankton debris from the ocean surface is said to produce a calcium and alkalinity deficit at the ocean surface (Meyer and Riebe- 
sell, 2015; Rost and Riebesell, 2004), producing additional acidification at the ocean surface by $\mathrm{CO}_{2}$ generation:

$\mathrm{Ca}\left(\mathrm{HCO}_{3}\right)_{2} \rightarrow \mathrm{CaCO}_{3}+\mathrm{H}_{2} \mathrm{O}+\mathrm{CO}_{2}$.

At least in part, this acidification is compensated for by assimilative generation of organic carbon by $\mathrm{CO}_{2}$ consumption. Both organic debris and $\mathrm{CaCO}_{3}$ become part of the ocean sediment. But if the organic debris is reoxidized during its journey downwards, some acidification could result from this. Acidification could result from this too if more $\mathrm{CO}_{2}$ is absorbed by the ocean than is assimilated and changed to organic debris. Sedimentation of organic debris and $\mathrm{CaCO}_{3}$ both increase, depending on the ISA-induced phytoplankton productivity.

The increasing amount of $\mathrm{CaCO}_{3}$ sedimentation within iron-fertilized ocean regions has been discussed by Salter et al. (2014). In a sufficiently mixed ocean, alkalinity loss at the surface is more than compensated for by the different sources of alkali and earth alkali cations at the ocean bottom and through continental weathering: in the first place these are the mechanisms of alkalinity generated by the ocean water reactions within the ocean sediments and their bedrock, the oceanic crust. The latter mechanisms are described in more detail in Sects. 4.1-4.3. The convection of the primary oxic ocean bottom water through the ocean crust generates alkalinity by the reduction of sulfate, nitrate and hydrogen carbonate, by the dissolution of silicates by reduced humic acids and further by the serpentinization of basalt and peridotite silicates (Alt and Shanks, 2003; Früh-Green et al., 2004). The alkalinity extracted from the oceanic crust mainly remains positioned in the dark water layers of the ocean basins if the decreased THC is not able to elevate the alkaline extract into the phytoplankton layer in sufficient quantities.

The THC activation by the ISA method is described in Sects. 4.1-4.3.

Sudden ISA-induced phytoplankton growth generates increased calcite-shell production. This lowers the Ca concentration at the ocean surface. Even if the vertical cycling is not fast enough to compensate for the Ca loss at once, or after a small time lag, this does no harm to phytoplankton growth because $\mathrm{Ca}$ is not essential to it. Just the opposite is true: phytoplankton use calcification as a detoxification measure to get rid of calcium ions from their bodies (Müller et al., 2015). As a consequence of this effect only the relation between $\mathrm{Ca}$ carbonate sequestration and organic carbon sequestration will decrease during the time lag.

By additional direct alkalinity production of the phytoplankton itself, at least parts of the acidity from lime shell production may be compensated for: ISA-controlled phytoplankton growth induces an increased synthesis of organic sulfur and of chlorine compounds (Matrai and Keller, 1994), emitted as DMS and MC (Carpenter et al., 2012). Synthesis of organic sulfur and halogen organics, as precursors of the volatile DMS and MC emission, is realized by phytoplankton, by a reduction of sulfate to organic sulfides and by the oxidation of chloride to carbon chlorine compounds. This precursor synthesis excretes equivalent $\mathrm{Na}^{+}$and/or $\mathrm{Ca}^{2+}$ alkalinity, as $\mathrm{Na}_{2} \mathrm{SO}_{4}$ reduction/formation to DMS generates $\mathrm{Na}$ alkalinity; $\mathrm{NaCl}$ oxidation/formation to $\mathrm{MC}$ also generates $\mathrm{Na}$ alkalinity: cations formerly bound to $\mathrm{SO}_{4}^{2-}$ or $\mathrm{Cl}^{-}$ lose their anions, producing alkalinity. According to Chen et al. (1996) and Fujita (1971) the sulfur content of phytoplankton exclusively exceeds the $\mathrm{Ca}^{2+}, \mathrm{Mg}^{2+}$ and $\mathrm{K}^{+}$alkaline load of phytoplankton lost with the phytoplankton debris. Only half of the organic carbon assimilated by phytoplankton derives from dissolved $\mathrm{CO}_{2}$. The other half derives from the ocean water $\mathrm{NaHCO}_{3}$ anion content (Cassar et al., 2004). Chemical reduction (the reduction of $\mathrm{HCO}_{3}^{-}$to organic $\mathrm{C}+\mathrm{O}_{2}$ by the assimilation of $\mathrm{HCO}_{3}^{-}$anions) produces alkalinity as another compensation of the alkalinity loss by calcification. $\mathrm{NaHCO}_{3}$ reduction/formation to organic carbon generates $\mathrm{Na}$ alkalinity. The cation previously bound to $\mathrm{HCO}_{3}^{-}$loses its anion and produces alkalinity.

These considerations demonstrate that any of the proposed enhanced weathering measures to prevent ocean acidification by increasing the alkalinity (Taylor et al., 2016) might not be necessary if the ISA method is in action and keeps the vertical ocean mixing sufficiently active.

During the down-dripping of the very finely shaped phytoplankton debris, bacterial oxidation, fish and other food chain links minimize the organic debris by up to 1 order of magnitude (Weber et al., 2016). Even the dissolution of the small carbonate debris reduces the carbonate fraction until it arrives at the sediment surface. In order to maximize the effect of the ISA method, within the main ISA precipitation regions, the oxidation and dissolution of the organic and carbonate phytoplankton debris during its dripping down through the ocean water column can be reduced. To reach this goal, we suggest farming fixed filter feeders such as mussels and oysters within the ISA precipitation region.

Mussels and oysters produce faeces and so-called "pseudo faeces" in the shape of fairly solid pellets. Compared to the time of the sedimentation of the unconditioned phytoplankton debris, this expands the sedimentation time difference between excreted filter feeder faeces and the phytoplankton faeces pellet sedimentation on the ocean floor by 1 order of magnitude. Bivalve farming would significantly reduce the oxidative and solution loss by phytoplankton debris attack. Mussel and oyster farming are well-known practices which have been employed for a long time as a measure to produce protein-rich food. They have been proposed as an element of climate engineering (Dimitrova et al., 2015; Lenton and Sen Gupta, 2010).

To further optimize the $\mathrm{CO}_{2}-\mathrm{C}$ conversion to sedimentbound $\mathrm{C}$ the biomass of oysters and mussels, including their shells and fixing systems, might be periodically dumped into the sediment.

Additional floating supports such as coral habitats, sponges, sea lilies and sea anemones between the mussel 
supports might complete and again optimize the ISA precipitation areas. The oceanic water deserts can be changed into productive ecosystems and protein sources for an increasing population by these measures, among others, for an optimized $\mathrm{CO}_{2}$ fixation induced by ISA.

A further proposal in order to maximize the $\mathrm{CO}_{2}$ fixation induced by ISA is our suggestion to integrate a solution to the plastic waste problem on the ocean surfaces into the ISA method. About 5 to 13 million metric tons of solid plastic waste per year are entering the oceans (Jambeck et al., 2015). Over the last years the plastic waste drifting on the ocean has developed into a huge problem for oceanic ecosystems (Law et al., 2014). Plastic keeps sunlight away from phytoplankton, hampering it from effective growth. The plastic waste drifts with the ocean currents. It then collects within accumulation zones predicted by a global surface circulation model (Cózar et al., 2014). Most plastic-covered ocean surfaces are concentrated in central-oceanic regions with a low iron content, predestined for the application of the ISA method. Due to the trash, there would be a reduction in the ISA efficiency so we propose the integration of the plastic depletion problem into our ISA method: specific technologies can be installed both inside and outside of a container ship vessel, i.e., plastic trash collection, plastic trash sorting, plastic trash extrusion, plastic trash burning, ISA production and emission. The aforementioned processes are well known and need no description here. Trash or waste burning has the advantages of delivering an effective hot carrier gas with high buoyancy for the uplift of ISA and for delivering $\mathrm{HCl}$ as a cocatalyst of ISA. With the plastic extruder, most carrier parts of floating supports on the reef coral, sponge and mussel habitats could be produced.

In addition to the larger plastic fragments, the fine floating plastic debris with particle diameters in the micrometer range is another problem (van Sebille et al., 2015). Instead of carrying out the micro-trash separation by technical means, mussel and oyster farming may remove this ocean surface environmental problem. The floating micro-trash particles are collected by the bivalves and excreted as pseudo-faeces pellets and ultimately become part of the sediment layer at the ocean bottom.

Within the iron cycle, the photolytically driven oxidant production with iron participation may not be reduced to $\cdot \mathrm{Cl}$ and $\cdot \mathrm{OH}$ in the troposphere and $\mathrm{O}_{2}$ by assimilation: when iron is cycled through the mantle at temperatures above $2500 \mathrm{~K}, \mathrm{Fe}(\mathrm{III})$ is reduced to $\mathrm{Fe}(\mathrm{II})$ by the release of $\mathrm{O}_{2}$ (Bykova et al., 2016). This phenomenon may be driven by the blackbody radiation containing a great fraction of photons with a wavelength shorter than $2 \mu \mathrm{m}$ at and above this temperature level.

\subsection{ISA activates the $\mathrm{O}_{2}$ input to the deep ocean}

Ocean ecosystems are based on certain balances between oxidizing and reducing agents. As a result of the ISA-triggered additional input of organic carbon to the ISA emission region (i.e., the ISA precipitation region), as described in Sect. 3.1, oxygen consumption by increasing organic debris precipitation could increase. The recent $\mathrm{O}_{2}$ decline in some oceanic regions may result, at least in part, from the deposition of soluble iron deriving from flue gas pollution. Also discussed in Sect. 3.1 is the decrease in the oxidation efficiency within the water column by measures to increase the sinking velocity of the organic-C-containing debris. The increase in the sinking velocity of the organic-C-containing debris is an effect that might completely compensate for the oxygen loss by the oxidation of the ISA-induced debris mass increase.

Recently, and without ISA influence, oxygen deficiency appears to have developed in many parts of the ocean as described in the introduction. Oxygen deficiency is usually due to insufficient vertical water exchange owing to an increased vertical density gradient rather than the result of increased phytoplankton production.

Oxygen deficiency (hypoxia) is found frequently between the oxic surface layer (the oxygenated one) and the oxic deep-water layer (Bruland, 2006; Capone and Hutchins, 2013). Due to the climate warming, the localities with a lack of oxygen seem to be intensifying and expanding already today (Kalvelage et al., 2013).

The deepest water layer of most ocean basins results from the Antarctic wintertime ocean surface ice generation by fractionating seawater into salt-poor sea ice and salt-rich dense brine. This results in the production of cold, highdensity oxic brines which sink to the bottom of the Southern Ocean. The cold high-density oxic brines spread as a thin oxic bottom layer as far as the ocean basins north of the equator. The most recent severe climate warming, which induced a disturbance of the THC, is likely to have been activated by the increasing inflow of fresh meltwater from Greenland into the North Atlantic. This inflow disturbs the downflow of the Gulf Stream water (Rahmstorf et al., 2015). Due to the increased melt of the glaciers of the Antarctic, the salt content of the ocean surface around Antarctica decreased. This effect increased the ocean surface covered by sea ice (Bintanja et al., 2013). This freezing of the salt-poor meltwater layer decreases the production of dense brines. This again decreases the downflow of brine, reducing again the vertical components of the ocean currents.

Through the ISA-induced cooling, the oxygen and $\mathrm{CO}_{2}$ flux into the deep-ocean basins will be restored due to the input of the cold dense oxygen and $\mathrm{CO}_{2}$-enriched polar surface water: a reduced meltwater production of the Greenlandic and Antarctic ice shields by falling surface layer temperatures will restore and intensify the thermohaline circulation within the northern polar regions by increasing the amount of Gulf Stream water reaching those regions and by producing the circum-Antarctic sea ice cover without meltwater dilution, which induces the production of cold high-density brines sinking to the ocean basin bottoms (Ohshima et al., 
2013; Rahmstorf, 2006). Figure 5 illustrates the ocean basin vertical mixing circles.

\subsection{Phytoplankton fertilizer extraction from ocean sediments and underlying crust}

The oceanic crust is composed of peridotites, basalts and serpentine rock and has a layer of sediment on top. Sediments and bedrock contain reductive and alkaline components extractable by seawater. The cause of the ocean water flow through the sediment layer and base rock is the temperaturedifference-driven convection. Sediment compaction by gravity, subduction-induced compaction and subduction-induced hydroxyl mineral dehydration may be further reasons for water movement through the sediment layer at the ocean bottom.

Olivine is one of the main mineral components of oceanic crust rock layers below the sediment layer. Hauck et al. (2016) simulated the effects of the annual dissolution of $3 \mathrm{Gt}$ olivine as a geoengineering climate cooling measure in the open ocean, with a uniform distribution of bicarbonate, silicic acid and iron produced by the olivine dissolution. An additional aim of this work was the development of a neutralization measure against the increasing acidification of seawater. All the components of olivine $\left(\mathrm{SiO}_{2}, \mathrm{Fe}(\mathrm{II})\right.$ and $\left.\mathrm{Mg}\right)$ are phytoplankton fertilizers. They calculated that the ironinduced $\mathrm{CO}_{2}$ removal saturates at on average $\sim 1.1 \mathrm{Pg} \mathrm{C} \mathrm{yr}^{-1}$ for an iron input rate of $2.3 \mathrm{Tg} \mathrm{Fe} \mathrm{yr}^{-1}$ (1\% of the iron contained in $3 \mathrm{Pg}$ olivine), while $\mathrm{CO}_{2}$ sequestered by alkalinization is estimated to be $\sim 1.1 \mathrm{Pg} \mathrm{Cyr}^{-1}$ and the effect of silicic acid represents a $\mathrm{CO}_{2}$ removal of $\sim 0.18 \mathrm{Pg} \mathrm{C} \mathrm{yr}^{-1}$. These data represent the enormous potential of the ocean crust rock as a source of phytoplankton fertilizer.

The flow of seawater through anoxic sediments and bedrock results in the reduction in its $\mathrm{SO}_{4}^{2-}$ content, as well as the extraction of the soluble fraction from the sediment, such as $\mathrm{Mn}(\mathrm{II}), \mathrm{Fe}(\mathrm{II}), \mathrm{NH}_{4}^{+}$and $\mathrm{PO}_{4}^{3-}$. The chemical and physical extraction processes are enhanced by the action of microbial attack at the border between oxic seawater and anoxic sediment parts within this huge aqueous system.

At suboxic conditions soluble $\mathrm{Fe}$ (II) and $\mathrm{Mn}$ (II) have optimum solubility or may be fixed as solid $\mathrm{Fe}(\mathrm{III})_{3}\left(\mathrm{PO}_{4}\right)_{2}$, $\mathrm{FeCO}_{3}, \mathrm{MnCO}_{3}, \mathrm{FeS}_{2}, \mathrm{~S}^{0}$ and other $\mathrm{Fe}-\mathrm{S}$ compounds (Ohman et al., 1991; Roden and Edmonds, 1997; Slomp et al., 2013; Swanson, 1988; Wallmann et al., 2008).

Silicon is mobilized too, from the dissolution of silicates and $\mathrm{SiO}_{2}$ in methanogenic conditions by complexation with reduced humic acid (HA) (Vorhies and Gaines, 2009; Wallmann et al., 2008). In the reduced conditions, HA is characterized by catechol and other polyphenolic functions, which allows HA to complex with silicon (Belton et al., 2010; Demadis et al., 2011; Jorgensen, 1976) and with other metal cations.

Silicate dissolution mobilized $\mathrm{Ca}^{2+}, \mathrm{Mg}^{2+}, \mathrm{Ba}^{2+}, \mathrm{Fe}^{2+}$, $\mathrm{Na}^{+}, \mathrm{K}^{+} \cdot \mathrm{Fe}^{2+}, \mathrm{Mn}^{2+}$ and $\mathrm{PO}_{4}^{3-}$ precipitate more or less as sulfides and carbonates within the sediment $\left(\mathrm{Fe}(\mathrm{II}) \mathrm{S}_{2}, \mathrm{CaCO}_{3}, \mathrm{MgCa}\left(\mathrm{CO}_{3}\right)_{2}, \mathrm{Fe}(\mathrm{II}) \mathrm{CO}_{3}, \mathrm{Mn}(\mathrm{II}) \mathrm{CO}_{3}\right.$, $\left.\mathrm{Fe}(\mathrm{II})_{3}\left(\mathrm{PO}_{4}\right)_{2}\right)$ and within its suboxic surface $\left(\mathrm{BaSO}_{4}\right)$ and at its oxic surface $\left(\mathrm{SiO}_{2}, \mathrm{Fe}(\mathrm{III}) \mathrm{OOH}, \mathrm{Mn}(\mathrm{IV}) \mathrm{O}_{2}\right.$, clay minerals). The authigenically formed ferromanganese nodules (Kastner, 1999) are formed by in situ microbial precipitation from sediment pore water, squeezed out to the seafloor on the sediment layer (Nayak et al., 2011; Wu et al., 2013). The main components of the nodules are the phytoplankton fertilizer components $\mathrm{SiO}_{2}$, Fe oxides and Mn oxides (Nayak et al., 2011).

Having left the border between anoxic and suboxic nearsurface sediment, the HA catechols are changed by reversible oxidation into quinone or quinhydrone configurations by the decay of the Si catechol complex. Like most of the chemical reactions within the sediment compartment, the oxidation of the HA-Si complex is directed by microorganisms. The microorganisms involved use HA as an external redox ferment (Benz et al., 1998; Bond and Lovley, 2002; Coates et al., 1998; Kappler et al., 2004; Lovley and Blunt-Harris, 1999; Lovley et al., 1999; Piepenbrock et al., 2014; Straub et al., 2005). After the arrival of the pore water originating from the anoxic deeper sediment or from the bedrock at the suboxic surface-near sediment layers, the oxidized HA releases $\mathrm{Si}(\mathrm{OH})_{4}$ and $\mathrm{NO}_{3}^{-}$produced by microbial $\mathrm{NH}_{4}^{+}$nitrification (Daims et al., 2015; van Kessel et al., 2015). Depending on the $\mathrm{Si}(\mathrm{OH})_{4}$ concentration produced, this can trigger the precipitation of layered silicates such as smectites, glauconite and celadonite as well as silica (Bjorlykke, 2010; Charpentier et al., 2011; Gaudin et al., 2005; Polgári et al., 2013; Pufahl and Hiatt, 2012; Zijlstra, 1995). Similar to HA, the clay mineral formation within the sediment and the use of the redox potential of these authigenic minerals are, at least in part, the result of microbial action (Konhauser and Urrutia, 1999; Kostka et al., 1996).

Due to its chelating properties, HA generate soluble to neutral Fe complexes of high stability even in oxic and weak alkaline ocean water conditions. As iron and HA have identical sources, especially chemoclines, even faeces HA can act as shuttles between Fe sources and phytoplankton (Schmidt et al., 2016). But within oxic ocean milieus they become depleted, ultimately like every organic $\mathrm{C}$ substance, by oxidation.

The deep-ocean currents take up the pore water percolates out of the sediment, and considerable amounts of the dissolved, colloidal or suspended sediment originating elements are THC-conveyed to the surface (Lam and Bishop, 2008), where they activate the phytoplankton production again. This also triggers the $\mathrm{CO}_{2}$ conversion to organic $\mathrm{C}$, resulting in a cooling of the troposphere as described in Sect. 3.1. It also repeatedly cools the troposphere by increasing the DMS formation as described in Sects. 2.5 and 3.1. 


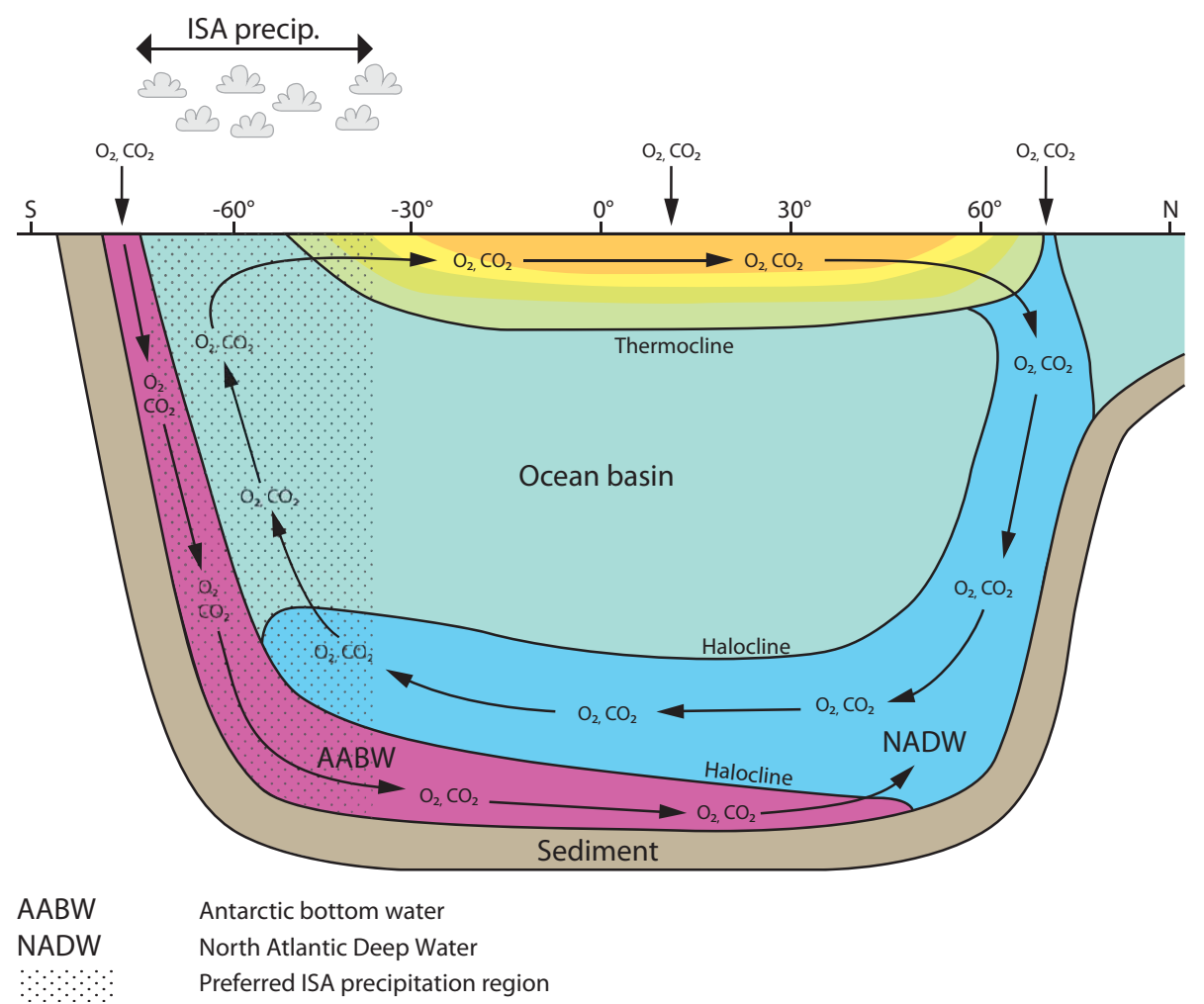

Figure 5. The motor of the Antarctic bottom water (AABW) current is the sea ice production of the Southern Ocean area bordering Antarctica. The North Atlantic Deep Water (NADW) current is driven by decreasing Gulf Stream temperature on its way north. Climate warming especially the faster temperature rise at higher latitudes, shifts the region of the Gulf Stream downflow and NADW further to the north, as a result of the lower $\Delta t$ between equatorial and polar surface water. This shift puts additional Greenlandic coast regions in contact with warm Gulf Stream water and rising air temperatures, as another component of poor increasing amounts of fresh meltwater on the ocean surface. The rising meltwater volume and the Gulf Stream, flowing further north, increase the contact region between Gulf Stream water and fresh meltwater. This produces increasing amounts of original Gulf Stream water, which are, however, too low in density to sink and to become part of NADW. Temperature rise at higher latitudes reduces the salt content of ocean surface water around Greenland and Antarctica, inducing reduced NADW and AABW volumes. Due to the reduced downflow current volumes, the amounts of $\mathrm{CO}_{2}$ and $\mathrm{O}_{2}$ to the deep-ocean basin are reduced as is the vertical fertilizer transport from the ocean basin bottom to the phytoplankton at the surface.

\section{The main cooling effects induced by the iron cycle on the ocean crust}

\subsection{Carbon storage as authigenic carbonate in the ocean crust}

The mechanism described in this section has the highest influence on the climate, due to its carbon storage capacity which is greater than that of their sediment layer. The convective water flow through the huge alkaline ocean crust volume is estimated to be about $20-540 \times 10^{3} \mathrm{~km}^{3} \mathrm{yr}^{-1}$ (Nielsen et al., 2006). The oceanic crust comprises the largest aquifer system of the Earth, with an estimated rock volume of $2.3 \times 10^{9} \mathrm{~km}^{3}$ and a fluid volume of $2 \%$ of the total ocean, or $\sim 10^{7} \mathrm{~km}^{3}$ (Orcutt et al., 2011). The system of the mid-ocean rifts (MOR) and subduction zones and the sector between these volcanically active regions are part of the Earth mantle convection cycle and part of interconnected aquifer system mentioned above. The bottom water of the ocean basins is in close contact with this conveyor-belt-like moving rock layer of the oceanic crust. New oceanic crust is produced at the MOR: during its cooling, it is pulled apart from the MOR by the moving underlying mantle, and ultimately the moving mantle draws the crust down into the deeper mantle below the subduction zones. The oceanic crust has a sediment layer on top of its assemblage of multi-fractured crystalline and volcanic rocks. Both sediment and igneous bedrock interior are in an anoxic reduced and alkaline state; the temperature on top of the sediment surface at the ocean bottom is round about $0{ }^{\circ} \mathrm{C}$, but the temperature increases up to $>1000^{\circ} \mathrm{C}$ within the igneous bedrock basement. As there is no effective sealing between cold bottom water and the high-temperature zone, the water content of sediments and the fractured basement flows through the crust in multiple thermal convection cycles positioned between the cold surface and the hot deep.

Alkalinity and alkalinity-inducing compounds of the ocean crust rock layers extract $\mathrm{CO}_{2}$ and $\mathrm{HCO}_{3}^{-}$from sea- 
water by carbonate precipitation in the fissures during seawater percolation through the multi-fractured rock (Coggon et al., 2012). A carbon uptake of 22 to $29 \mathrm{MtC} \mathrm{yr}^{-1}$ is estimated during the hydrothermal alteration of the oceanic crust (Kelemen and Manning, 2015). This is more than the carbon uptake by the overlying sediment layer of the oceanic crust, which is estimated to be 13 to $23 \mathrm{MtC} \mathrm{yr}^{-1}$ (Kelemen and Manning, 2015). The oceanic crust is composed of peridotites, basalts and serpentine rock, with a sediment layer on top. Said rock layers contain reductive and alkaline components. Seawater circling through these rock layers loses its oxygen, sulfate and nitrate and even part of its hydrogen carbonate content by reduction and precipitation and becomes enriched with methane and other reductants (Evans, 2008; Janecky and Seyfried, 1986; Kelemen et al., 2011; Müntener, 2010; Oelkers et al., 2008; Sanna et al., 2014; Schrenk et al., 2013; Sissmann et al., 2014).

Figure $6 \mathrm{a}$ and $\mathrm{b}$ illustrate, respectively, the differences between a poorly and a sufficiently mixed ocean.

Due to the opposing chemical milieu differences between the oxic ocean water inflow and anoxic reduced and alkaline sediment and basement, the ocean water convection cycles through the ocean crust act as continuous chemical reaction systems and form habitats of intense microbial action (Ivarsson et al., 2016). The greatest chemical reaction intensity is found at MOR, subduction zones and volcanic sea mounts; between MOR and subduction within the abyssal plain, convection cycling occurs (Orcutt et al., 2011). Because the hydrogen carbonate load of the ocean water inflow reaches precipitation as carbonates of $\mathrm{Ca}, \mathrm{Mg}, \mathrm{Fe}$ and $\mathrm{Mn}$ within the alkaline rock interior and by chemical reduction of sulfate, nitrate and hydrogen carbonate, the ocean basements act as huge $\mathrm{CO}_{2}$-carbon storages. There is no doubt that the ocean crust carbonate depot is the most effective carbon storage, more effective than any other organic carbon storage.

Within the huge ocean crust contact volume, seawater changes the alkaline pyroxenes and basalts into serpentine, diabase and carbonates by producing heat, hydrogen and rock volume expansion and by a permanent production of numerous fissures. The ocean water sulfates react with the silicate components to magnetite, pyrite and barite. The seawater hydrogen carbonate load precipitates within the rock fissures as magnesite, calcite, siderite and dolomite. By heat transfer from hot rock and chemical reaction, heat circling through the primary and newly generated multiple fissures in the former mantle rock, the seawater inflow heats up, producing convective flow. At fissures where the alkalized flow of convection water containing hot $\mathrm{CH}_{4}$ and $\mathrm{H}_{2}$ comes out with $\mathrm{pH} 9$ to 11 and comes into contact with fresh seawater, carbonate precipitates and builds up carbonate chimneys as high as skyscrapers (Kelley et al., 2005).

The convective seawater flowing only through the MOR system is estimated to be about 20 to $540 \times 10^{3} \mathrm{~km}^{3} \mathrm{yr}^{-1}$ (Nielsen et al., 2006). This volume is more than the global river flow of about $50 \mathrm{~km}^{3} \mathrm{yr}^{-1}$ (Rast et al., 2001).
The weathering reaction conditions and the seawater alkalization during the intense seawater contact with the alkaline MOR rocks are much more aggressive, and thus more effective, compared to reaction conditions and alkalization during the precipitation water contact and during weathering reactions of continental rocks. This is confirmed by the alkaline $\mathrm{pH}$ of up to 11 of the "white smoker" MOR outflow in spite of its haline salt-buffered seawater origin (Kelley et al., 2005). Even the most alkaline runoff from limestone karst spring freshwaters or within karst cave freshwaters does not exceed pH levels of 8.5 (Li et al., 2010; Raeisi and Karami, 1997; Righi-Cavallaro et al., 2010). Because of the enormous carbonate absorption capacity of the oceanic crust, it has been proposed to use it as a storage of $\mathrm{CO}_{2}$ (Kelemen and Matter, 2008). As the igneous crust rock aquifer generates $\mathrm{H}_{2}$ during its contact with ocean water parts of the carbonate precipitation, carbonate is reduced in part to organic and/or graphitic $\mathrm{C}$, depending on the reaction temperatures by biotic or abiotic reduction (Galvez et al., 2013; Holm et al., 2015; Malvoisin et al., 2012; Rumble, 2014; X. Wang et al., 2014).

There is no doubt that the efficiency of the $\mathrm{pH}$-dependent $\mathrm{CO}_{2}$ absorption, carbonic acid neutralizing at the ocean surfaces, and the hydrogen carbonate precipitation to carbonate processes at and within the oceanic crust are dependent on the activity of the THC within the ocean basins. During cold climate epochs, with unstratified water columns and undisturbed THC, the $\mathrm{CO}_{2}$ conversion to ocean crust carbonate is activated, as is the $\mathrm{CO}_{2}$ conversion to the organic fraction of ocean sediments. Just the opposite has been found to be true for the burial of organic $\mathrm{C}$ in ocean basin bottom sediments: according to Lopes et al. (2015) the overwhelming organic debris fraction produced during the main glacial episodes from the phytoplankton habitat at the surface is oxidized and remineralized in the well-mixed ocean basin (Lopes et al., 2015). As the $\mathrm{CO}_{2}$ level in the atmosphere is at its lowest during the main glacials, the remaining $\mathrm{C}$ sinks of the oceans seem to be of much greater efficiency than the iron-induced production of organic $\mathrm{C}$ by assimilation: the most prominent $\mathrm{C}$ sink is the authigenic carbonate $\mathrm{C}$ burial in the alkaline ocean crust. There seems to be no doubt that the vertical well-mixed ocean during the main glacials works as an efficient pump to transport dissolved $\mathrm{CO}_{2}$ and $\mathrm{O}_{2}$ to the ocean basin bottoms: there, $\mathrm{O}_{2}$ acts as a mineralizer of organic $\mathrm{C}$, and $\mathrm{CO}_{2} \mathrm{C}$ is buried as authigenic carbonate $\mathrm{C}$ in the oceanic crust.

Table 2 gives an overview of some trends in $\mathrm{C}$ burial depending on the climate condition change between main glacial and interglacial.

Lopes et al. (2015) found just the opposite in ocean sediment layers produced during the warm interstadial compared to the cold main glacial, i.e., a high burial rate of organic $\mathrm{C}$ in the ocean bottom sediment. But in spite of the high organic $\mathrm{C}$ burial rate, the interstadial $\mathrm{CO}_{2}$ levels were kept higher than those of the main glacial. Even in this regard, the Lopes et al. (2015) results fit in well to our $\mathrm{CO}_{2}$ sink model. Dur- 

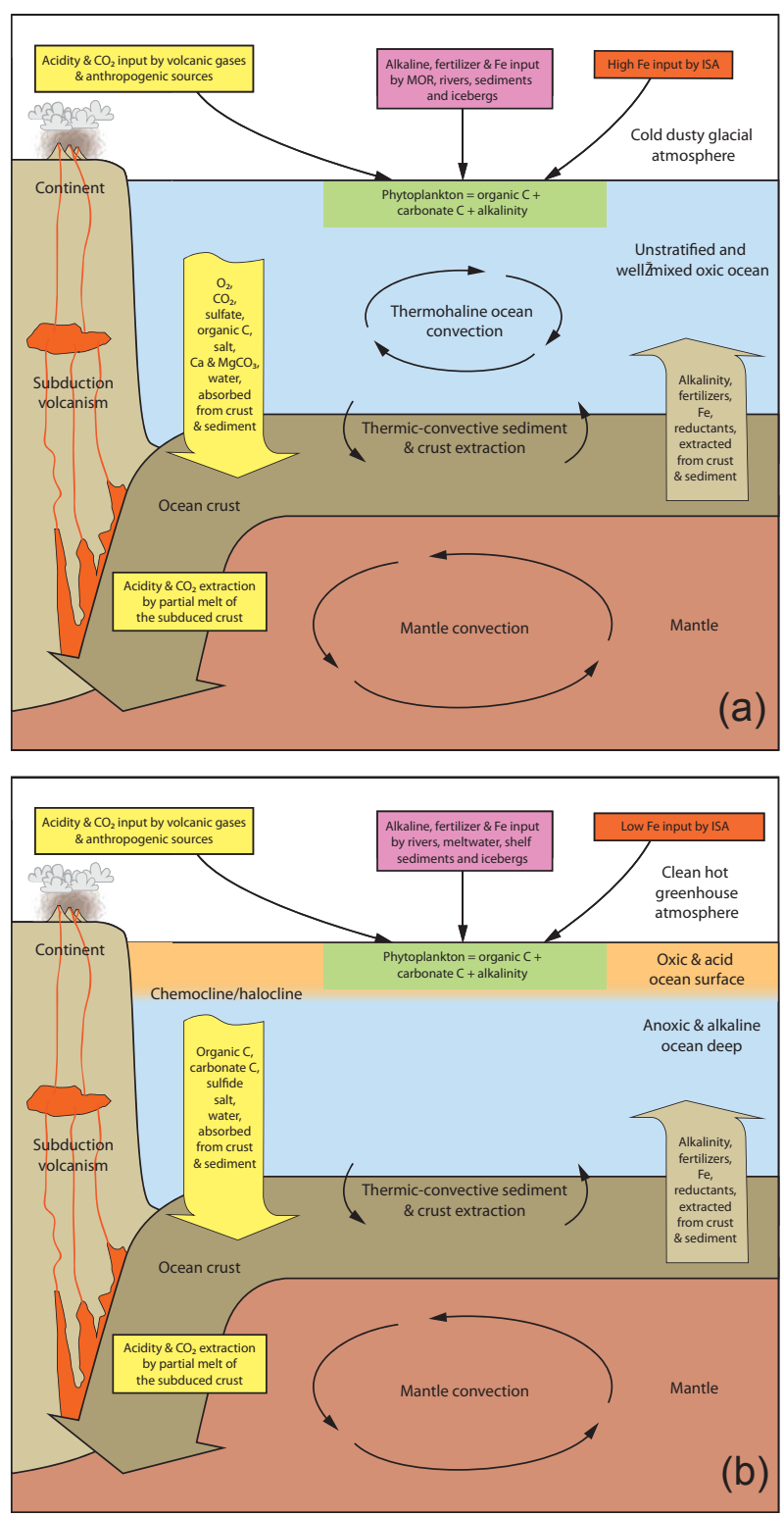

Figure 6. This figure presents the essential differences between an unstratified well-mixed ocean basin under a cold and dusty atmosphere during the cold main glacial, with low atmospheric GHG concentrations (a) and a stratified ocean basin with a meltwater layer on top of a saline ocean water layer during a warm interglacial, with a hot and dust-free greenhouse atmosphere (b). Panel (a): due to the unstratified well-mixed water column in Basin $6 \mathrm{~A}, \mathrm{CO}_{2}$ and $\mathrm{O}_{2}$ absorbed at the water surface are distributed within all parts of the basin. There are high production rates of organic carbon produced by phytoplankton in the top layer, and this carbon is oxidized on its way down to the sediment layer, with only a minor generation of organic sediment. Carbonate carbon produced by the phytoplankton becomes dissolved to a great extent within the deeper basin parts generating $\mathrm{HCO}_{3}^{-}, \mathrm{CO}_{2}$ and $\mathrm{HCO}_{3}^{-}$. By cycling the basin bottom water through the alkaline bottom sediment and ocean crust aquifer, $\mathrm{CO}_{2}$ and $\mathrm{HCO}_{3}^{-}$become precipitated and buried as carbonate $\mathrm{C}$. The recycled bottom water becomes enriched by Fe fixed to organic chelators and is transported back to the surface. Due to the unrestricted downflow and transfer of $\mathrm{CO}_{2}$ from the former surface water into sediments and into underlying base rock as carbonate carbon, the buried carbonate $\mathrm{C}$ exceeds the buried organic $\mathrm{C}$ amount. Panel (b): an interglacial episode with high GHG levels accompanied by elevated surface temperatures generates increased meltwater and surface water runoff. Because the saline-poor water layer spreads to the saline ocean water and induces at least a regional stratification of the ocean basins water column, the production of brine-induced surface water downflow is stopped, as meltwater freezing generates neither brine nor any vertical surface water movement. This stops any down transport of absorbed $\mathrm{CO}_{2}$ and $\mathrm{O}_{2}$ too and generates anoxic conditions within the underlying saline layer. The anoxic saline layer becomes anoxic and alkaline by sulfate and nitrate reduction. Any phytoplankton-induced organic and carbonate litter trickles down through the anoxic and alkaline layer: $\mathrm{CaCO}_{3}$ without dilution in the alkaline water and organic $\mathrm{C}$ without oxidation in the anoxic milieu. Carbonates of $\mathrm{Ca}$ and $\mathrm{Mg}$ may precipitate in small amounts at the chemocline between light acidic $\mathrm{CO}_{2}$ saturated water and the alkaline saline layer. The carbonate precipitate then mixes with the down-falling phytoplankton-originating litter. 
Table 2. Interglacial climate episodes were hot, nearly dust-free and had elevated levels of GHGs. The interglacials coincided with stratified water columns. The stratified ocean has much reduced activity due to the reduced $\mathrm{CO}_{2}$ transport to the bottom of the ocean basin. As the $\mathrm{O}_{2}$ transport is reduced and the lower part of the basin is anoxic, the oxidative mineralization of the organic litter fall from phytoplankton activity at the surface is reduced and generates sediments rich in organic substances. As sulfate, nitrate and in part $\mathrm{CO}_{2}$ within the anoxic water column are reduced to sulfide, ammonium and $\mathrm{CH}_{4}$, the $\mathrm{pH}$ increases to alkaline. This can induce carbonate precipitation near the chemocline. During the glacial maxima with cold temperatures, dustiness and low greenhouse gas levels, the ocean basins had well and vertically mixed water columns with highest carbonate $\mathrm{C}$ burial and lowest organic $\mathrm{C}$ burial.

\begin{tabular}{|c|c|c|c|}
\hline Effect on & & $\begin{array}{l}\text { Sediment }+ \\
\text { crust below } \\
\text { well and } \\
\text { vertically mixed } \\
\text { water column }\end{array}$ & $\begin{array}{l}\text { Sediment }+ \\
\text { crust below } \\
\text { stratified and } \\
\text { anoxic water } \\
\text { column }\end{array}$ \\
\hline $\begin{array}{l}\text { Mass ratio of buried } \\
\text { sediment and crust } \\
\text { carbon }\end{array}$ & $\begin{array}{l}\text { sediment } C \text { : } \\
\text { oceanic crust } C\end{array}$ & $\ll 1$ & $<1$ to 1 or $>1$ \\
\hline $\begin{array}{l}\text { Mass ratio of buried } \\
\text { sediment and crust } \\
\text { carbon }\end{array}$ & $\begin{array}{l}\text { organic } \mathrm{C}: \\
\text { carbonate } \mathrm{C}\end{array}$ & $\ll 1$ & up to 1 or $>1$ \\
\hline $\begin{array}{l}\text { Authigenic carbonate } \\
\text { produced within the } \\
\text { water column }\end{array}$ & & No & Yes \\
\hline $\begin{array}{l}\text { Tropospheric } \\
\text { parameters }\end{array}$ & $\begin{array}{l}\text { Dust } \\
\mathrm{CO}_{2} \\
\mathrm{CH}_{4} \\
\text { Temperature }\end{array}$ & $\begin{array}{l}\text { High } \\
\text { Low } \\
\text { Low } \\
\text { Cold }\end{array}$ & $\begin{array}{l}\text { Low } \\
\text { High } \\
\text { High } \\
\text { Warm }\end{array}$ \\
\hline
\end{tabular}

ing the glacial climate warming events, enormous meltwater volumes were generated and induced stratification effects in ocean basins by placing a meltwater blanket on the saline ocean water surface (Praetorius et al., 2015). The transport of $\mathrm{CO}_{2}$ and $\mathrm{O}_{2}$ into the basin bottoms became interrupted. The drizzle of phytoplankton litter remained un-oxidized, and as a further consequence the amount of carbonate $\mathrm{C}$ burial within the ocean crust decreased.

The continuous availability of chemical activity, as a chemical reaction vessel and as an alkalinity reservoir of the oceanic crust, is maintained by the continuous generation of new crustal rock material of $21 \mathrm{~km}^{3} \mathrm{yr}^{-1}$ (Orcutt et al., 2011). This huge rock volume production capacity has enough alkalinity and fertilizer reserves to maintain the absorption, neutralization and precipitation of a multiple of the recent incoming $\mathrm{CO}_{2}$ and $\mathrm{HCO}_{3}^{-}$.

THC is the main transport medium of carbon from the atmosphere into the deep on Earth. This makes THC the most prominent climate stabilization element.

The realization of the significance of THC as a stabilization element of our recent-climate model raises questions about the stability of the THC. As stated in Sect. 1, the main factor for destabilizing the THC seems to be the stratification of the water column by the desalting of surface ocean layers by freshwater dilution from increasing ice melting (Hansen et al., 2016). The low-density meltwater generates a layer on the ocean water, producing a stratified water column. The stratification hampers or prevents the transport of $\mathrm{CO}_{2}$ and $\mathrm{O}_{2}$-containing surface water into the deep-ocean basin parts. The most severe consequence of such stratification, to oceanic ecosystems, is the development of anoxic milieus within the stratified ocean basins.

Typical characteristics of episodes with stratified water columns in ocean basins are the black shales and black limestones representing sapropel remnants. The repeated development of stratified ocean basins during the Phanerozoic epoch occurred as a consequence of elevated $\mathrm{CO}_{2}$ levels in the atmosphere. This caused high sea surface temperatures (Meyers, 2014) and as a global consequence a global increase in evaporation, precipitation and production of brines of higher concentrations.

Hansen et al. (2016) also pointed out that the increasing meltwater runoff from polar and subpolar ice layers can induce the cover of denser ocean water by a meltwater layer. But the generation of increasing precipitation and surface water runoff accompanied by increasing brine production during hot high- $\mathrm{CO}_{2}$ climate episodes had exactly the same consequences in the past geological epochs, as we learn from Meyers (2014).

We now have to fear this combination of the $\mathrm{CO}_{2}$ dependent temperature-rise-generated precipitation increase and the meltwater increase from glacier melt. Mankind now 
has to find the appropriate tool to rise to this challenge or will otherwise fail to meet it.

A melt increase might drive the destabilization of THC. And at first the top layers of the ocean basins will suffer from acidification, and the deep layers will become alkaline and anoxic.

By starting the ISA process, the induced climate cooling will decrease the Greenland glacier melt. The minimized freshwater inflow to the North Atlantic Ocean reduces the dilution of the salty Gulf Stream and increases the downflow quantity of oxic and $\mathrm{CO}_{2}$-containing salty surface water. In parallel, the surface increase in sea ice produced on the Southern Ocean surrounding the Antarctic continent is followed by increased downflow of oxic and $\mathrm{CO}_{2}$ containing cold brine to the bottoms of the oceanic basins. Both effects increase the THC activation: the flow of alkaline, phytoplankton-fertilizer-enriched and oxygen-depleted deep-ocean water to the surface. This activates $\mathrm{CO}_{2}$ absorption from the atmosphere by phytoplankton growth and by $\mathrm{CO}_{2}$ absorption

One of the proposed alternative climate engineering measures aims to absorb atmospheric $\mathrm{CO}_{2}$ by reducing the surface ocean acidity and by producing phytoplankton fertilizers. To transfer $1.1 \times 10^{9} \mathrm{tyr}^{-1} \mathrm{CO}_{2}$ carbon into the ocean, it would be necessary to crush $3 \times 10^{9} \mathrm{t} \mathrm{yr}^{-1}$ of the ocean crust and mantle rock mineral olivine to a particle diameter of $1 \mu \mathrm{m}$ and suspend it at the ocean surface (Hauck et al., 2016; Köhler et al., 2010, 2013). These numbers seem to be 2 orders of magnitude too high. Keleman and Manning (2015) calculate a carbon mass subduction of about $50 \times 10^{6} \mathrm{tC} \mathrm{yr}^{-1}$ ( $\mathrm{C}$ in oceanic crust, bedrock and sediment layer). Regardless of which of the two calculations is wrong, the technology to implement the Hauck et al. (2016) proposal is far from being an economic reality.

The proposed reaction of $\mathrm{CO}_{2}$ with olivine is carried out with much better effectiveness by nature, without any costs and within the ocean crust in sufficient quantity. To minimize $\mathrm{CO}_{2}$ emission it has been proposed to minimize power station flue gas $\mathrm{CO}_{2}$ by absorption by lime suspension (Haas et al., 2014). This measure seems to be unnecessary when the ISA method comes into practice.

The fertilizing elements which phytoplankton needs, such as $\mathrm{Si}, \mathrm{P}$ and $\mathrm{Fe}$, are all present in the ocean crust (Lyubetskaya and Korenaga, 2007) and a property of the ocean crust water extract. The intensification of the THC would also increase the fertilizer concentration at the ocean surface in the phytoplankton layer. As demonstrated, the undisturbed THC is essential for keeping the climate stabilized (Coogan and Gillis, 2013).

The ocean crust from the warm Mesozoic epoch, which had no frozen polar regions, contained about 5 times more authigenic carbonate than ocean crust younger than 60 million years (Coogan and Gillis, 2013). Coogan and Gillis (2013) interpreted this as possible consequences of higher bottom water temperature and/or different seawater composition. Insua et al. (2014) found evidence that the salinity of the ocean bottom water during the Last Glacial Maximum had been up to $4 \%$ greater than today. It seems evident that the cause of the latter had been the higher volume of brine produced during sea ice freezing. This fact demonstrates that disturbed or weakened THCs might be the cause of the reduced carbonate $\mathrm{C}$ uptake of the ocean crust. The quantity of carbonate precipitation depends on the $\mathrm{CO}_{2}$ and/or $\mathrm{HCO}_{3}^{-}$input with seawater. As a consequence, the quantity of the ocean crust $\mathrm{CO}_{3}$ uptake varies depending on the activities of the THCs or stratified ocean basins: strong THCs increase the crust carbon content; weak THCs decrease it.

Independently of the cause of stratification events (by brine generation, by freezing or by evaporation), the ocean basins possess a removal mechanism which extracts salt from the brine and change the brine to seawater of a normal salt concentration. This mechanism has kept the salt concentration of seawater fairly constant during the past geological epochs. This effect, which achieves a constant salinity level, depletes any brine-induced stratification and restores wellmixed ocean basins again.

According to Hovland et al. (2006a, b, 2014), this desalination takes place by continuous salt removal from the brine or seawater within the hot ocean crust. This desalination works independently of the salt concentration of brine or seawater. The salt removal process acts within the ocean crust aquifer at near-critical to supercritical seawater temperature and pressure conditions. During the subduction of the salty crust, rock chloride and carbonate change their cations with silicate and are dissolved as $\mathrm{HCl}$ and $\mathrm{CO}_{2}$. Accompanied by $\mathrm{H}_{2} \mathrm{O}$, these gases are recycled to the atmosphere, mainly by subduction volcanism, but this is done to a much lesser extent by MOR and similar alkaline volcanism.

During the time lag between the onset of the ISA method cooling and the appearance of the alkalinity and fertilizer increase at the ocean surface, the cooling effect of ISA remains reduced. But after this time lag, the ISA method increases to optimal efficiency. Even from an economic viewpoint, it seems better to compensate for this by increasing the ISA emission at the beginning during the time lag than doing the proposed suspending of olivine dust at the ocean's surface. Even lime-shell-bearing phytoplankton is able to accept small $\mathrm{pH}$ changes in $\mathrm{CO}_{2}$-induced dependent acidification because it uses the buildup of calcium carbonate shells as a detoxification measure to get rid of calcium ions from their bodies (Müller et al., 2015). As a consequence of this effect, only the relation between $\mathrm{Ca}$ carbonate sequestration and organic carbon sequestration may decrease during the time lag.

To sum up, through the huge aquifers of the alkaline and reducing ocean crust, any transport of former surface water enriched by $\mathrm{CO}_{2}$ or $\mathrm{HCO}_{3}^{-}$induces carbonate $\mathrm{C}$ burial within the aquifer interior. This is the situation within wellmixed ocean basins without stratification. Any stratification 
decreases carbonate burial or even stops it. Stratification changes the redox milieu below the stratification-induced chemocline. The MOR and sediment-induced exhalation of Fe and other metals by black smokers into the sulfidic stratified ocean basin are prevented from contact with the planktonic surface water habitat. But surface water runoff, as well as meltwater inflow and iceberg melt during warm glacial climate intervals, may compensate for the lack of Fe from the MOR and bottom sediment sources, as well as from the decreasing dust fall during the warm climate intervals (Hansen et al., 2016; van Helmond et al., 2015).

\subsection{Carbon storage as organic and inorganic marine debris and as authigenic carbonate in the ocean sediment}

The uptake of authigenic hydrogen carbonate from the ocean and its precipitation to the sediment also seem to play a major role in the carbon cycle (Schrag et al., 2013). According to Kelemen and Manning (2015), the carbon uptake by the sediment layer of the oceanic crust can be estimated to be 13 to

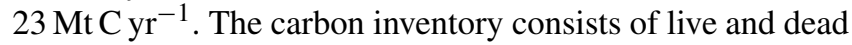
organic carbon, carbonate carbon, and authigenic carbonate produced by excess alkalinity deriving mainly from sulfate reduction and silicate solution by reduced humic acids. According to Sun and Turchyn (2014), the formation of calcium carbonate and its burial in marine sediments accounts for about $80 \%$ of the total carbon removed from the Earth surface (Sun and Turchyn, 2014). Moreover, it seems possible to distinguish between marine-formed sediment carbonate and authigenic carbonate (Zhao et al., 2016).

As evidenced in Sect. 4.1, stratified ocean basins can differ widely in the quantity and quality of the buried $\mathrm{C}$ depending on the prevailing climate conditions and their direct and indirect influences on ocean basin conditions. Table 2 lists some of the most prominent results.

The cooling of the troposphere by ISA action stops meltwater inflow, destructs the stratification and starts the vertical mixture. During the previous stratification event, the alkalized deep-water layer had enormous $\mathrm{CO}_{2}$ absorption capacity. The alkalized anoxic sediment behaves in a similar manner. This leads to much increased $\mathrm{CO}_{2}$ absorption activity at the beginning of the movement.

Accordingly, excess alkalinity is produced by the dissolution of silicates such as illite, kaolinite and feldspars, volcanic ash, pyroxene, or other silicate components of ocean sediments and even opal by $\mathrm{Si}$ complexation with reduced HA in methanogenic conditions (Meister et al., 2011; Roden and Edmonds, 1997; Solomon et al., 2014; Wallmann et al., 2008). Compensation by hydrogen carbonate induces authigenic precipitation of microbial dolomite (Roberts et al., 2004), Ca or Fe carbonate (Dewangan et al., 2013; Merinero et al., 2008; Solomon et al., 2014; Sun and Turchyn, 2014; Vorhies and Gaines, 2009; Wallmann et al., 2008), and other minerals (Tribovillard et al., 2013).
As mentioned in Sect. 4.1, the biological processes of chemical sediment reduction induced by the ISA fertilization change $\mathrm{NO}_{3}^{-}, \mathrm{SO}_{4}^{2-}, \mathrm{Fe}(\mathrm{III}), \mathrm{Mn}(\mathrm{III} / \mathrm{IV})$ and $\mathrm{HCO}_{3}^{-}$to their deoxygenated and reduced species, including $\mathrm{CH}_{4}$, and $\mathrm{NH}_{4}^{+}$ generation produces a $\mathrm{pH}$ increase and additional alkalinity. Furthermore, a $\mathrm{pH}$ drop is induced by $\mathrm{H}_{2}$ evolution from $\mathrm{FeS}_{2}$ generation from $\mathrm{FeS}$ and $\mathrm{H}_{2} \mathrm{~S}$ (Drobner et al., 1990; Rickard and Luther, 1997), accompanied by $\mathrm{CO}_{2}$ reduction to $\mathrm{CH}_{4}$ (Conrad, 1999) as well as $\mathrm{N}_{2}$ reduction to $\mathrm{NH}_{3}$ (Dörr et al., 2003). The alkalinity excess converts dissolved $\mathrm{HCO}_{3}^{-}$ into solid lime and dolomite (Berner et al., 1970; Krause et al., 2012; Luff and Wallmann, 2003; Raiswell and Fisher, 2004). The solid carbonates and $\mathrm{CH}_{4}$ hydrate stabilize the sediment. Outside the polar permafrost region, methane hydrates are stable below $300 \mathrm{~m}$ b.s.l. (below sea level) and at ocean temperatures of nearly $0{ }^{\circ} \mathrm{C}$ (Maekawa et al., 1995). The carbonate precipitation sequesters additional amounts of $\mathrm{CO}_{2}$, prevents the ocean water from acidifying and ultimately improves the $\mathrm{CO}_{2}$ absorption by ocean water from the atmosphere. This again cools the troposphere.

The enhanced dissolution of silicates from the ISA induced by methanogenic sedimentation additionally compensates for the enhanced alkalinity loss at the ocean surface, attributed to the calcification due to foraminifera and coccolithophores phytoplankton growth by ISA fertilization.

To sum up, within a well-mixed and unstratified ocean basin the surface layer absorbs $\mathrm{CO}_{2}$ and $\mathrm{O}_{2}$ and becomes well mixed into the unstratified ocean basin by the thermohaline basin convection. Consequences of the good mixing are a nearly quantitative oxidation of the food chain debris to $\mathrm{CO}_{2}$ produced by phytoplankton. Most $\mathrm{C}$ is buried as carbonate in the ocean crust and its overlying sediment. The ratio of organic $\mathrm{C}$ burial to carbonate $\mathrm{C}$ burial is much smaller than 1 . The results of Lopes et al. (2015) from northeast Pacific sediments demonstrate that, although primary productivity was estimated to be highest during the Last Glacial Maximum, organic $\mathrm{C}$ burial was lowest. This coincides with our proposed optimum mixed $\mathrm{O}_{2}$-rich milieu throughout the whole water column.

During situations with stratified water columns in the ocean basins or parts of them THC convection is disturbed or does not exist at all. A surface water layer enriched with $\mathrm{CO}_{2}$ and $\mathrm{O}_{2}$ absorbed from the atmosphere cannot penetrate through the stratified water column to the bottom of the basin. This induces sulfate-reducing conditions below the surface layer. Only small amounts of surface layer $\mathrm{CO}_{2}$ are changed into carbonate $\mathrm{C}$ at the chemocline, with the alkaline sulfidic and anoxic parts below the chemocline. Below the chemocline, the water column is anoxic; the organic debris sediment shows minor oxidation. It is likely that the ratio of organic $\mathrm{C}$ burial to carbonate $\mathrm{C}$ burial increases greatly during stratified conditions. Concerning the huge fraction of organic $\mathrm{C}$ buried during the warm glacial intervals, according to the results of Lopes et al. (2015) from the northeast Pa- 
cific, sediments demonstrate stratification events within the research area of Lopes et al.

Stratification events may develop by warming the upper water layer, as well as by evaporation and precipitation (Friedrich et al., 2008; Hansen et al., 2016; van Helmond et al., 2015).

\subsection{Minimizing $\mathrm{CH}_{4}$ emissions from sediments and igneous bedrock}

The reaction product of oceanic crust minerals containing $\mathrm{Fe}$ (II) such as olivine and pyrrhotite with seawater is hydrogen (Bayrakci et al., 2016; Mayhew et al., 2013; Neubeck et al., 2014). The hydrogen production rate along the MOR alone is estimated to be $\sim 10^{12} \mathrm{~mol} \mathrm{H}_{2} \mathrm{yr}^{-1}$ (Worman et al., 2016). Hydrogen is fermented by microbes with hydrogen carbonate into methane. Methane is known as a constituent of the springs emitted by the ocean crust rocks (Früh-Green et al., 2004).

Such and other $\mathrm{CH}_{4}$ emissions, such as anoxic sediments outside the $\mathrm{CH}_{4}$ hydrate stable pressure and temperature region, induce deoxygenation within the overlying water layer by $\mathrm{CH}_{4}$ emission (Römer et al., 2014; Yamamoto et al., 2014). $\mathrm{CH}_{4}$ emissions are induced for instance by hydrothermal springs (Suess et al., 1999), sediment movement (Krastel et al., 2014; Paull et al., 2007), seawater warming induced by climate change (Serov et al., 2015; Shakhova et al., 2005), changing ocean circulation (Berndt et al., 2014) and ocean sediment subduction (Elvert et al., 2000; Fischer et al., 2013). At lower vertical sediment to ocean surface distances, the $\mathrm{CH}_{4}$ emissions reach the troposphere. As the Arctic Ocean suffers most from the climate-change-induced warming, the $\mathrm{CH}_{4}$ release within this region rises extraordinarily (Phrampus et al., 2014). The most elevated global surface-near oceanic $\mathrm{CH}_{4}$ concentrations are located within the Arctic Ocean and the Arctic troposphere (Shakhova et al., 2008). This might be one of the reasons for the temperature rise in the Arctic region being higher than the average surface Earth warming.

Within the sediment and within the suboxic ocean water column, $\mathrm{CH}_{4}$ is oxidized by sulfate. Iron is an accelerator of this microbial fermentation reaction (Sivan et al., 2014). The ocean water column and the underlying sediment having had contact with ISA-originating iron are elevated in their iron content. This has different cooling effects on the troposphere:

- First, the elevated iron content in the uppermost suboxic sediment reduces the $\mathrm{CH}_{4}$ content emitted by the sediment by the anaerobic oxidation of methane by sulfatereducing bacteria. Below regions with ISA precipitation, not only the sediment but also the whole water column of the ocean basin is enriched by iron. Any $\mathrm{CH}_{4}$ molecule, regardless of whether it is found in the sediment or just above in the water phase or whether it is excreted into the water column as bubbles, is oxidized before it arrives at the water column top. With the help of Fe-containing enzymes, methane oxidation by sulfate is possible. This prevents the water layers above the sulfate oxidation zone from oxygen loss. Sulfate oxidizers of $\mathrm{CH}_{4}$ are archaea and bacteria (Basen et al., 2011). As these microbes use Fe-containing enzymes for their anaerobic methane oxidation processes, they work better in iron-rich than in iron-poor environments (Sivan et al., 2011, 2016). The iron-containing debris fall of ISAfed dead phytoplankton and phytoplankton-dependent food chain links feeds the methane-depleting sulfate reducer community within or near the sediment surface.

- Second, the iron content reduces the $\mathrm{CH}_{4}$ bubbledevelopment within the sediment layer, preventing catastrophic $\mathrm{CH}_{4}$ eruptions by sediment destabilization, $\mathrm{CH}_{4}$ bursts and sediment avalanches.

- Thirdly, an elevated iron content prevents the ocean water column from $\mathrm{CH}_{4}$-induced oxygen deficiency by the formation of ammonium. This oxygen deficiency prevention protects against the generation of the extremely stable and very effective $\mathrm{GHG} \mathrm{N}_{2} \mathrm{O}$ (Naqvi et al., 2010).

The oxygen-dependent life will develop problems due to the decreasing oxygen content within a decreased vertically mixed ocean basin induced by climate warming. An additional input of $\mathrm{CH}_{4}$ would increase the oxygen-deficit death zones. Any $\mathrm{CH}_{4}$ injection into regional oxygen-deficit zones will immediately increase their volume. Climate models predict declines in oceanic dissolved oxygen with global warming. The climate-warming-dependent decline in the oxygen content in many ocean regions has meanwhile become manifest (Stramma et al., 2010). Braking or reversing this trend by reducing the oxygen-depleting $\mathrm{CH}_{4}$ emissions should at least help to protect regions within the ocean basins from methane-induced oxygen deficit.

The glacial age proved that in spite of the multiplicity of the cooling processes induced, they caused little disturbance to the ecosystems. This predestines ISA as a steering tool to prevent climate fluctuations such as the recent climate warming mankind is suffering from. The present study aims to describe in Sect. 5 the technical means to realize this climate engineering project by the ISA method.

This result is contradictious to the calculations of Duprat et al. (2016). They found an increased phytoplankton concentration within the iron-containing meltwater trail of the giant Antarctica icebergs. Duprat et al. (2016) assume that the iceberg-induced carbon export increases by a factor of 5 to 10 within its locality of influence, and they expect an increase in carbon export by the predicted increase in the iceberg production (for instance, Joughin et al., 2014). We interpret the ongoing increase in icebergs and ice melt as a further severe warning sign that the ongoing destabilization might end soon in an insufficiently mixed ocean. 
The only artificially realizable restoration tool to change an insufficiently or poorly mixed ocean into a well-mixed ocean is definitely climate cooling. The ISA method appears to be the climate cooling method of choice because it accelerates the conversion of atmospheric carbons into solid and even liquid carbons with the means of nature. Compared to the artificial aerosol systems based on $\mathrm{TiO}_{2}$ or $\mathrm{H}_{2} \mathrm{SO}_{4}$ (Pope et al., 2012), sea-salt aerosol has advantages, such as better controllability and economy.

\section{Iron effects on shore}

\subsection{Importance of iron for terrestrial landscapes}

As seen in previous sections, the atmospheric deposition of iron together with other macronutrients and micronutrients set important controls on marine ecology and biogeochemistry: for terrestrial ecology and biogeochemistry the importance of iron is similar.

Iron is one of 17 essential elements for plant growth and reproduction (Pérez-Sanz and Lucena, 1995). Iron is an essential micronutrient (or trace element) only required by plants in small amounts for bio-functions such as the production of chlorophyll and photosynthesis (Hochmuth, 2011). Iron is involved in many other important physiological processes such as nitrogen fixation and nitrate reduction and is required for certain enzyme functions (Morrissey and Guerinot, 2009).

Iron is the fourth most abundant element of the earth's crust $(4.2 \%)$ and thus iron is seldom deficient, as despite its high abundance in soil, iron solubility is extremely low and its availability depends on the whole soil system and chemistry. Chlorosis (yellowing) is associated with iron deficiency in plants on land (Anderson, 1982; Mengel and Geurtzen, 1986), but the chemistry of iron in soils and its availability to plants (Lindsay and Schwab, 1982) is outside the scope of this review; thus, only a brief overview is given. However, while small amounts are necessary for growth, iron can become toxic to plants. Iron toxicity is associated with large concentrations of $\mathrm{Fe}^{2+}$ in the soil solution (Becker and Asch, 2005) and leads to oxidative stress. As a consequence, ironuptake systems are carefully regulated to ensure that iron homeostasis is maintained. Iron availability represents a significant constraint on plant growth, and plants have developed distinct strategies to ensure Fe solubilization and uptake (Forieri and Hell, 2014). In forests, microorganisms such as fungi and bacteria play a role in nutrient cycling (Philpott, 2006). A particularly efficient iron acquisition system involves the solubilization of iron by siderophores (Kraemer, 2004), which are biogenic chelators with a high affinity and specificity for iron complexation.

Iron-deficiency-induced chlorosis represents the main nutritional disorder in orchards and in crops grown on calcareous and/or alkaline soils (Abadía et al., 2011) in many areas of the world. Iron deficiency is a worldwide problem as calcareous soils cover over $30 \%$ of the earth's land surface (Basar et al., 2014), especially in arid and semiarid regions, and it has a large economical impact because crop quality and yield can be severely compromised (El-Jendoubi et al., 2014; Rombolà and Tagliavini, 2006); thus, several methods of correction have been developed. Iron canopy fertilization (foliar fertilization) can be a cheaper, more environmentallyfriendly alternative to soil treatments with synthetic Fe(III) chelates for the control of Fe chlorosis in fruit trees (Fernández et al., 2013). But iron chelates are expensive and have to be applied annually. Several sprays aiming to activate the Fe pools in a chlorotic leaf by foliar iron fertilization have been tested and were generally as effective as simple spay fertilization with iron sulfate (Abadía et al., 2011), and both are effective in regreening treated leaf areas, both in peach trees and sugar beet plants (El-Jendoubi et al., 2014). Iron deficiency chlorosis in soybean was solved by foliar sprays, which significantly increased the yield of three cultivars tested, and the yield responses obtained were about $300 \mathrm{~kg} \mathrm{ha}^{-1}$ (Goos and Johnson, 2000).

Although foliar Fe fertilization seems to be potentially effective, the scientific background for this practice is still scarce, and we did not find evidence that soluble iron contained in atmospheric dust aerosols has already been proved to be able to play this role.

The fertilizing role of African dust in the Amazon rain forest is well known (Yu et al., 2015b) but attributed to the P input. On a basis of the 7-year average of transatlantic dust transportation, Yu et al. (2015a) calculated that $182 \mathrm{Tg} \mathrm{yr}^{-1}$ dust leaves the coast of North Africa $\left(15^{\circ} \mathrm{W}\right)$, of which $43 \mathrm{Tg} \mathrm{yr}^{-1}$ reaches America $\left(75^{\circ} \mathrm{W}\right)$. The dust reaching the Caribbean and the Amazon comes mainly from northwestern Africa (Algeria, Mali and Mauritania) (Gläser et al., 2015).

The average dust deposition into the Amazon Basin over 7 years is estimated to be $29 \mathrm{~kg} \mathrm{ha}^{-1} \mathrm{yr}^{-1}$ (Yu et al., 2015b), providing about to $23 \mathrm{~g} \mathrm{ha}^{-1} \mathrm{yr}^{-1}$ of phosphorus to fertilize the Amazon rain forest, together with $\mathrm{Mg}$ and $\mathrm{Fe}$. Although not directly related to ISA, this dust deposition allows biomass fertilization and thus $\mathrm{CO}_{2}$ removal from the atmosphere.

The widespread tropical soils, mostly laterites, are deficient in phosphate and nitrogen but not in autochthonous iron. The only exception to this applies to all the epiphyte plants and the plants growing in soil-free localities without any autochthonous iron. These plants might profit from the ISA method. Such plant communities are localized for instance on top of the well-known tepuis (table mountains north of the Amazon basin near the borders of Brazil, Venezuela and Guyana) and on the tree branches in the rain forests without roots in the ground. From Köhler et al. (2007) the epiphytes flora on the tree branches of the rain forests may contain up to $16 \mathrm{tha}^{-1}$ (Costa Rica) up to $44 \mathrm{tha}^{-1}$ (Colombia) of epiphyte plant + humus dry weight on the tree branches. 
The epiphytes, but much more the tepui plants, would profit from ISA and even from undissolved iron oxides because plant roots and fungal hyphae secrete iron-solubilizing organic acids and complexants. Microbial ferments have enough time to turn all kinds of undissolvable Fe into dissolvable Fe.

Is there a climate relevance to rain forest fertilizing by dust? Rizzolo et al. (2016) state that the iron-limited Amazon rain forest profits from the seasonal deposition of iron by Saharan dust. In particular, the deposition of iron plus other nutrients on Amazon biota is likely to increase both epiphytic growth and fungal and bacterial decomposition within the canopy (Rizzolo et al., 2016). The increase in iron bioavailability is also known to increase nutrient cycling within the forest.

Large fractions of the organic biomass produced with the help of iron and other eolic nutrients leave the Amazon region, are transported into the South Atlantic basin, and ultimately become part of the shelf and basin sediments. These are aquatic-life plants such as water hyacinth and water fern, and plant litter such as driftwood, leaves, and, in particular, colloidal and dissolved humic and fulvic acids. According to Ertel et al. (1986), the flux of dissolved organic carbon fraction at Óbidos, situated about $800 \mathrm{~km}$ upstream of the Amazon mouth, is $2 \times 10^{13} \mathrm{~g} \mathrm{C} \mathrm{yr}^{-1}$.

Some rain forests, such as the Amazonian one, benefit from sporadic dust plume fertilization of Saharan origin. Others may profit from an artificial ISA precipitation resulting in a significant additional epiphyte plant growth.

\subsection{Importance of iron for human food and health}

All organisms on Earth ride upon a "ferrous wheel" made up of different forms of iron that are essential for life (PérezGuzmán et al., 2010). Iron is an important micronutrient used by most organisms, including higher animals and human beings, and is required for important cellular processes such as respiration and oxygen transport in the blood. Its bioavailability is of concern for all the Earth's living organisms, especially in aquatic ecosystems, including clear-water and oceanic ones.

In humans, iron deficiency and anemia remain the most common nutritional disorders in the world today (Abbaspour et al., 2014).

The World Health Organization (WHO, 2013) states that a lack of sufficient micronutrients such as Fe and $\mathrm{Zn}$ represents a major threat to the health and development of the world population. The WHO (2013) estimates that over $30 \%$ of the world's population are anemic, and the percentage is even higher in developing countries (every second pregnant woman and about $40 \%$ of preschool children). Iron deficiency affects more people than any other condition, and iron deficiency exacts its heaviest overall toll in terms of ill health, premature death and lost earnings. Iron deficiency and anemia reduce the work capacity of individuals and of entire populations and cause maternal hemorrhage, impaired physical and cognitive development, reduced school performance, and lowered productivity, bringing serious economic consequences and obstacles to national development.

Iron deficiency in humans has been associated with heart failure (Avni et al., 2012; Cohen-Solal et al., 2014); gastric ulceration and anemia induced by Helicobacter pylori (Beckett et al., 2016); negative impacts on skeletal integrity (Medeiros, 2016); and cognitive disorders (Ünüsan, 2013). Iron deficiency in infancy leads to long-term deficits in executive function and recognition memory (Lukowski et al., 2013). In experiments with animals, even if the iron and the hemoglobin levels return to normal after treatment for early iron deficiency, there are long-lasting cognitive, physiological and hematological effects (Yehuda et al., 2008). Thus, several strategies and technologies have been elaborated on to manage iron deficiency in humans (Saini et al., 2016), such as food fortification (adding iron to food) (Allen, 2006) and biofortification (the process of enriching the nutrient content of crops, vegetables or fruit as they grow). The WHO, FAO and UNICEF issue guidelines or recommendations on food fortification with micronutrients (WHO, FAO and UNICEF, 2009), for instance adding ferrous sulfate, ferrous fumarate or iron complexes to wheat and maize flour (from 15 to $60 \mathrm{ppm}$, depending on the regional average consumption ranges and on other iron food vehicles). Biofortification can be achieved by utilizing crop and soil management practices to increase micronutrient concentrations in the edible crop parts (Zuo and Zhang, 2011) and can provide a sustainable solution to malnutrition worldwide, as other methods, such as diversifying people's diets or providing dietary supplements, have proved impractical, especially in developing countries. Together with dietary modification and iron dietary supplementation, iron fortification (suitable food vehicle containing higher levels of bioavailable iron) is the main recommendation of the WHO to increase iron intake, improve nutritional status and stop iron deficiency anemia. Increasing available iron levels in major staple food crops is an important strategy to reduce iron deficiency in people. The WHO anticipates that the benefits are substantial as timely treatment can restore personal health and raise national productivity levels by as much as $20 \%$.

The biofortification of bioavailable iron in staple plants provides a sustainable and economical tool to use in order to relieve iron deficiency in target populations globally (Jeong and Guerinot, 2008).

In contrast with fruit trees, where foliar iron fertilization is generally used in chlorotic leaves, canopy, Fe fertilization is increasingly being used in cereal crops to increase the Fe concentration in grains, in what is called biofortification. In these crops, which are generally treated with foliar iron sprays when there is no leaf chlorosis, applied iron has been shown to re-translocate efficiently to other plant organs, both in wheat (Zhang et al., 2010) and rice (Wei et al., 2012). Zuo and Zhang (2011) have developed strategies to increase iron 
uptake by roots and transfer it to edible plant portions, allowing absorption by humans from plant food sources.

\subsection{Active inhibition of methane emissions from wetlands, lakes and sediments}

Lipson et al. (2010) found that in Arctic peat ecosystem, Fe and humic reduction competes with methanogenesis as electron acceptors and inhibits some $\mathrm{CH}_{4}$ production; on the basis of conservative measurements of net Fe reduction rates, this process is comparable in magnitude to methanogenesis.

In wet sedge tundra landscapes, Miller et al. (2015) conducted experiments that showed an inverse relationship between dissolved iron and $\mathrm{CH}_{4}$ concentrations and found that net $\mathrm{CH}_{4}$ fluxes were significantly suppressed following the experimental addition of iron and humic acids. Iron and humic acid amendments significantly suppressed in situ net methane flux.

Lipson et al. (2013) conducted experiments on two different ecosystems: one with permafrost and naturally high levels of soil $\mathrm{Fe}$ and one with no permafrost and naturally low levels of soil Fe. The addition of Fe(III) and humic acids (electron acceptors) significantly reduced net $\mathrm{CH}_{4}$ flux for at least several weeks post-treatment, without significantly altering $\mathrm{CO}_{2}$ fluxes. There was no significant difference between the reduction in $\mathrm{CH}_{4}$ flux caused by $\mathrm{Fe}$ (III) and the one caused by humic acids. The future release of GHGs from high-latitude wetland ecosystems can significantly be altered by this natural and widespread phenomenon. These results also show that the suppression of $\mathrm{CH}_{4}$ flux in this type of ecosystem can be induced by the artificial addition of $\mathrm{Fe}(\mathrm{III})$, humic acids or other electron acceptors.

L. Zhang et al. (2009) found methanogenesis and sulfate reduction inhibition after ferric salt dosing of anaerobic sewer biofilms. Similar methanogenesis inhibition and even increases in rice productivity by ferric salt addition have been described by others (Ali et al., 2008; Liu et al., 2012, 2016; W. Wang et al., 2014).

Amos et al. (2012) found support for the hypothesis that $\mathrm{Fe}$ (III) mediates $\mathrm{CH}_{4}$ oxidation in a crude contaminated aquifer.

Although some iron oxides such as magnetite and hematite have different properties and may facilitate methanogenesis by some types of microorganisms (Zhou et al., 2014), it is worth noting that the iron solubility and bioavailability properties of the ISA are similar to the ferrihydrite which inhibits methanogenesis in the same experiments (Zhou et al., 2014), and in general $\mathrm{Fe}(\mathrm{III})$ reduction by methanogens contributes to Fe(III) inhibition of methanogenesis (Van Bodegom et al., 2004).

Experiments conducted in humid tropical forest soils, which are also an important source of atmospheric $\mathrm{CH}_{4}$ and where $\mathrm{Fe}(\mathrm{III})$-reducing bacteria coexist with methanogens, show that upon the addition of acetate, the production increase in $\mathrm{CH}_{4}$ is much greater (67 times) than that in $\mathrm{Fe}^{2+}$
(2 times), indicating that the two processes were acetate limited and suggesting that $\mathrm{Fe}(\mathrm{III})$-reducing bacteria were suppressing methanogenesis when acetate availability is limited (Teh et al., 2008). For Roden and Wetzel (1996) a significant suppression of $\mathrm{CH}_{4}$ production in freshwater wetlands could be mediated by $\mathrm{Fe}$ (III) oxide reduction within globally extensive iron-rich tropical and subtropical soil regimes.

All these results support the hypothesis that additional to the many photolysis-dominated $\mathrm{CH}_{4}$ depletion actions by ISA in the troposphere, even after ISA precipitation on wetlands, marshes, lakes, rice paddies and shelf sediments, ISA will inhibit the emission of $\mathrm{CH}_{4}$. The degree to which $\mathrm{Fe}$ (III) reduction suppresses $\mathrm{CH}_{4}$ emissions under different soil conditions should be considered by regional and global models of GHG dynamics.

No published studies were found about the biogeochemical cycle of iron to the continents and land in specialized journals such as Global Biogeochemical Cycles nor in the chapter about the biogeochemical cycles of the latest IPCC report, and the recent Iron Model Intercomparison Project (FeMIP) seems to focus on ocean interactions (Tagliabue et al., 2015; Tagliabue and Dutkiewicz, 2016).

It is now well known that in large areas of the open ocean, iron is a key limiting nutrient and that in alkaline terrestrial landscapes iron deficiency induces plant chlorosis. The authors' hope is that bringing together in this review seemingly disparate lines of research from diverse disciplines will result in a more global understanding of the global biogeochemical iron cycle, especially over terrestrial landscapes, peat bogs and other wetlands.

\section{Estimations of the ISA demand by the ISA method}

\subsection{ISA can induce a significant $\mathrm{CH}_{4}$ depletion}

Wittmer et al. (2015a, b, 2016) and Wittmer and Zetzsch (2016) reported that the ISA method is very efficient for $\cdot \mathrm{Cl}$ generation. Hence, ISA induces the depletion of GHG methane. This results in a prior colling effect. Therefore, ISA appears to be a very promising cooling method with technical and economic stakes. But the answer depends strongly on the volume of ISA to be produced and emitted. Indeed, the ISA plume should be released high enough in the troposphere to get sufficient distribution and residence time in combination with $\cdot \mathrm{Cl}$ generation quantity.

Based on results of $\mathrm{Fe}$-photolysis-induced $\cdot \mathrm{Cl}$ production, Wittmer et al. (2015a) estimated the feasibility of $\mathrm{CH}_{4}$ depletion by $\mathrm{NaCl}$-diluted ISA. Wittmer et al. found $\mathrm{a} \cdot \mathrm{Cl}$ emission of $1.9 \times 10^{5} \cdot \mathrm{Cl} \mathrm{cm}^{-3}$ at a $\mathrm{Cl}^{-} / \mathrm{Fe}$ (III) molar ratio of 101 within the $\mathrm{pH}$ range of $2.1-2.3$. The same $\cdot \mathrm{Cl}$ generation was found at the suboptimal $\mathrm{pH}$ of 3.3-3.5 and at a $\mathrm{Cl}^{-} / \mathrm{Fe}$ (III) molar ratio of 51 . This $\mathrm{Cl}$ generation is 4 times higher than the reference which corresponds to a significant $\mathrm{CH}_{4}$ lifetime reduction in the troposphere (Wittmer et al., 2015a). A $\mathrm{pH}$ range of around 2 corresponds to the natural aerosol $\mathrm{pH}$ 
within the oceanic boundary layer. The optimum efficiency of $\cdot \mathrm{Cl}$ production by the photolysis of ISA corresponds to $\mathrm{pH} 2$, whatever the source of $\mathrm{Cl}^{-}, \mathrm{NaCl}$ or gaseous $\mathrm{HCl}$ and if ISA is an iron(III) oxide or an iron(III) chloride aerosol (Wittmer et al., 2015a).

According to Lim et al. (2006) and to Meyer-Oeste (2010) the optimum $\cdot \mathrm{Cl}$ production by sunlight photolysis of $\mathrm{FeCl}_{3}$ solutions or ISA is generated in the acidic $\mathrm{pH}$ range. The efficient $\cdot \mathrm{Cl}$ generation is necessary for an efficient $\mathrm{CH}_{4}$ depletion by ISA. $\mathrm{FeCl}_{3}$ has an acidic $\mathrm{pH}$ from the beginning because it hydrolyzes in accordance with Eq. (4), except if it has come about by the condensation and hydrolysis of $\mathrm{FeCl}_{3}$ vapor, by the nebulization of pure $\mathrm{FeCl}_{3}$ solution, or by combustion to pyrogenic $\mathrm{FeOOH}$ and reaction and hydrolysis with $\mathrm{HCl}$ and $\mathrm{H}_{2} \mathrm{O}$ to $\mathrm{FeCl}_{3}$ solution.

$\mathrm{FeCl}_{3}+2 \mathrm{H}_{2} \mathrm{O} \rightarrow \mathrm{FeCl}_{2} \mathrm{OH}+\mathrm{H}_{3} \mathrm{O}^{+}+\mathrm{Cl}^{-}$

\subsection{ISA demand calculation}

Current $\mathrm{CH}_{4}$ depletion by $\cdot \mathrm{Cl}$ is estimated to be $3.3 \%$ (Platt et al., 2004) to $4.3 \%$ (Allan et al., 2007). According to the results of Wittmer et al. (2015a), at a $\mathrm{Cl}^{-} / \mathrm{Fe}$ (III) molar ratio of 101, this amount would rise 4-fold from 13 to $17 \%$.

Wittmer et al. (2015a) used their results obtained at a $\mathrm{Cl}^{-} / \mathrm{Fe}$ (III) ratio of 51 at the $\mathrm{pH}$ of 3.3-3.5: $1.9 \times 10^{5} \cdot \mathrm{Cl} \mathrm{cm}^{-3}$. We consider that this $\mathrm{pH}$ is suboptimal. Instead the results obtained at a $\mathrm{Cl}^{-} / \mathrm{Fe}$ (III) ratio of 101 at the $\mathrm{pH}$ of 2.1-2.3: $1.9 \times 10^{5} \cdot \mathrm{Cl} \mathrm{cm}^{-3}$ should be used.

Moreover, Wittmer et al. (2015a) made two limitative estimations:

- They only focused on the $\mathrm{Cl}$ delivery in the condensed state by coagulation as a $\mathrm{Cl}^{-}$transfer option between ISA particles and the $\mathrm{Cl}$ source sea-salt aerosol, ignoring other $\mathrm{Cl}$ sources, $\mathrm{Cl}$ aggregate states and $\mathrm{Cl}$ transfer mechanisms.

- According to this model, the ISA particles should continuously lose their $\mathrm{Cl}^{-}$load by $\cdot \mathrm{Cl}$ emission in the daylight, and as a consequence they could only gain back $\mathrm{Cl}$ by coagulation with sea-salt aerosol particles. As further consequences of this model, the $\mathrm{Cl}^{-} / \mathrm{Fe}$ (III) ratio of ISA particles would decrease, their diameter would increase and their residence time in the troposphere would decrease.

But according to Graedel and Keene (1996) and Keene et al. (1999), the next prominent source of inorganic $\mathrm{Cl}$ in the troposphere beside sea-salt aerosol is vaporous $\mathrm{HCl}$. This is the main source from which the ISA particles can refill the chloride lost by photolysis. The main $\mathrm{Cl}$ uptake mechanism from this $\mathrm{Cl}$ source is sorption from the gaseous phase.

The main $\mathrm{HCl}$ sources are the sea-salt reaction with acids, $\mathrm{CH}_{4}$ and other hydrocarbon reactions with $\cdot \mathrm{Cl}$ (Keene et al., 1999), flue gases of coal, and biomass and garbage combus- tion (McCulloch et al., 1999), as shown in the global Reactive Chlorine Emissions Inventory (Keene et al., 1999), $\mathrm{HCl}$ from chlorocarbons being a significant part (Sanhueza, 2001), in particular from $\mathrm{CH}_{3} \mathrm{Cl}$, which is the largest, natural contributor to organic chlorine in the atmosphere (Lobert et al., 1999). Wittmer et al. (2015a) estimate that the global production rate of $1785 \mathrm{Tg} \mathrm{yr}^{-1}$ of sea-salt aerosol $\mathrm{Cl}^{-}$has to be doped with iron at a $\mathrm{Cl}^{-} \mathrm{Fe}$ (III) molar ratio of 51; however, we consider that it has to be estimated at a molar ratio of 101 (according to the first point above).

The calculations made with these limitative assumptions resulted in an iron demand of $56 \mathrm{Tg} \mathrm{yr}^{-1} \mathrm{Fe}$ (III) to obtain the desired $\mathrm{CH}_{4}$ depletion effect (Wittmer et al., 2015a). However, with the limitative assumption that there is no $\mathrm{Cl}^{-}$ source other than sea salt, the calculations with a $\mathrm{Cl}^{-} / \mathrm{Fe}$ (III) ratio of 101 result in an $\mathrm{Fe}(\mathrm{III})$ demand of only $18 \mathrm{Tg} \mathrm{yr}^{-1}$.

ISA can be produced from pyrogenic iron oxides according to method I (see Sect. 7). Pyrogenic oxides have particle sizes lower than $0.1 \mu \mathrm{m}$. Diameters of the $\mathrm{NaCl}$-diluted ISA particles of the Wittmer tests (Wittmer et al., 2015a) are round about $0.5 \mu \mathrm{m}$. This confirms the test results of Wittmer et al. (2015a) as a calculation basis.

But Wittmer et al. (2015a) made two other limitative assumptions:

- ISA has the same particle size and corresponding surface range as sea salt.

- ISA has the same residence time as sea-salt aerosol in the troposphere.

Due to their coarse aerosol particle range, the residence time of sea-salt particles in the troposphere is inferior to 1 day (Jaenicke, 1980), while the artificial ISA particles with diameters lower than $0.5 \mu \mathrm{m}$ have residence times in the troposphere from at least 10 days to several weeks (Kumar et al., 2010; Penner et al., 2001).

Known salt aerosol generation methods by vapor condensation or nebulization (Biskos et al., 2006; Gupta et al., 2015) allow not only the flame-descending ISA type 1 (Oeste, 2004) but also the condensation- and nebulizationdescending ISA variants 2 and 3 (see Sect. 7) to be produced with aerosol particle diameters between 0.1 and $0.01 \mu \mathrm{m}$. Diameters of salt aerosol particles from these physical aerosol generation methods are up to, or more, than 1 order of magnitude smaller than of those used in the experiments by Wittmer et al. (2015a).

Analogously to $\mathrm{CCN}$ behavior in cloud processing (Rosenfeld et al., 2008), most of the small-sized ISA particles are protected by their small sizes from coagulation or coalescence with sea-salt aerosol particles. This effect prevents ISA from leaving the optimum active atomic chlorine emission conditions: a low $\mathrm{pH}$ and low particle diameter range.

The residence time difference of more than 1 order of magnitude in comparison to sea-salt aerosol further reduces the 
Fe demand for ISA production from $18 \mathrm{Tg} \mathrm{yr}^{-1}$ to less than $1.8 \mathrm{Tg} \mathrm{yr}^{-1}$.

The properties of the ISA particles produced by the most preferred ISA method variant are explained in Sect. 4. The difference between them and the NaCl-diluted ISA tested by Wittmer et al. (2015a) is that ISA particles are made of $\mathrm{FeCl}_{3} \times \mathrm{nH}_{2} \mathrm{O}$, undiluted by $\mathrm{NaCl}$, or $\mathrm{FeOOH}$ coated by $\mathrm{FeCl}_{3} \times \mathrm{nH}_{2} \mathrm{O}$, undiluted by $\mathrm{NaCl}$ (Meyer-Oeste, 2010; Oeste, 2009). The $\mathrm{Cl}^{-} / \mathrm{Fe}(\mathrm{III})$ molar ratios of $\mathrm{FeCl}_{3} \times \mathrm{nH}_{2} \mathrm{O}$ are at 3 or even lower. The $\mathrm{Cl}^{-} / \mathrm{Fe}(\mathrm{III})$ molar ratio of typical ISA particles is at least 30 times smaller than the molar $\mathrm{Cl}^{-} / \mathrm{Fe}$ (III) ratio of 101 of the ISA tested by Wittmer et al. (2015a). This reduces the Fe demand for ISA production again at least by 1 order of magnitude from $<1.8 \mathrm{Tg} \mathrm{yr}^{-1}$ to about $<0.2 \mathrm{Tg} \mathrm{yr}^{-1}$.

Wittmer et al. (2015a) considered only sea-salt aerosol particles as transport vehicles for ISA and as the only possible contact medium to gain chloride ions as $\cdot \mathrm{Cl}$ source. It is well known that coal combustion is a major source of active chlorine (Keene et al., 1999; McCulloch et al., 1999; Sanhueza, 2001) as well as iron (Ito et al., 2016; Luo et al., 2008; Sedwick et al., 2007; Wang et al., 2015b); thus, both iron and chlorine are jointly issued by other mechanisms and sources.

As stated in our Sect. 6.2, sea-salt aerosol has residence times in the troposphere of less than 1 day depending on its coarse-particle diameters; it is not possible to for aerosol to cross intercontinental distances in this time.

In reality the chloride transfer between sea-salt aerosol particles and ISA particles may take place without any contact or coagulation because the troposphere is an acidic environment. The troposphere is a source of organic and inorganic acids, which are in permanent contact with sea-salt aerosol. The acid ingredients in contact with sea spray produce $\mathrm{HCl}$. Furthermore, ISA is produced by combustion and is elevated by flue gas plumes: acid precursors such as $\mathrm{SO}_{2}$ or $\mathrm{NO}_{x}$ have higher concentrations within the flue gas plume compared to the tropospheric environment. The acids generated by flue gas plume produce additional $\mathrm{HCl}$ by reaction with the sea-salt aerosol (von Glasow, 2000). As a result, ISA and ISA precursors may absorb any chloride requirement via $\mathrm{HCl}$ vapor from the sea spray source itself (Wittmer and Zetzsch, 2016).

Additionally to the $\cdot \mathrm{Cl}$ emission increase with increasing iron concentration in the aerosols tested, the results of Wittmer et al. verify an increase in $\cdot \mathrm{Cl}$ emission with decreasing $\mathrm{pH}$ (Wittmer et al., 2015a). According to Wittmer and Zetzsch (2016), Meyer-Oeste (2010) and Oeste (2009), oxidic ISA aerosol particles may be generated free of any $\mathrm{pH}$-buffering alkaline components. This hampers their $\mathrm{pH}$ decrease by air-borne $\mathrm{HCl}$ to the optimum $\mathrm{pH}$ of around 2 . Sea-salt buffering of the absorbed $\mathrm{HCl}$ (Sullivan et al., 2007) by the alkali and earthen alkali content of sea-salt aerosol can occur only by coagulation, most probable in a minor ISA particle fraction but not in the bulk. From the beginning of its action in the troposphere, ISA remains in the optimum $\cdot \mathrm{Cl}$ emission mode: low $\mathrm{pH}$ and high iron concentration levels.

Preferred ISA is produced by the ISA method variant 1 or variant 3 as described in Sect. 7. Hence, ISAs are composed of particles made by flame pyrolysis or iron salt vapor condensation. The ISA particles mentioned have diameters of $1 / 10$ of the particle diameters of the Wittmer tests. These ISA particles have an optimum chlorine activation efficiency

- in an appropriate chloride content or chloride delivering environment;

- at a $\mathrm{pH}<2$;

- if they are emitted above the tropospheric boundary layer.

In such cases, the Fe demand may even fall short of the cal-

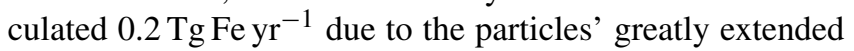
surface area and greatly extended residence time in the atmosphere.

It has to be noted that this ISA demand calculation result refers only to the ISA cooling property depending on $\mathrm{CH}_{4}$ depletion; other cooling properties depending on cloud albedo, the depletion of $\mathrm{CO}_{2}$, black and brown aerosol, ozone decrease, and other causes are still unconsidered.

Other oxidation activity on GHGs and aerosols is induced by the $\cdot \mathrm{OH}$ generation activity of ISA: volcanic eruption plumes contain high concentrations of $\cdot \mathrm{Cl}$ plus $\cdot \mathrm{OH}$ (Baker et al., 2011) and are characterized by decreased $\mathrm{CH}_{4}$ concentrations (Rose et al., 2006). The co-absorption of $\mathrm{H}_{2} \mathrm{O}$ and $\mathrm{HCl}$ is the main reason for the generation of volcanic ash particle coats containing soluble-Fe salts originating from insolubleFe oxides and Fe silicates (Hoshyaripour et al., 2015; Martin et al., 2012). Gaseous $\mathrm{HCl}$ from the eruption plume entails $\mathrm{Fe}$ chlorides covering the surfaces of volcanic ash particles (Ayris et al., 2014). Therefore, it is reasonable that the photolysis of those chlorides is the origin of both: $\cdot \mathrm{Cl}$ and $\cdot \mathrm{OH}$ generation in volcanic plumes.

Hydroxide radical $\cdot \mathrm{OH}$ can change from the liquid aerosol phase into the gaseous phase (Nie et al., 2014) but not nearly as easily as $\cdot \mathrm{Cl}$ can. Indeed, the Henry's law solubility constant of $\cdot \mathrm{OH}$ is about 1 order of magnitude higher than that of $\cdot \mathrm{Cl}$ and is in the same range as that of $\mathrm{NH}_{3}$ (Sander, 2015). But when their hygroscopic water layer shrinks in dry air or by freezing, ISA particles might act as $\cdot \mathrm{OH}$ emitters. These additional $\cdot \mathrm{OH}$ emissions might further increase the $\mathrm{CH}_{4}$ oxidation potential of volcanic ash or artificial ISA and thus reduce even more the Fe demand for ISA; though this has not been tested yet, it cannot be ruled out.

In order to take care not to increase the cooling effect too much, a reasonable goal might be to start the ISA method

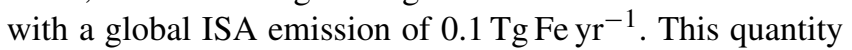
corresponds to the magnitude of the actual $\mathrm{Fe}$ input from the atmosphere into the oceans in the form of soluble salt, which is estimated to be from 0.1 up to $0.26 \mathrm{Tg} \mathrm{yr}^{-1}$ (Ito and Shi, 
2016; Johnson and Meskhidze, 2013; Myriokefalitakis et al., 2014). Doubling or even tripling this input quantity by the ISA method is technically easy and economically feasible as will been seen in Sect. 7.

\section{The ISA method: how to increase artificial iron emissions}

The preceding calculation shows that the ISA method has the potential to cut back on the rise in $\mathrm{CH}_{4}$ and $\mathrm{CO}_{2}$ and the small decline in atmospheric oxygen content (Keeling and Shertz, 1992; Manning and Keeling, 2006) because it acts through a bundle of chemical and physical means. The ISA method might retard, stop or even help to restore these GHG contents to preindustrial levels. By the ISA method, doubling or tripling the ISA level in the troposphere seems to be possible by feasible technical and economical means.

Since 2004 proposals have been published (Meyer-Oeste, 2010; Oeste, 2004, 2009, 2015; Oeste and Ries, 2011) to modify combustion processes and flue gas emissions from traffic and power-generating combustions and their warm uplifting flue gases in order to use them as ISA plume emission sources in the troposphere. Any hot flue gas plumes emitted by ship and air traffic and fossil and solar power are predestined for the ISA method.

At least three variants of ISA production are proposed.

- Variant 1: the emission of flame pyrolytic $\mathrm{FeOOH}$ aerosol with particle diameters smaller than $100 \mathrm{~nm}$ (Buyukhatipoglu and Clyne, 2010; Kammler et al., 2001) as an ISA precursor by co-combustion of organic iron or carbonyl iron additives with liquid or gaseous fuels or heating oils combusted in ship or and jet engines or by oil or gas combustors. The co-combustion of iron compounds is a possible measure in coal power stations by mixing the ISA-precursor-containing "oil" combustion flue gas to the coal combustion flue gas after the dry flue gas cleaning stage. Useful side effects of iron additives are fuel efficiency optimization and soot emission minimization (Kasper et al., 1998; Kim et al., 2008; Madhu et al., 2015; Weiser et al., 2007). The emitted $\mathrm{FeOOH}$ aerosol plumes convert into the ISA plume immediately after leaving the emission sources due to the high reactivity of flame pyrolytic Fe oxides. The time it takes to cover the flame-pyrolytic $\mathrm{FeOOH}$ particle surface with $\mathrm{Fe}(\mathrm{III})$ chlorides through $\mathrm{HCl}$ absorption from the gaseous phase is several times shorter that than necessary for the generation of iron chlorides from natural iron oxide minerals in loess dust particles (Rubasinghege et al., 2010; Sullivan et al., 2007).

- Variant 2: the injection of vaporous ISA precursor iron compounds such as $\mathrm{FeCl}_{3}$ into a carrier gas. By coming into contact with the carrier gas and/or the atmosphere, the vaporous iron compounds condense and/or convert by physical and/or chemical means directly into ISA. Contrary to all other ISA precursors, the sunlit $\mathrm{FeCl}_{3}$ vapor is photoreduced by concomitant generation of $\cdot \mathrm{Cl}$ (Rustad and Gregory, 1980). Thus, methane-depleting - $\mathrm{Cl}$ emission can start even before this ISA precursor has changed into hydrated $\mathrm{FeCl}_{3}$.

- Variant 3: the injection of an ultrasonic nebulized aqueous $\mathrm{FeCl}_{3}$ solution as an ISA precursor into a carrier gas. ISA is generated by water evaporation from the aerosol droplets.

The preferred heights of ISA plume generation in the troposphere are $1000 \mathrm{~m}$ above ground or at higher altitudes in order to pass the boundary layer. There, the ISA plumes have optimum conditions to spread over a large area due to sufficient lifetimes. The necessary buoyancy to lift up the ISA plumes can be regulated by controlling their carrier gas temperatures. Uplift towers (Ming, 2016), vortex generators (Michaud and Renno, 2011) or tethered balloons (Davidson et al., 2012; Kuo et al., 2012) are preferential means to direct ISA by carrier gas uplift to the heights mentioned.

The primary ochre-colored $\mathrm{FeOOH}$ aerosol particles emitted by ISA method I have diameters of $<0.05 \mu \mathrm{m}$. According to previous studies, iron oxides are strong absorbers at visible wavelengths and might play a critical role in climate perturbation caused by dust aerosols (Sokolik and Toon, 1999; X. L. Zhang et al., 2015). But this effect is not applicable to the ISA methods $\mathrm{FeOOH}$ aerosol because it is emitted by flue gas plumes generated in parallel and containing $\mathrm{SO}_{2}$ and $\mathrm{NO}_{x}$ as sulfuric and nitric acid generators. Due to their smalldiameter-dependent high surface area the aerosol particles immediately react with $\mathrm{HCl}$. $\mathrm{HCl}$ is generated by the reaction between sea-salt aerosol and flue-gas-borne acids.The primary reaction product is the orange-colored $\mathrm{FeCl}_{3}$ aerosol: ISA. But daytime sun radiation bleaches ISA by $\mathrm{FeCl}_{2}$ and - $\mathrm{Cl}$ generation; nighttime reoxidation of ISA plus $\mathrm{HCl}$ absorption regenerates $\mathrm{FeCl}_{3}$ again. $\mathrm{FeCl}_{2}$ is colorless at low humidity and pale green at high humidity.

The provision of phytoplankton to optimize its growth with other nutrients such as $\mathrm{Mn}, \mathrm{Zn}, \mathrm{Co}, \mathrm{Cu}, \mathrm{Mo}, \mathrm{B}, \mathrm{Si}$ and $\mathrm{P}$ by the ISA method is possible by at least variants 1-3 of the ISA method, i.e., by co-combustion, co-condensation or co-nebulizing.

Global fixing regulations of $\mathrm{GHG}$ emission certificate prices, values and ISA emission certificate credit values would be simple but effective measures for the quickest worldwide implementation of the ISA flue gas conditioning method.

Anderson (2016) mentioned that "the complete set of 400 IPCC scenarios for a $50 \%$ or better chance of $2{ }^{\circ} \mathrm{C}$ assume either an ability to travel back in time or the successful and large-scale uptake of speculative negative emission technologies". He refers to going back in time because some scenarios assume "the successful implementation of a stringent and global mitigation regime in 2010.' 
A large part of the research devoted to climate engineering methods concerns SRM (sunlight reduction methods), such as mimicking the effects of large volcanic emissions by adding sulfate aerosols to the stratosphere as suggested for instance by Crutzen (2006). Numerous other types of particles have been suggested for these aerosols, for instance titania by Jones et al. (2015). But SRM only buys time and has numerous drawbacks.

On the one hand, SRM does not address the main cause of global warming (GHG emissions) nor does it prevent ocean acidification. On the other hand, several carbon dioxide removal (CDR) technologies do, but their costs are much larger than SRM and the scale requested poses many technological challenges; see, for instance, "Scaling up carbon dioxide capture and storage: from megatons to gigatons" (Herzog, 2011).

Very few CDR methods without the emission of disadvantageous pollution are known. One of those is the terra preta method: it is characterized by the mixing of ground biochar into agricultural soils. The climate relevancies of this method are a sustained fixation of former $\mathrm{CO}_{2}$ carbon, minimization of fertilizer consumption and $\mathrm{N}_{2} \mathrm{O}$ emission reduction from the fertilized terra preta soils. Char has similar properties within the soil environment as humic substances, but in the environment, char is resistant against oxidation.

Comparing the terra preta method to other CDR methods, such as fertilizing the ocean by micronutrients, shows that lower specific material expenses are needed by CDR methods per unit of $\mathrm{CO}_{2}$ removed from the atmosphere (Betz et al., 2011). The ISA method we propose is a member of this CDR group; thus, this result is also valid. In addition, the further climate effects of the ISA method (such as the depletion of $\mathrm{CH}_{4}$, tropospheric ozone and soot, plus cloud whitening) reduce the specific material expense level. Furthermore, the ISA method mimics a natural phenomenon (mineral irondust transport and deposition) and only proposes to improve the efficiency of an already existing anthropogenic pollution. Myriokefalitakis et al. (2015) estimates that "The present level of atmospheric deposition of DFe [dissolved iron] over the global ocean is calculated to be about 3 times higher than for 1850 emissions, and about a $30 \%$ decrease is projected for 2100 emissions. These changes are expected to impact most on the high-nutrient-low-chlorophyll oceanic regions." Their model "results show a 5-fold decrease in Fe emissions from anthropogenic combustion sources $(\sim 0.013 \mathrm{Tg}$ $\mathrm{Fe} \mathrm{yr}^{-1}$ in the year 2100 against $\sim 0.070 \mathrm{Tg}^{-\mathrm{Fe} \mathrm{yr}^{-1}}$ in the present day), and about $45 \%$ reduction in mineral-Fe dissolution $\left(\sim 0.078 \mathrm{Tg}_{-} \mathrm{Fe} \mathrm{yr}^{-1}\right)$ compared to the present day $\left(\sim 0.175 \mathrm{Tg}^{-F e} \mathrm{yr}^{-1}\right)$.". Meanwhile the model used by Misumi et al. (2014) predicts an iron supply increase to highnutrient, low-chlorophyll (HNLC) surface waters by 2090, especially in the eastern equatorial Pacific, attributed by the authors to changes in the meridional overturning and gyrescale circulations that might intensify the advective supply of iron to surface waters. Furthermore, several authors (Annett et al., 2015; Bhatia et al., 2013; Hawkings et al., 2014;
Raiswell et al., 2008, 2016) point out that both glacial and deep-water Fe sources may increase with continued climate warming due to Fe input from other sources, such as shelf sediments, meltwater, icebergs, rivers, surface water runoff and dust input.

Recently, Boyd and Bressac (2016) suggested rapidly starting tests to determine the efficiency and side effects of CDR ocean iron fertilizing methods and analyzed possible geopolitical conflicts together with some other geoengineering methods (Boyd, 2016).

Several experts, for instance Hansen et al. (2016), recently expressed the urgent warning that mankind only has a short time left to address and control climate warming. As a consequence, it is necessary for mankind to find climate controlling substances which might generate the most effective and reversible climate cooling effects within the shortest period as soon as possible. Lifetimes of ISA emissions in the troposphere are much shorter than those of sulfates in the stratosphere. Of course, such tools and agents have to be rapidly evaluated against side effects to ecosystems, human health and, last but not least, their economic burdens.

\section{Interaction of the ISA method with other measures to protect the environment}

According to Wittmer and Zetzsch (2016), an elevated $\mathrm{HCl}$ content in the atmosphere triggers the methane-depleting coating of oxidic ISA precursors by photolytic active Fe(III) chlorides. Any measure triggering the reduction in the $\mathrm{HCl}$ content of the atmosphere would impair the effectiveness of the ISA method based on this kind of method.

In this sense all kinds of measures to reduce the sulfur and $\mathrm{NO}_{x}$ content of the flue gas content of gaseous, liquid and gaseous fuels would decrease the effectiveness of oxidic ISA precursors, as the $\mathrm{S}$ and $\mathrm{NO}_{x}$ oxidation products sulfuric acid aerosol and gaseous nitric acid are the main producers of $\mathrm{HCl}$ by changing sea-salt aerosol into sulfate and nitrate aerosol. Even the measures of reducing the energy production from fuel burning by changing to wind and photovoltaic energy would reduce this $\mathrm{HCl}$ source.

Sea-salt aerosols produce $\mathrm{HCl}$ after contact with organic aerosol and organic volatile matter as the organic compounds generate acid oxidation products such as oxalic acid (Drozd et al., 2014; Laskin et al., 2012; B. Wang et al., 2014). A large fraction of organic aerosols and secondary organic aerosols originates from anthropogenic sources such as combustion. The change to wind and photovoltaic energy would reduce this $\mathrm{HCl}$ source.

The proposed climate engineering measure of producing sulfuric acid aerosol within the stratosphere by inducing an albedo increase would increase the $\mathrm{HCl}$ content, through contact of the precipitating acid aerosol with tropospheric sea-salt aerosol. Even the proposed climate engineering measure of increasing the sea-salt aerosol content of the tropo- 
sphere by artificial sea-salt aerosol as a cloud whitening measure could be used as an ISA method trigger if flue gas is used to elevate the sea-salt aerosol.

\section{Discussion}

In order to fight global warming, this review proposes to enhance the natural actions of $\mathrm{Cl}$ atoms in the troposphere, together with the synergistic action of iron in the atmosphere, ocean, oceanic sediment and land compartments, as a climate engineering method. The main results expected are a diminution of long-lived well-mixed atmospheric methane and carbon dioxide, but the diminution of local short-lived tropospheric ozone is also possible, as well as effects on the Earth albedo, the restoration of the oxygen flux into the deep-ocean basins, organic carbon storage, etc.

The most important actor in the process of $\mathrm{CO}_{2}-\mathrm{C}$ transfer from the atmosphere to the Earth interior is the carbonate $\mathrm{C}$ precipitation in the crust rocks and sediments below the ocean. The ocean crust acts like a conveyor belt between crust evolution at MOR and its subduction zones into the mantle. The media transported are carbonate $\mathrm{C}$, small amounts of organic $\mathrm{C}$, ocean salt, ocean water and sediments. This process is part of the homeostasis of the planet. Disturbances of this system are induced by stratification processes within the ocean basins caused by density differences between different layers of the water column. Most stratification events are induced by climate warmings. Any of these homeostasis disturbances are removed by the system on geological timescales. Signs of such disturbances are more or less prominent events of extinction and of elevated organic $\mathrm{C}$ content in the ocean sediments. Because the recent climate warming will induce a new ocean stratification event, mankind must stop it. Like several interglacial stratification events in the glacial periods, the actual stratification is also induced by increasing meltwater discharge. The past interruptions of the interglacial climate warmings teach us that the interruption events were accompanied, as a rule, by dust events. As demonstrated, the climate cooling effects of these dust events are induced by the chemical and physical actions of ISA.

In high-nutrient, low-chlorophyll oceanic areas, where the contribution of atmospheric deposition of iron to the surface ocean could account for about $50 \%$ of $\mathrm{C}$ fixation, as well as in oceanic nitrogen-limited areas, where atmospheric iron relieves the iron limitation of diazotrophic organisms (thus contributing to the rate of $\mathrm{N}$ fixation), atmospheric deposition of iron has the potential to augment atmospherically supported rates of $\mathrm{C}$ fixation (Okin et al., 2011) and thus "cool the Earth" by removing $\mathrm{CO}_{2}$ from the atmosphere.

Maybe the iron atmospheric deposition over terrestrial landscapes and wetlands has similar effects? Are there possible benefits of atmospheric deposition of soluble iron over the continents in which iron deficiency in plants occurs over
$30 \%$ of their area and which have high $\mathrm{pH}$ calcareous soils that make soil Fe unavailable for plants (Abadía et al., 2011)? Iron-deficiency-induced chlorosis in plants can be solved by the addition of soluble-iron complexes to the soil or by foliar application of sprays containing mineral iron (for instance $\mathrm{FeSO}_{4}$ ) (Basar et al., 2014) or iron chelates (Fe-EDTA among others) (Fernández et al., 2013). Iron, sulfate and several organic iron complexes such as iron oxalate are known constituents of atmospheric dust (Johnson and Meskhidze, 2013), but unfortunately no published work was found about possible effects on plant chlorosis by foliar deposition of soluble iron from atmospheric dust.

We did not find studies about the impacts of atmospheric iron nutrient deposition on terrestrial ecosystem productivity. More research is needed to continue to enhance our understanding of the possible benefits of iron cycling in freshwater and terrestrial landscape environments, as well as in atmospheric and sediment environments, in particular of its numerous potential capacities to fight global warming. The cooling effects of ISA and iron reviewed in this article already provide an insight into the progress made on understanding the iron cycles from a range of perspectives.

There is abundant literature on the many geoengineering methods that have been proposed to cool the Earth (Lackner, 2015; Z. Zhang et al., 2015). In particular, the injection of sulfate aerosols into the stratosphere is the most studied method, as it mimics the episodic action of natural volcanoes (Ming et al., 2014; Pope et al., 2012). Injected particles into the stratosphere reduce the radiative balance of Earth by scattering solar radiation back to space, so several types of particles are envisioned with a wide range of side effects (Jones et al., 2015).

The literature also describes many options to deliver sulfates, their precursors (or other particles), to the stratosphere (Davidson et al., 2012). For instance, airplane delivery of the sulfate aerosols by the kerosene combustion process requires military jets due to commercial aircrafts' limited altitude of $10 \mathrm{~km}$ (30000 feet) where $20 \mathrm{~km}$ are required (Davidson et al., 2012).

In the case of ISA, the altitude needed to cool the Earth is much lower (it is in the troposphere), and the total quantities to deliver are 1 order of magnitude smaller. So air travel is a possible means for ISA delivery. But the global jet fuel consumption is only about $240000 \mathrm{tyr}^{-1}$. Even by assuming the very high emission rate of $1 \mathrm{~kg}$ ISA precursor iron per ton of jet fuel, only $24 \mathrm{t} \mathrm{yr}^{-1}$ might be emitted. This seems far from the order of magnitude of the target ISA emissions.

From the many other possible delivery strategies envisioned for SRM by stratospheric aerosols, many are not suited for ISA, such as artillery, missiles and rockets (Davidson et al., 2012); it would be cheaper and cause less pollution to use the flue gas of a reduced number of thermal power plants. This might be efficient enough to deliver the artificial iron aerosol needed over the boundary layer in order for 
aerosols to stay in the troposphere for several days or weeks and become widely distributed (Williams et al., 2002).

According to Luo et al. (2008), the deposition of soluble iron from combustion already contributes 20 to $100 \%$ of the soluble-iron deposition over many ocean regions.

As an example, we calculated the possible production and emission of the ISA precursor $\mathrm{FeOOH}$ aerosol using the flue gas of the German power station Niederaußem; with an input of 25 million $\mathrm{yr}^{-1}$ of lignite (brown coal), this power station produces $3600 \mathrm{MW}$.

According to ISA production variant 1 (Sect. 6), the ISA precursor $\mathrm{FeOOH}$ aerosol may be produced by the burning of a ferrocene $\left(\mathrm{Fe}\left(\mathrm{C}_{5} \mathrm{H}_{5}\right)_{2}\right)$ oil solution containing $1 \%$ ferrocene in a separate simple oil burner. The hot oil-burner flue gas containing the ISA precursor $\mathrm{FeOOH}$ aerosol is injected and mixed into the cleaned power station flue gas. The power station flue gas emission rate is calculated to be $9000 \mathrm{~m}^{3}$ flue gas per ton of lignite. As the ISA precursor containing flue gas will be elevated to heights of more than $1000 \mathrm{~m}$ above ground, dust levels of the ISA precursor $\mathrm{FeOOH}$ aerosol of $20 \mathrm{mg} \mathrm{m}^{-3}$ flue gas seem to be acceptable. This allows a quantity of $180 \mathrm{~g}$ of $\mathrm{FeOOH}$ per ton of combusted lignite $\left(9000 \mathrm{~m}^{3} \mathrm{t}^{-1} \times 0.02 \mathrm{~g} \mathrm{~m}^{-3}\right)$. At a lignite quantity of 25 million $\mathrm{yr}^{-1}$, this corresponds to $4500 \mathrm{tFeOOH} \mathrm{yr}^{-1}$. FeOOH has an iron content of $63 \%$. This corresponds to a possible iron emission of $2831 \mathrm{t} \mathrm{yr}^{-1}$ and a possible ferrocene consumption of $9438 \mathrm{t} \mathrm{yr}^{-1}$.

Corresponding to this calculation, about 100 of such huge power stations should have the ability to produce a sufficient

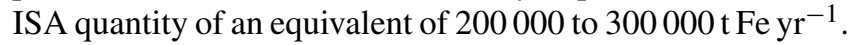
Further optimization of the cooling capacity of the produced ISA is possible by a co-emission of $\mathrm{HCl}$, for instance by coburning an organic $\mathrm{HCl}$ precursor.

This example illustrates that ISA emission at only 100 power stations, or any similar ISA emission measures, is quite feasible compared to the alternative of carbon capture and storage (CCS) through $\mathrm{CO}_{2}$ capture of $40 \mathrm{Gt} \mathrm{yr}^{-1}$ from the flue gas and compression of the $\mathrm{CO}_{2}$ until the liquid state is reached, followed by the transportation and $\mathrm{CO}_{2}$ storage by injection into underground rock aquifers or into old and depleted fossil fuel reservoirs.

In order to increase the effectiveness of the buoyancy capacity of the power stations the usual wet cooling tower might be replaced by a dry cooling tower to mix the dry and warm air emission from the cooling tower with the hot flue gas as additional buoyancy and dew point reduction mean. Furthermore, the flue gas buoyancy may increase by increasing the flue gas temperature. This or other simple techniques to realize ISA plumes may be used within the troposphere.

One alternative delivery method that seems promising and can easily be adapted to the ISA method is the use of tethered balloons (Davidson, 2012), which will cost much less as 1 or $2 \mathrm{~km}$ altitude will be sufficient for ISA emissions, requiring much lower pressures in the pipes than for $\mathrm{SO}_{2}$ delivery at $20 \mathrm{~km}$ for the geoengineering method. Technical and economic feasibility have already been studied for the SPICE project (Kuo et al., 2012), which planned to release seawater spray at $1 \mathrm{~km}$ altitude.

Furthermore, iron emissions only stay in the troposphere for weeks compared to SRM sulfates in the stratosphere, which stay for 1 or 2 years. In the case of any unintentional side effect or problem occurring, stopping the emissions quickly is possible and the reversibility of their effects are much shorter than for solar radiation management by sulfate aerosols.

Other geoengineering strategies to cool the Earth, such as carbon dioxide removal by iron fertilization (Williamson et al., 2012) have several pros and cons, such as localized release and less dispersion, in a form that is not readily bioavailable, resulting in restricted cooling effects and high expenses.

The idea of ocean fertilization by iron to enhance the $\mathrm{CO}_{2}$ conversion by phytoplankton assimilation arose within the last 2 decades. The mixing of an iron salt solution by ships into the ocean surface was proposed. This idea was debated controversially. An example of this debate is the discussion between Johnson and Karl (2002) and Chisholm et al. (2002). Deeper insight into this debate is given by Boyd and Bressac (2016).

The iron fertilization procedure tests done so far have been restricted to relatively small ocean regions (Boyd et al., 2007; Johnson et al., 2002a, b). These tests produced iron concentrations some orders of magnitude above those produced by natural ISA processing, which are on the order of tens of milligrams of additional dissolved iron input per square meter per year. In this sense the ISA method is quite different from iron fertilization. As known from satellite images, phytoplankton blooms are induced by natural dust emission events from the Sahara, Gobi and other dust sources; there is no doubt about the fertilizing effect of iron. Moreover, this kind of natural iron fertilization enhancing the transfer of $\mathrm{CO}_{2} \mathrm{C}$ into organic sediment carbon via the oceanic food chain seems to be uncontradicted and accepted (Hansen et al., 2016).

The ISA method allows the use of the same atom of iron several times by catalytic and photocatalytic processes in the atmosphere, with different cooling effects (such as albedo modification and the enhancement of the methane destruction), and then through gravity or by rain precipitation, it sinks and reaches the ocean surface, with further cooling effects such as the enhancement of $\mathrm{CO}_{2}$ carbon fixation.

Harrison (2013) estimates that a single ship-based fertilization of the Southern Ocean will result only in a net sequestration of $0.01 \mathrm{tC} \mathrm{km}^{-2}$ for 100 years at a cost of USD 457 per ton of $\mathrm{CO}_{2}$, as the economic challenge of distributing low concentrations of iron over large ocean surface areas has been underestimated (Aumont and Bopp, 2006); in addition to this, there are the numerous loss processes (i.e., solubleiron loss and organic carbon that does not sink to the bottom 
of the ocean), resulting in reduced net storage of carbon per square kilometer of ocean fertilized.

Figure 7 summarizes many of the cooling effects of the ISA method.

The organic $\mathrm{C}$ / carbonate $\mathrm{C}$ burial ratio in sediments and bedrock increase after the ISA method starts, until it reaches a maximum. Then this ratio begins to decrease as soon as the vertical current components in the ocean basin begin to act. Then the ratio reaches a very low permanent level, while the total of buried $\mathrm{C}$ reaches a permanent maximum level when the maximum vertical mixing conditions have been achieved by the ISA method.

Why does ISA appear to be more effective than ocean iron fertilization? For ocean iron fertilization several tons of $\mathrm{Fe}$ (II) are dispersed in a short time (hours) over only some square kilometers of ocean with several drawbacks; a massive algae bloom can change the local biotopes. By contrast, ISA releases iron continuously, reaching the entire 510 million $\mathrm{km}^{2}$ of Earth's surface. The current iron inputs (in the form of soluble salts) into the oceans are estimated to be between 0.1 and $0.26 \mathrm{Tg} \mathrm{yr}^{-1}$ (Ito and Shi, 2016; Johnson and Meskhidze, 2013; Myriokefalitakis et al., 2014). As water covers nearly $72 \%$ of Earth's surface

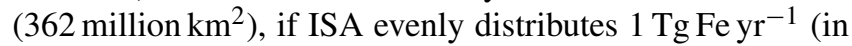
addition to current natural and anthropogenic emissions), which is 4 times more than the expected needs (Sect. 5.2), on average every square kilometer of ocean will receive $5.4 \mathrm{~g} \mathrm{Fe} \mathrm{km}^{-2}$ day $^{-1}\left(1 / 510 \mathrm{tFe} \mathrm{km}^{-2} \mathrm{yr}^{-1}\right)$.

\section{Conclusion}

In ideal circumstances the ocean acts as an optimum transport medium for $\mathrm{CO}_{2}$ carbon from the atmosphere into the ocean crust. Such circumstances are present when the vertical cycling components between the ocean surface and ocean bottom are undisturbed.

Any stratification event disturbs this cycling and interrupts $\mathrm{CO}_{2}$ transport. Climate warming can induce stratification events by producing huge amounts of meltwater. Recent research found signs of at least a regional development of a beginning stratification.

The numerous climate cooling effects of natural dust shown in this review, according to its soluble-iron content, demonstrate that dust is of a central significance as a steering element of this carbon transport from the atmosphere into the ocean crust.

This review article demonstrates the enormous effects of atmospheric iron dusts and focuses first on the tropospheric aerosol particles composed partly of iron and chloride (iron salt aerosols, ISAs), showing their cooperation and interactions with several components of the atmosphere, for instance with $\mathrm{CH}_{4}$, as the chlorine atom is responsible for the removal of a significant part of this GHG (3 to $4 \%$ of $\mathrm{CH}_{4}$ ) in the troposphere (Allan et al., 2007; Graedel and Keene,
1996). This article summarizes a dozen of other possible direct and indirect natural climate cooling mechanisms induced by iron biogeochemistry in all the Earth compartments: the atmosphere, oceans, land (surface, soil), the sediment and the crust.

These dozen possible climate cooling effects due to the multistage chemistry of iron within the atmosphere, hydrosphere, geosphere and lithosphere are described together for the first time and are summarized in Table 3, which shows the most probable climate cooling effects of ISA. They include the ocean fertilization effect, which allows enhanced algal and phytoplankton growth, which in turn removes mineral $\mathrm{CO}_{2}$ from the atmosphere and transforms it in organic carbon, part of which can sink to the bottom of the oceans and be stored for long periods of time by the different mechanisms that are described.

In order to explicitly address the interaction of climate and biogeochemistry, the complex interactions between climate and the cycles of $\mathrm{C}, \mathrm{N}, \mathrm{P}, \mathrm{H}_{2} \mathrm{O}$ and micronutrients call for models that integrate global biogeochemical cycles of terrestrial, oceanic and atmospheric components of the biosphere.

While the iron biogeochemical cycle between the atmosphere and the ocean is considered in numerous publications, the treatment of key processes and feedbacks within the terrestrial compartment has been rather limited, and further development is urgently needed.

Mineral dust aerosols containing iron and other important nutrients or micronutrients are well-studied components of the iron biogeochemical cycle in the atmosphere and the oceans, but the absence of recent publications about the full iron biogeochemical cycle over terrestrial landscapes, soils, wetlands and all clear-water compartments (glaciers, ice, snow, lakes and groundwater) points to a lack of an up-todate overview. In our opinion, atmospheric chemistry models need to incorporate all relevant interaction compartments of the Fe cycle with sun radiation, chlorine, sulfur, nitrogen, oxygen, carbon and water in order to model several planetary cooling effects of the iron cycle.

Acid rain sulfate $\left(\mathrm{SO}_{4}^{2-}\right)$ deposition on peatlands and wetlands from natural sources (volcanoes), or anthropogenic sources (fossil fuel combustion) is a known suppressant of $\mathrm{CH}_{4}$ production (Nedwell and Watson, 1995; Watson and Nedwell, 1998) and emissions (Gauci et al., 2002, 2004, 2005) and may be an important process in terms of global climate. The importance of the Fe input associated with anthropogenic aerosol deposition in terrestrial biogeochemistry deserves further investigation as do the possible impacts of a drastic diminution of anthropogenic iron and sulfate emissions from combustion processes expected by 2050 to satisfy the Paris climate agreement.

This review completes the previous global iron cycle predictions (Archer and Johnson, 2000; Johnson et al., 2002b; Johnson and Meskhidze, 2013; Krishnamurthy et al., 2009; Martin et al., 1994; Moore et al., 2004; Parekh et al., 2004; Pérez-Guzmán et al., 2010) and advocates a balanced ap- 


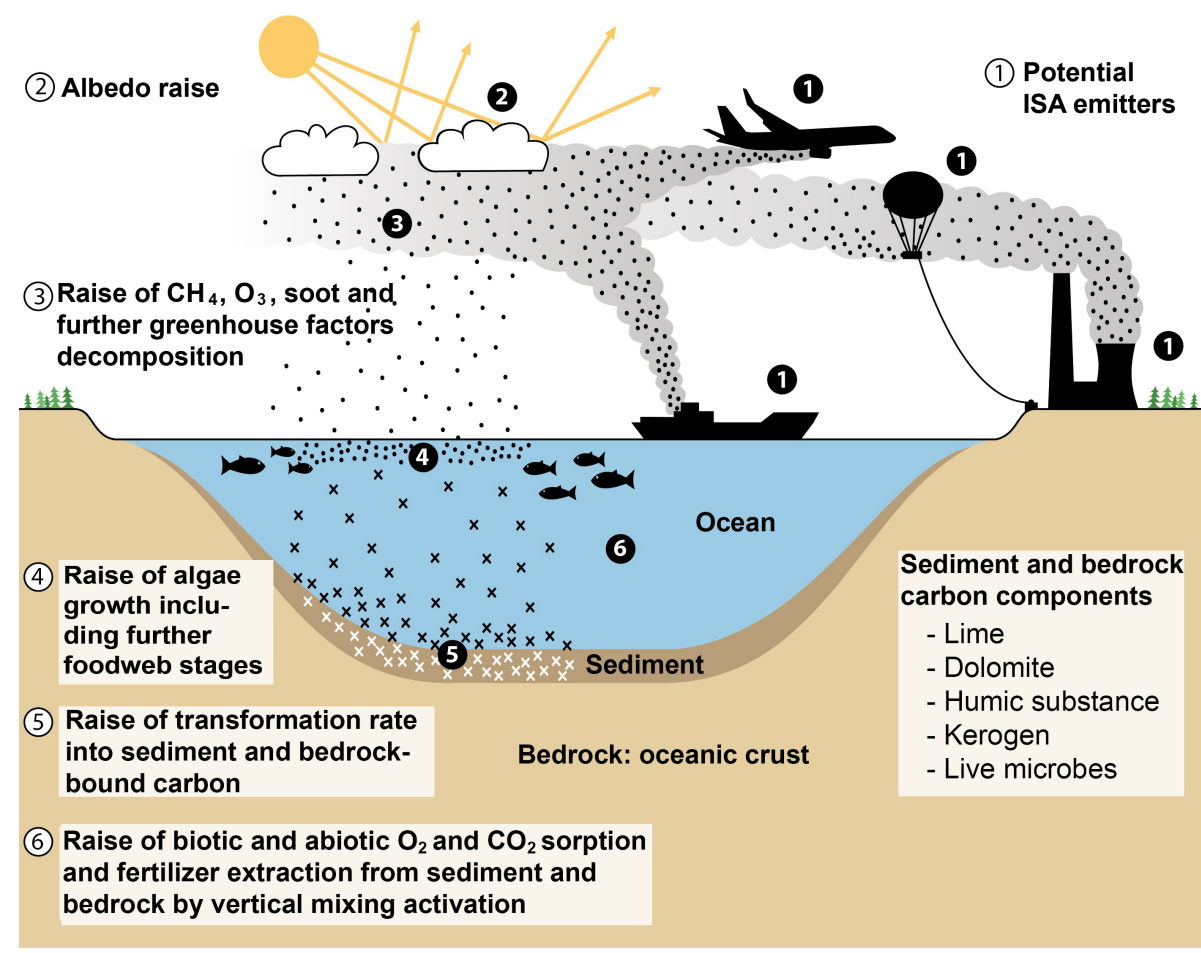

Figure 7. Summary of the principal cooling effects of the proposed iron salt aerosol method.

proach to profit from the iron cycle to fight global warming by enhancing natural processes.

Climate cooling by natural ISA involves the troposphere, dry solid surfaces, ocean waters, ocean sediment, the ocean crust and land. Several GHG factors are controlled by ISA: $\mathrm{CO}_{2}, \mathrm{CH}_{4}$, tropospheric $\mathrm{O}_{3}$, black carbon, dust, cloud albedo and vertical ocean mixing.

Using mineral dust as a natural analogue tool, this article proposes to enhance the natural ISA in order to raise and heighten the cooling impacts of at least two of the dozen natural effects found: i.e., $\mathrm{CH}_{4}$ removal by tropospheric $\cdot \mathrm{Cl}$ and $\mathrm{CO}_{2}$ removal by soluble-Fe ocean fertilization.

The ISA method proposed is feasible, probably with few to no environmental side effects, as it relates to chemical and/or physical combustion processes occurring currently. Actual iron production and coal combustion together with other combustion sources already release a very significant part of the global bioavailable iron in the northern oceans into the atmosphere: from 15\% (Ito and Shi, 2016) to $80 \%$ (Lin et al., 2015; Wang et al., 2015b), depending on the iron solubility parameters taken into account.

The present level of atmospheric deposition of soluble $\mathrm{Fe}$ over the global ocean is considered to be about 3 times higher than for 1850 emissions (Myriokefalitakis et al., 2015), as increases in anthropogenic and biomass burning emissions resulted in both enhanced Fe combustion emissions and a more acidic environment and thus more than twice the soluble-Fe deposition (nearly $0.5 \mathrm{Tg}-\mathrm{Fe}_{\mathrm{yr}}{ }^{-1}$ today versus nearly $0.2 \mathrm{Tg}$ -

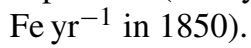

The inevitable reduction in aerosol emissions to improve air quality in the future might accelerate the decline in oceanic productivity per unit warming and accelerate a decline in oceanic net primary productivity (NPP; Wang et al., 2015a). The Myriokefalitakis model-projected results for 2100 indicate about a quarter decrease in the atmospheric deposition of soluble $\mathrm{Fe}$, with a 5 -fold decrease in $\mathrm{Fe}$ emissions from anthropogenic combustion sources $(\sim 0.070 \mathrm{Tg}$ -

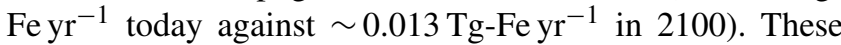
changes are expected to impact most on the high-nutrientlow-chlorophyll oceanic regions. According to Myriokefalitakis et al. (2015), in view of the importance of Fe as a micronutrient for marine ecosystems, the calculated projected changes in soluble-iron emissions require the implementation of comprehensive mineral-Fe dissolution processes as well as $\mathrm{Fe}$ combustion emissions in coupled climatebiogeochemistry models to account for feedbacks between climate and biogeochemical cycles. This review shows that the effects on $\mathrm{CH}_{4}$ of ISA and of anthropogenic Fe emissions in the troposphere also deserve to be taken into account.

According to Wang et al. (2015b), taking into consideration the relatively high solubility of anthropogenic iron, combustion source contributions to soluble-Fe supply for northern Pacific and northern Atlantic oceanic ecosystems could be amplified by 1-2 orders of magnitude. To stop global warming, we estimated the requirements in terms of ISA by 
Table 3. Principal effects of the ISA method proposed - or its natural equivalent - and their probable consequences for the different biosphere compartments.

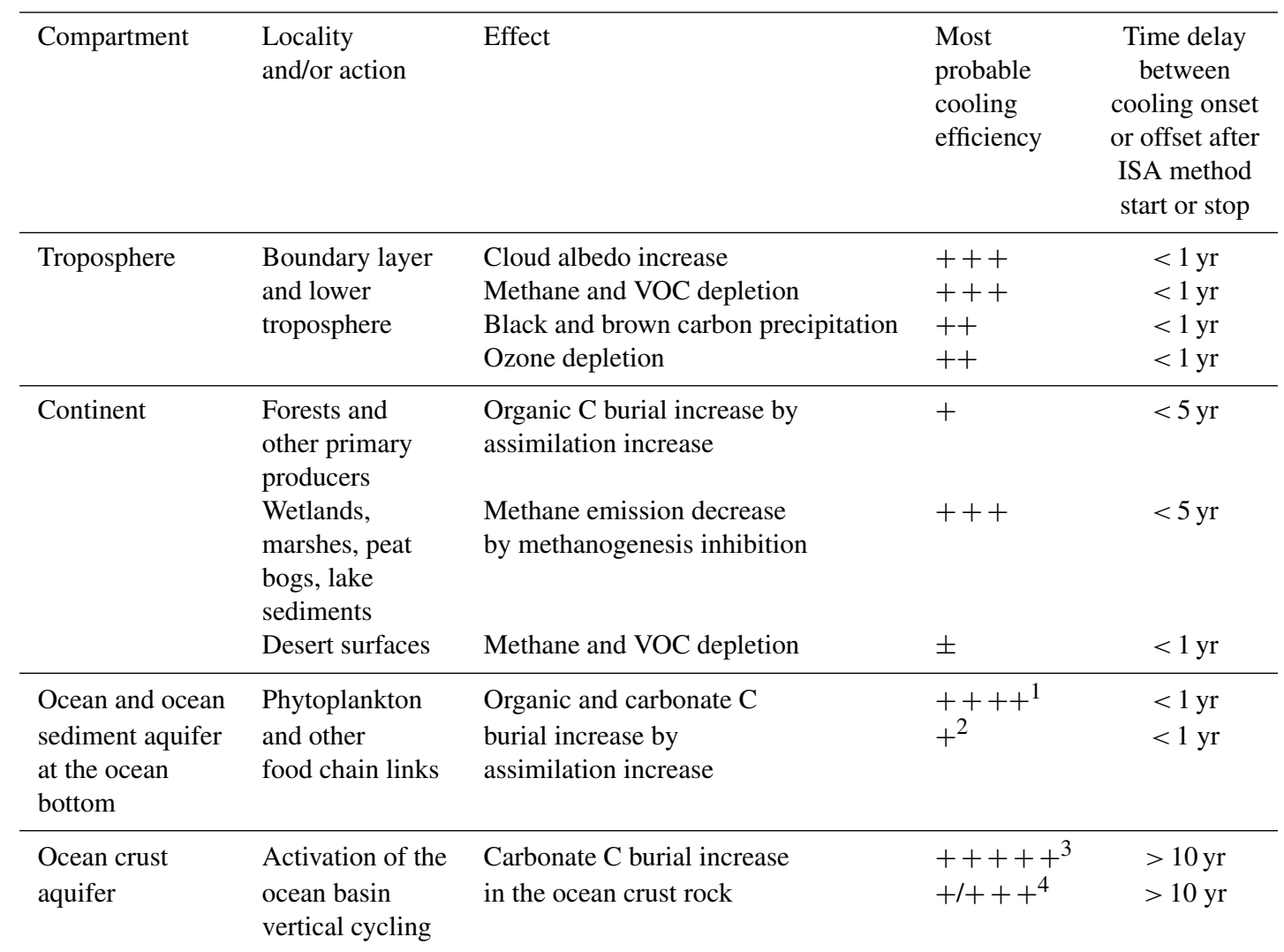

\footnotetext{
1 The euxinic and alkaline bottom water of the stratified ocean have no oxidation and calcite solution capacity, thus producing a high burial rate of organic sediment $\mathrm{C}$ and carbonate $\mathrm{C} .{ }^{2}$ The oxic, hydrogen carbonate and $\mathrm{CO}_{2}$-containing bottom water of the well-mixed ocean have a high oxidation capacity and high calcite dissolving capacity, thus producing a low burial rate of organic and inorganic sediment $\mathrm{C}$. ${ }^{3}$ The high inorganic $\mathrm{C}$ load of the oxic, hydrogen carbonate and $\mathrm{CO}_{2}$-containing bottom water of the well-mixed ocean reaches total precipitation within the alkaline and reducing crust aquifer, thus producing a very high burial rate of inorganic $\mathrm{C}$ and small amounts of organic $\mathrm{C}$ precipitation. ${ }^{4}$ The euxinic and alkaline bottom water of the stratified ocean has a low content of dissolved inorganic $\mathrm{C}$ and contains methane $\mathrm{C}$ up to saturation, thus producing a low to medium $\mathrm{C}$ burial rate during cycling through the crust aquifer.
}

the extrapolation of the experiments on iron-catalyzed activation by artificial sea-salt aerosols (Wittmer et al., 2015a; Wittmer and Zetzsch, 2016). Our first estimations show that by doubling the current natural Fe emissions by ISA emis-

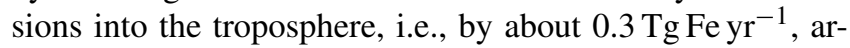
tificial ISA would enable the prevention or even the reversal of GW.

The adjustable flue gas temperatures for different types of combustion are a means to lift the ISA plumes to optimal heights within the troposphere. Thus, we believe that the ISA method proposed integrates technical and economically feasible tools that can help to stop GW.

In accordance with our remarks in Sect. 2, the reactions of ISA in the troposphere provide the most prominent results for a surface temperature decrease (Meyer-Oeste, 2010). This stops further ice melting, which activates the different vertical ocean water movements. As a result, the dissolved $\mathrm{CO}_{2}$ is then buried as carbonate $\mathrm{C}$ within the ocean bottom sediments and crust.
Author contributions. Franz Dietrich Oeste suggested the review idea and performed an initial bibliographical search completed by Renaud de Richter. Franz Dietrich Oeste and Renaud de Richter prepared the paper and the figures with contributions from all coauthors. Tingzhen Ming and Sylvain Caillol also contributed to structuring the paper, ideas, bibliographical entries and English corrections.

Competing interests. The authors declare that they have no conflict of interest.

Acknowledgement. This research was supported by the Scientific Research Foundation of Wuhan University of Technology (No. 40120237) and the ESI Discipline Promotion Foundation of WUT (No. 35400664).

The coauthors would like to thank both reviewers (S. M. Elliott and an anonymous reviewer) for their constructive and thoughtful 
reviews, which greatly improved this paper, in particular Sects. 5, 9 and 10. We also thank Rolf Sander and Cornelius Zetzsch for their constructive comments and Louise Phillips for grammatical corrections and rereading. The authors would like to thank the Copernicus production office for language editing and corrections, which greatly improved this article.

Edited by: B. Kravitz

Reviewed by: S. M. Elliott and one anonymous referee

\section{References}

Abadía, J., Vázquez, S., Rellán-Álvarez, R., El-Jendoubi, H., Abadía, A., Álvarez-Fernández, A., and López-Millán, A. F.: Towards a knowledge-based correction of iron chlorosis, Plant Physiol. Biochem., 49, 471-482, 2011.

Abbaspour, N., Hurrell, R., and Kelishadi, R.: Review on iron and its importance for human health, J. Res. Med. Sci., 19, 164-174, 2004.

Al-Abadleh, H. A.: Review of the bulk and surface chemistry of iron in atmospherically relevant systems containing humic-like substances, RSC Advances, 5, 45785-45811, 2015.

Albani, S., Mahowald, N., Murphy, L., Raiswell, R., Moore, J., Anderson, R., McGee, D., Bradtmiller, L., Delmonte, B., and Hesse, P.: Paleodust variability since the Last Glacial Maximum and implications for iron inputs to the ocean, Geophys. Res. Lett., 43, 3944-3954, 2016.

Ali, M. A., Lee, C. H., and Kim, P. J.: Effect of silicate fertilizer on reducing methane emission during rice cultivation, Biol. Fert. Soils, 44, 597-604, 2008.

Allan, W., Struthers, H., and Lowe, D.: Methane carbon isotope effects caused by atomic chlorine in the marine boundary layer: Global model results compared with Southern Hemisphere measurements. J. Geophys. Res.-Atmos., 112, D04306, doi:10.1029/2006JD007369, 2007.

Allen, C. C., Westall, F., and Schelble, R. T.: Importance of a martian hematite site for astrobiology, Astrobiology, 1, 111-123, 2001.

Allen, L. H.: Guidelines on food fortification with micronutrients, World Health Organization, Dept. of Nutrition for Health and Development, WHO, FAO, Geneva, http://www.who.int/nutrition/publications/guide_food_ fortification_micronutrients.pdf (last access: 8 January 2017), 2006.

Alt, J. C. and Shanks, W. C.: Serpentinization of abyssal peridotites from the MARK area, Mid-Atlantic Ridge: sulfur geochemistry and reaction modeling, Geochim. Cosmochim. Ac., 67, 641-653, 2003.

Alterskjær, K. and Kristjánsson, J.: The sign of the radiative forcing from marine cloud brightening depends on both particle size and injection amount, Geophys. Res. Lett., 40, 210-215, 2013.

Amos, R., Bekins, B., Cozzarelli, I., Voytek, M., Kirshtein, J., Jones, E., and Blowes, D.: Evidence for iron-mediated anaerobic methane oxidation in a crude oil-contaminated aquifer, Geobiology, 10, 506-517, 2012.

Anderson, K.: Duality in climate science, Nat. Geosci., 8, 898-900, 2016.

Anderson, R. F., Barker, S., Fleisher, M., Gersonde, R., Goldstein, S. L., Kuhn, G., Mortyn, P. G., Pahnke, K., and Sachs, J. P.: Bi- ological response to millennial variability of dust and nutrient supply in the Subantarctic South Atlantic Ocean, Philos. T. Roy. Soc. Lond. A, 372, 20130054, doi:10.1098/rsta.2013.0054, 2014. Anderson, W. B.: Diagnosis and correction of iron deficiency in field crops - an overview, J. Plant Nutr., 5, 785-795, 1982.

Andreae, M. O. and Gelencsér, A.: Black carbon or brown carbon? The nature of light-absorbing carbonaceous aerosols, Atmos. Chem. Phys., 6, 3131-3148, doi:10.5194/acp-6-3131-2006, 2006.

Anenberg, S. C., Schwartz, J., Shindell, D. T., Amann, M., Faluvegi, G. S., Klimont, Z., Janssens-Maenhout, G., Pozzoli, L., Dingenen, R. V., and Vignati, E.: Global air quality and health cobenefits of mitigating near-term climate change through methane and black carbon emission controls, Environ. Health Persp., 120, 831-839, doi:10.1289/ehp.1104301, 2012.

Annett, A. L., Skiba, M., Henley, S. F., Venables, H. J., Meredith, M. P., Statham, P. J., and Ganeshram, R. S.: Comparative roles of upwelling and glacial iron sources in Ryder Bay, coastal western Antarctic Peninsula, Mar. Chem., 176, 21-33, 2015.

Archer, D. and Johnson, K.: A model of the iron cycle in the ocean, Global Biogeochem. Cy., 14, 269-279, 2000.

Ardon-Dryer, K., Huang, Y.-W., and Cziczo, D. J.: Laboratory studies of collection efficiency of sub-micrometer aerosol particles by cloud droplets on a single-droplet basis, Atmos. Chem. Phys., 15, 9159-9171, doi:10.5194/acp-15-9159-2015, 2015.

Aumont, O. and Bopp, L.: Globalizing results from ocean in situ iron fertilization studies, Global Biogeochem. Cy., 20, GB2017, doi:10.1029/2005GB002591, 2006.

Avni, T., Leibovici, L., and Gafter-Gvili, A.: Iron supplementation for the treatment of chronic heart failure and iron deficiency: systematic review and meta-analysis, Eur. J. Heart Fail., 14, 423429, 2012.

Ayris, P. M., Delmelle, P., Cimarelli, C., Maters, E. C., Suzuki, Y. J., and Dingwell, D. B.: HCl uptake by volcanic ash in the high temperature eruption plume: Mechanistic insights, Geochim. Cosmochim. Ac., 144, 188-201, 2014.

Bai, H., Jiang, W., Kotchey, G. P., Saidi, W. A., Bythell, B. J., Jarvis, J. M., Marshall, A. G., Robinson, R. A., and Star, A.: Insight into the mechanism of graphene oxide degradation via the photoFenton reaction, J. Phys. Chem. C, 118, 10519-10529, 2014.

Baker, A. K., Rauthe-Schöch, A., Schuck, T. J., Brenninkmeijer, C. A., van Velthoven, P. F., Wisher, A., and Oram, D. E.: Investigation of chlorine radical chemistry in the Eyjafjallajökull volcanic plume using observed depletions in non-methane hydrocarbons, Geophys. Res. Lett., 38, L13801, doi:10.1029/2011GL047571, 2011.

Baker, A. K., Sauvage, C., Thorenz, U. R., Brenninkmeijer, C. A., Oram, D. E., van Velthoven, P., Zahn, A., and Williams, J.: Evidence for widespread tropospheric $\mathrm{Cl}$ chemistry in free tropospheric air masses from the South China Sea, EGU General Assembly 2015, Abstract 1710370B, 12-17 April 2015, Vienna, Austria, 2015.

Bakun, A., Black, B., Bograd, S. J., Garcia-Reyes, M., Miller, A., Rykaczewski, R., and Sydeman, W.: Anticipated effects of climate change on coastal upwelling ecosystems, Curr. Clim. Change Rep., 1, 85-93, 2015.

Barbusiński, K.: Fenton reaction-controversy concerning the chemistry, Ecol. Chem. Eng., 16, 347-358, 2009. 
Bartels-Rausch, T., Jacobi, H.-W., Kahan, T. F., Thomas, J. L., Thomson, E. S., Abbatt, J. P. D., Ammann, M., Blackford, J. R., Bluhm, H., Boxe, C., Domine, F., Frey, M. M., Gladich, I., Guzmán, M. I., Heger, D., Huthwelker, Th., Klán, P., Kuhs, W. F., Kuo, M. H., Maus, S., Moussa, S. G., McNeill, V. F., Newberg, J. T., Pettersson, J. B. C., Roeselová, M., and Sodeau, J. R.: A review of air-ice chemical and physical interactions (AICI): liquids, quasi-liquids, and solids in snow, Atmos. Chem. Phys., 14, 1587-1633, doi:10.5194/acp-14-1587-2014, 2014.

Basar, H., Gürel, S., Ataç, T., and Çelik, H.: Effect of foliar iron applications on contents of iron forms and mineral composition of sweet cherry (Prunus avium L.), Indo-Am. J. Agr. Vet. Sci., 2, $1-11,2014$

Basen, M., Krüger, M., Milucka, J., Kuever, J., Kahnt, J., Grundmann, O., Meyerdierks, A., Widdel, F., and Shima, S.: Bacterial enzymes for dissimilatory sulfate reduction in a marine microbial mat (Black Sea) mediating anaerobic oxidation of methane, Environ. Microbiol., 13, 1370-1379, 2011.

Bauer, S. E. and Menon, S.: Aerosol direct, indirect, semidirect, and surface albedo effects from sector contributions based on the IPCC AR5 emissions for preindustrial and present-day conditions, J. Geophys. Res.-Atmos., 117, D01206, doi:10.1029/2011JD016816, 2012.

Bayrakci, G., Minshull, T., Sawyer, D., Reston, T. J., Klaeschen, D., Papenberg, C., Ranero, C., Bull, J., Davy, R., and Shillington, D.: Fault-controlled hydration of the upper mantle during continental rifting, Nat. Geosci., 9, 384-388, 2016.

Becker, M. and Asch, F.: Iron toxicity in rice - conditions and management concepts, J. Plant Nutr. Soil Sci., 168, 558-573, 2005.

Beckett, A. C., Piazuelo, M. B., Noto, J. M., Peek, R. M., Washington, M. K., Algood, H. M. S., and Cover, T. L.: Dietary composition influences incidence of Helicobacter pylori-induced iron deficiency anemia and gastric ulceration, Infect. Immun., 84, 3338 3349, 2016.

Belton, D. J., Deschaume, O., Patwardhan, S. V., and Perry, C. C.: A solution study of silica condensation and speciation with relevance to in vitro investigations of biosilicification, J. Phys. Chem. B, 114, 9947-9955, 2010.

Benz, M., Schink, B., and Brune, A.: Humic acid reduction by Propionibacterium freudenreichii and other fermenting bacteria, Appl. Environ. Microbiol., 64, 4507-4512, 1998.

Bernardello, R., Marinov, I., Palter, J. B., Galbraith, E. D., and Sarmiento, J. L.: Impact of Weddell Sea deep convection on natural and anthropogenic carbon in a climate model, Geophys. Res. Lett., 41, 7262-7269, 2014a.

Bernardello, R., Marinov, I., Palter, J. B., Sarmiento, J. L., Galbraith, E. D., and Slater, R. D.: Response of the ocean natural carbon storage to projected twenty-first-century climate change, J. Climate, 27, 2033-2053, 2014b.

Berndt, C., Feseker, T., Treude, T., Krastel, S., Liebetrau, V., Niemann, H., Bertics, V., Dumke, I., Dünnbier, K., Ferré, B., Graves, C., Gross, F., Hissmann, K., Hühnerbach, V., Krause, S., Liesner, K., Schauer, J., and Steinle, L.: Methane hydrates and global warming: Dissolution of hydrates off Svalbard caused by natural processes, Pressemitteilung des GEOMAR Helmholz-Zentrum für Ozeanforschung Kiel, Kiel, 2014.

Berner, R. A., Scott, M. R., and Thomlinson, C.: Carbonate alkalinity in the pore waters of anoxic sediments, Limnol. Oceanogr., $15,544-549,1970$.
Betz, G., Brachatzeck, N., Cacean, S., Güssow, K., Heintzenberg, J., Hiller, S., Hoose, C., Klepper, G., Leisner, T., Oschlies, A., Platt, U., Proelß, A., Renn, O., Rickels, W., Schäfer, S., and Zürn, M.: Gezielte Eingriffe in das Klima? Eine Bestandsaufnahme der Debatte zu Climate Engineering, Kiel Earth Institute, Kiel, 2011.

Bhatia, M. P., Kujawinski, E. B., Das, S. B., Breier, C. F., Henderson, P. B., and Charette, M. A.: Greenland meltwater as a significant and potentially bioavailable source of iron to the ocean, Nat. Geosci., 6, 274-278, 2013.

Bintanja, R., Van Oldenborgh, G., Drijfhout, S., Wouters, B., and Katsman, C.: Important role for ocean warming and increased ice-shelf melt in Antarctic sea-ice expansion, Nat. Geosci., 6, 376-379, 2013.

Biskos, G., Malinowski, A., Russell, L., Buseck, P., and Martin, S.: Nanosize effect on the deliquescence and the efflorescence of sodium chloride particles, Aerosol Sci. Tech., 40, 97-106, 2006.

Bjorlykke, K.: Petroleum geoscience: From sedimentary environments to rock physics, Springer Science \& Business Media, Springer-Verlag, Berlin, Heidelberg, doi:10.1007/978-3642-02332-3, 2010.

Blasing, T.: Recent greenhouse gas concentrations, Carbon Dioxide Information Analysis Center, Oak Ridge National Laboratory, US Department of Energy, http://cdiac.ornl.gov/pns/ current_ghg.html (last access: 8 January 2017), 2010.

Blasing, T.: Recent Greenhouse Gas Concentrations, Carbon Dioxide Information Analysis Center CDIAC, DOE, Oak Ridge, doi:10.3334/CDIAC/atg.032, 2016.

Blechschmidt, A.-M., Richter, A., Burrows, J. P., Kaleschke, L., Strong, K., Theys, N., Weber, M., Zhao, X., and Zien, A.: An exemplary case of a bromine explosion event linked to cyclone development in the Arctic, Atmos. Chem. Phys., 16, 1773-1788, doi:10.5194/acp-16-1773-2016, 2016.

Bleicher, S., Buxmann, J. C., Sander, R., Riedel, T. P., Thornton, J. A., Platt, U., and Zetzsch, C.: The influence of nitrogen oxides on the activation of bromide and chloride in salt aerosol, Atmos. Chem. Phys. Discuss., 14, 10135-10166, doi:10.5194/acpd-1410135-2014, 2014.

Bloss, W. J., Evans, M. J., Lee, J. D., Sommariva, R., Heard, D. E., and Pilling, M. J.: The oxidative capacity of the troposphere: Coupling of field measurements of $\mathrm{OH}$ and a global chemistry transport model, Faraday Discuss., 130, 425-436, 2005.

Bond, D. R. and Lovley, D. R.: Reduction of Fe (III) oxide by methanogens in the presence and absence of extracellular quinones, Environ. Microbiol., 4, 115-124, 2002.

Bond, T. C., Doherty, S. J., Fahey, D., Forster, P., Berntsen, T. DeAngelo, B., Flanner, M., Ghan, S., Kärcher, B., and Koch, D.: Bounding the role of black carbon in the climate system: A scientific assessment, J. Geophys. Res.-Atmos., 118, 5380-5552, 2013.

Borch, T., Kretzschmar, R., Kappler, A., Cappellen, P. V., GinderVogel, M., Voegelin, A., and Campbell, K.: Biogeochemical redox processes and their impact on contaminant dynamics, Environ. Sci. Technol., 44, 15-23, 2009.

Boucher, O.: Biogeochemical Effects and Climate Feedbacks of Aerosols, in: Atmospheric Aerosols, Springer Netherlands, 247269, doi:10.1007/978-94-017-9649-1_11, 2015.

Boyd, P. W.: Development of geopolitically-relevant ranking criteria for geoengineering methods, Earth's Future, 4, 523-531, doi:10.1002/2016EF000447, 2016. 
Boyd, P. W. and Bressac, M.: Developing a test-bed for robust research governance of geoengineering: the contribution of ocean iron biogeochemistry, Philos. T. Roy. Soc. A, 374, 20150299, doi:10.1098/rsta.2015.0299, 2016.

Boyd, P. W. and Ellwood, M.: The biogeochemical cycle of iron in the ocean, Nat. Geosci., 3, 675-682, 2010.

Boyd, P. W., Jickells, T., Law, C., Blain, S., Boyle, E., Buesseler, K., Coale, K., Cullen, J., De Baar, H., and Follows, M.: Mesoscale iron enrichment experiments 1993-2005: Synthesis and future directions, Science, 315, 612-617, 2007.

Branch, T. A., DeJoseph, B. M., Ray, L. J., and Wagner, C. A.: Impacts of ocean acidification on marine seafood, Trends Ecol. Evol., 28, 178-186, 2013.

Breitbarth, E., Achterberg, E. P., Ardelan, M. V., Baker, A. R., Bucciarelli, E., Chever, F., Croot, P. L., Duggen, S., Gledhill, M., Hassellöv, M., Hassler, C., Hoffmann, L. J., Hunter, K. A., Hutchins, D. A., Ingri, J., Jickells, T., Lohan, M. C., Nielsdóttir, M. C., Sarthou, G., Schoemann, V., Trapp, J. M., Turner, D. R., and Ye, Y.: Iron biogeochemistry across marine systems progress from the past decade, Biogeosciences, 7, 1075-1097, doi:10.5194/bg-7-1075-2010, 2010.

Bruland, K.: A review of the chemistries of redox sensitive elements within suboxic zones of oxygen minimum regions, Gayana (Concepc.), 70, 6-13, 2006.

Buyukhatipoglu, K. and Clyne, A. M.: Controlled flame synthesis of $\alpha \mathrm{Fe}_{2} \mathrm{O}_{3}$ and $\mathrm{Fe}_{3} \mathrm{O}_{4}$ nanoparticles: effect of flame configuration, flame temperature, and additive loading, J. Nanopart. Res., 12, 1495-1508, 2010.

Bykova, E., Dubrovinsky, L., Dubrovinskaia, N., Bykov, M., McCammon, C., Ovsyannikov, S., Liermann, H.-P., Kupenko, I., Chumakov, A., and Rüffer, R.: Structural complexity of simple $\mathrm{Fe}_{2} \mathrm{O}_{3}$ at high pressures and temperatures, Nat. Commun., 7, 10661, doi:10.1038/ncomms10661, 2016.

Capone, D. G. and Hutchins, D. A.: Microbial biogeochemistry of coastal upwelling regimes in a changing ocean, Nat. Geosci., 6, 711-717, 2013.

Carpenter, L. J., Archer, S. D., and Beale, R.: Ocean-atmosphere trace gas exchange, Chem. Soc. Rev., 41, 6473-6506, 2012.

Cartapanis, O., Bianchi, D., Jaccard, S. L., and Galbraith, E. D.: Global pulses of organic carbon burial in deep-sea sediments during glacial maxima, Nat. Commun., 7, 10796, doi:10.1038/ncomms10796, 2016.

Cassar, N., Laws, E. A., Bidigare, R. R., and Popp, B. N.: Bicarbonate uptake by Southern Ocean phytoplankton, Global Biogeochem. Cy., 18, GB2003, doi:10.1029/2003GB002116, 2004.

Charlson, R. J., Lovelock, J. E., Andreae, M. O., and Warren, S. G.: Oceanic phytoplankton, atmospheric sulphur, cloud albedo and climate, Nature, 326, 655-661, 1987.

Charpentier, D., Buatier, M., Jacquot, E., Gaudin, A., and Wheat, C.: Conditions and mechanism for the formation of iron-rich Montmorillonite in deep sea sediments (Costa Rica margin): Coupling high resolution mineralogical characterization and geochemical modeling, Geochim. Cosmochim. Ac., 75, 1397-1410, 2011.

Chemizmu, K. and Fentona, R.: Fenton reaction-controversy concerning the chemistry, Ecol. Chem. Eng., 16, 347-358, 2009.

Chen, C.-T. A., Lin, C.-M., Huang, B.-T., and Chang, L.-F.: Stoichiometry of carbon, hydrogen, nitrogen, sulfur and oxygen in the particulate matter of the western North Pacific marginal seas, Mar. Chem., 54, 179-190, 1996.

Chisholm, S. W., Falkowski, P. G., and Cullen, J. J.: Response to the letter of Johnson, K. S. and Karl, D. M., Science, 296, 467-468, 2002.

Claeys, M., Vermeylen, R., Yasmeen, F., Gómez-González, Y., Chi, X., Maenhaut, W., Mészáros, T., and Salma, I.: Chemical characterisation of humic-like substances from urban, rural and tropical biomass burning environments using liquid chromatography with UV/vis photodiode array detection and electrospray ionisation mass spectrometry, Environ. Chem., 9, 273-284, 2012.

Coates, J. D., Ellis, D. J., Blunt-Harris, E. L., Gaw, C. V., Roden, E. E., and Lovley, D. R.: Recovery of humic-reducing bacteria from a diversity of environments, Appl. Environ. Microbiol., 64, 1504-1509, 1998.

Coggon, R. M., Teagle, D., Harris, M., John, C., Smith-Duque, C., and Alt, J.: Why Does Calcium Carbonate Precipitate in the Ocean Crust?, AGU Fall Meeting, vol. 1, abstract \#B33D-0545, 3-7 December 2012, San Francisco, Calif., p. 545, 2012.

Cohen-Solal, A., Leclercq, C., Deray, G., Lasocki, S., Zambrowski, J.-J., Mebazaa, A., de Groote, P., Damy, T., and Galinier, M.: Iron deficiency: an emerging therapeutic target in heart failure, Heart, 100, 1414-1420, doi:10.1136/heartjnl-2014-305669, 2014.

Conrad, R.: Contribution of hydrogen to methane production and control of hydrogen concentrations in methanogenic soils and sediments, FEMS Microbiol. Ecol., 28, 193-202, 1999.

Conway, T., Wolff, E., Röthlisberger, R., Mulvaney, R., and Elderfield, H.: Constraints on soluble aerosol iron flux to the Southern Ocean at the Last Glacial Maximum, Nat. Commun., 6, 7850, doi:10.1038/ncomms8850, 2015.

Coogan, L. A. and Gillis, K. M.: Evidence that low-temperature oceanic hydrothermal systems play an important role in the silicate-carbonate weathering cycle and long-term climate regulation, Geochem. Geophy. Geosy., 14, 1771-1786, 2013.

Cooper, O. R., Parrish, D., Ziemke, J., Balashov, N., Cupeiro, M., Galbally, I., Gilge, S., Horowitz, L., Jensen, N., and Lamarque, J.-F.: Global distribution and trends of tropospheric ozone: An observation-based review, Elementa, 2, 000029 , doi:10.12952/journal.elementa.000029, 2014.

Cózar, A., Echevarría, F., González-Gordillo, J. I., Irigoien, X., Úbeda, B., Hernández-León, S., Palma, Á. T., Navarro, S., García-de-Lomas, J., and Ruiz, A.: Plastic debris in the open ocean, P. Natl. Acad. Sci. USA, 111, 10239-10244, 2014.

Crutzen, P. J.: Albedo enhancement by stratospheric sulfur injections: a contribution to resolve a policy dilemma?, Climatic Change, 77, 211-220, 2006.

Crutzen, P. J. and Oppenheimer, M.: Learning about ozone depletion, Climatic Change, 89, 143-154, 2008.

Cunningham, K. M., Goldberg, M. C., and Weiner, E. R.: Mechanisms for aqueous photolysis of adsorbed benzoate, oxalate, and succinate on iron oxyhydroxide (goethite) surfaces, Environ. Sci. Technol., 22, 1090-1097, 1988.

Daims, H., Lebedeva, E. V., Pjevac, P., Han, P., Herbold, C., Albertsen, M., Jehmlich, N., Palatinszky, M., Vierheilig, J., and Bulaev, A.: Complete nitrification by Nitrospira bacteria, Nature, 528, 504-509, 2015.

Davidson, P.: Up and away!, TCE, 28-32, http://www. thechemicalengineer.com/ /media/Documents/TCE/Articles/ 
2012/851/851geoengineering.pdf (last access: 8 January 2017), 2012.

Davidson, P., Burgoyne, C., Hunt, H., and Causier, M.: Lifting options for stratospheric aerosol geoengineering: advantages of tethered balloon systems, Philos. T. Roy. Soc. Lond. A, 370, 4263-4300, 2012.

Death, R., Wadham, J. L., Monteiro, F., Le Brocq, A. M., Tranter, M., Ridgwell, A., Dutkiewicz, S., and Raiswell, R.: Antarctic ice sheet fertilises the Southern Ocean, Biogeosciences, 11, 26352643, doi:10.5194/bg-11-2635-2014, 2014.

De Laat, J., Le, G. T., and Legube, B.: A comparative study of the effects of chloride, sulfate and nitrate ions on the rates of decomposition of $\mathrm{H}_{2} \mathrm{O}_{2}$ and organic compounds by $\mathrm{Fe}(\mathrm{II}) / \mathrm{H}_{2} \mathrm{O}_{2}$ and $\mathrm{Fe}$ (III) $/ \mathrm{H}_{2} \mathrm{O}_{2}$, Chemosphere, 55, 715-723, 2004.

de Lavergne, C., Palter, J. B., Galbraith, E. D., Bernardello, R., and Marinov, I.: Cessation of deep convection in the open Southern Ocean under anthropogenic climate change, Nat. Clim. Change, 4, 278-282, 2014.

de Richter, R. and Caillol, S.: Fighting global warming: the potential of photocatalysis against $\mathrm{CO}_{2}, \mathrm{CH}_{4}, \mathrm{~N}_{2} \mathrm{O}, \mathrm{CFCs}$, tropospheric $\mathrm{O}_{3}$, BC and other major contributors to climate change, J. Photochem. Photobiol. C, 12, 1-19, 2011.

de Richter, R., Ming, T., Caillol, S., and Liu, W.: Fighting global warming by GHG removal: Destroying CFCs and HCFCs in solar-wind power plant hybrids producing renewable energy with no-intermittency, Int. J. Greenhouse Gas Control, 49, 449-472, $2016 \mathrm{a}$.

de Richter, R., Ming, T., Shen, S., and Caillol, S.: Fighting global warming by greenhouse gas removal: destroying atmospheric nitrous oxide thanks to synergies between two breakthrough technologies, Environ. Sci. Poll. Res., 23, 6119-6138, 2016 b.

de Richter, R., Ming, T., Davies, P., Liu, W., and Caillol, S.: Removal of non- $\mathrm{CO}_{2}$ greenhouse gases by large-scale atmospheric solar photocatalysis, Prog. Energy Combust. Sci., submitted, 2017.

Demadis, K. D., Mavredaki, E., and Somara, M.: Additive-Driven Dissolution Enhancement of Colloidal Silica. 2. Environmentally Friendly Additives and Natural Products, Indust. Eng. Chem. Res., 50, 13866-13876, 2011.

Dewangan, P., Basavaiah, N., Badesab, F., Usapkar, A., Mazumdar, A., Joshi, R., and Ramprasad, T.: Diagenesis of magnetic minerals in a gas hydrate/cold seep environment off the KrishnaGodavari basin, Bay of Bengal, Mar. Geol., 340, 57-70, 2013.

Dick, G. J., Anantharaman, K., Baker, B. J., Li, M., Reed, D. C., and Sheik, C. S.: The microbiology of deep-sea hydrothermal vent plumes: ecological and biogeographic linkages to seafloor and water column habitats, Front. Microbiol., 4, 1-16, doi:10.3389/fmicb.2013.00124, 2013.

Dimitrova, K., Sarkisyan, A., and Koleva, V.: Vertical mussel reef farming: Exploring climate change solutions with economic and ecologic significance, Climate Engineering Research Symposium, Berlin, 2015.

Dorfman, J., Stoner, J., Finkenbinder, M., Abbott, M., Xuan, C., and St-Onge, G.: A 37,000-year environmental magnetic record of aeolian dust deposition from Burial Lake, Arctic Alaska, Quaternary Sci. Rev., 128, 81-97, 2015.

Dorn, R. I.: The Rock Varnish Revolution: New Insights from Microlaminations and the Contributions of Tanzhuo Liu, Geogr. Compass, 3, 1804-1823, 2009.
Dörr, M., Käßbohrer, J., Grunert, R., Kreisel, G., Brand, W. A., Werner, R. A., Geilmann, H., Apfel, C., Robl, C., and Weigand, W.: A possible prebiotic formation of ammonia from dinitrogen on iron sulfide surfaces, Angew. Chem. Int. Edn., 42, 1540-1543, 2003.

Drobner, E., Huber, H., Wächtershäuser, G., Rose, D., and Stetter, K. O.: Pyrite formation linked with hydrogen evolution under anaerobic conditions, Nature, 346, 742-744, 1990.

Drozd, G., Woo, J., Häkkinen, S. A. K., Nenes, A., and McNeill, V. F.: Inorganic salts interact with oxalic acid in submicron particles to form material with low hygroscopicity and volatility, Atmos. Chem. Phys., 14, 5205-5215, doi:10.5194/acp-14-52052014, 2014.

Drushel, H. V. and Hallum, J. V.: The Organic Nature of Carbon Black Surfaces. II. Quinones and Hydroquinones by Coulometry at Controlled Potential, J. Phys. Chem., 62, 1502-1505, 1958.

Duggen, S., Croot, P., Schacht, U., and Hoffmann, L.: Subduction zone volcanic ash can fertilize the surface ocean and stimulate phytoplankton growth: Evidence from biogeochemical experiments and satellite data, Geophys. Res. Lett., 34, L01612, doi:10.1029/2006GL027522, 2007.

Duprat, L. P., Bigg, G. R., and Wilton, D. J.: Enhanced Southern Ocean marine productivity due to fertilization by giant icebergs, Nat. Geosci., 9, 219-221, doi:10.1038/ngeo2633, 2016.

Eckert, S., Brumsack, H.-J., Severmann, S., Schnetger, B., März, C., and Fröllje, H.: Establishment of euxinic conditions in the Holocene Black Sea, Geology, 41, 431-434, 2013.

Eder, J. M.: Über die Zersetzung des Eisenchlorides und einiger organischer Ferridsalze im Lichte, Chem. Month., 1, 755-762, 1882.

Eder, J. M.: Ausführliches Handbuch der Photographie, Erster Band, 2. Teil: Photochemie (die chemischen Wirkungen des Lichtes), Wilhelm Knapp, Halle, Germany, 1906.

El-Jendoubi, H., Vázquez, S., Calatayud, Á., Vavpetič, P., VogelMikuš, K., Pelicon, P., Abadía, J., Abadía, A., and Morales, F.: The effects of foliar fertilization with iron sulfate in chlorotic leaves are limited to the treated area. A study with peach trees (Prunus persica L. Batsch) grown in the field and sugar beet (Beta vulgaris L.) grown in hydroponics, Front. Plant Sci., 5, 1-16, doi:10.3389/fpls.2014.00002, 2014.

Elrod, V. A., Berelson, W. M., Coale, K. H., and Johnson, K. S.: The flux of iron from continental shelf sediments: A missing source for global budgets, Geophys. Res. Lett., 31, L12307, doi:10.1029/2004GL020216, 2004.

Elvert, M., Suess, E., Greinert, J., and Whiticar, M. J.: Archaea mediating anaerobic methane oxidation in deep-sea sediments at cold seeps of the eastern Aleutian subduction zone, Org. Geochem., 31, 1175-1187, 2000.

Enami, S., Sakamoto, Y., and Colussi, A. J.: Fenton chemistry at aqueous interfaces, P. Natl. Acad. Sci. USA, 111, 623-628, 2014.

Ertel, J. R., Hedges, J. I., Devol, A. H., Richey, J. E., and Ribeiro, M. D. N. G.: Dissolved humic substances of the Amazon River system, Limnol. Oceanogr., 31, 739-754, 1986.

Evans, B. W.: Control of the products of serpentinization by the $\mathrm{Fe}_{2}+\mathrm{Mg}-1$ exchange potential of olivine and orthopyroxene, J. Petrol., 49, 1873-1887, 2008.

Fenton, H.: LXXIII. - Oxidation of tartaric acid in presence of iron, T. J. Chem. Soc., 65, 899-910, 1894. 
Fernández, V., Sotiropoulos, T., and Brown, P. H.: Foliar Fertilization: Scientific Principles and Field Pratices, International fertilizer industry association, Paris, France, 2013.

Fischer, D., Mogollón, J. M., Strasser, M., Pape, T., Bohrmann, G., Fekete, N., Spiess, V., and Kasten, S.: Subduction zone earthquake as potential trigger of submarine hydrocarbon seepage, Nat. Geosci., 6, 647-651, 2013.

Flanner, M. G., Zender, C. S., Randerson, J. T., and Rasch, P. J.: Present-day climate forcing and response from black carbon in snow, J. Geophys. Res.-Atmos., 112, D11202, doi:10.1029/2006JD008003, 2007.

Forieri, I. and Hell, R.: Micronutrient use efficiency-cell biology of iron and its metabolic interactions in plants, in: Nutrient use efficiency in plants, Springer International Publishing Switzerland, 133-152, doi:10.1007/978-3-319-10635-9, 2014.

Forster, P., Ramaswamy, V., Artaxo, P., Berntsen, T., Betts, R., Fahey, D. W., Haywood, J., Lean, J., Lowe, D. C., and Myhre, G.: Changes in atmospheric constituents and in radiative forcing, in: chap. 2, Climate Change 2007, The Physical Science Basis, http://www.ipcc.ch/pdf/assessment-report/ar4/wg1/ ar4-wg1-chapter2.pdf (last access: 8 January 2017), 2007.

Friedrich, O., Erbacher, J., Moriya, K., Wilson, P. A., and Kuhnert, H.: Warm saline intermediate waters in the Cretaceous tropical Atlantic Ocean, Nat. Geosci., 1, 453-457, 2008.

Früh-Green, G. L., Connolly, J. A., Plas, A., Kelley, D. S., and Grobéty, B.: Serpentinization of oceanic peridotites: implications for geochemical cycles and biological activity, in: The subseafloor biosphere at mid-ocean ridges, Geophys. Monogr. Ser., vol. 144, AGU, Washington, D.C., 399 pp., 2004.

Fry, J. L., Draper, D. C., Barsanti, K. C., Smith, J. N., Ortega, J., Winkler, P. M., Lawler, M. J., Brown, S. S., Edwards, P. M., and Cohen, R. C.: Secondary organic aerosol formation and organic nitrate yield from $\mathrm{NO}_{3}$ oxidation of biogenic hydrocarbons, Environ. Sci. Technol., 48, 11944-11953, 2014.

Fujita, T.: Concentration of major chemical elements in marine plankton, Geochem. J., 4, 143-156, 1971.

Galvez, M. E., Beyssac, O., Martinez, I., Benzerara, K., Chaduteau, C., Malvoisin, B., and Malavieille, J.: Graphite formation by carbonate reduction during subduction, Nat. Geosci., 6, 473-477, 2013.

Gammons, C., Parker, S., and Nimick, D.: Diel iron cycling in acidic rivers of southwestern Spain, Goechimica et Cosmochimica Acta, Pergamon - Elsevier Science Ltd, Oxford, England, A305-A305, 2007.

Gauci, V., Dise, N., and Fowler, D.: Controls on suppression of methane flux from a peat bog subjected to simulated acid rain sulfate deposition, Global Biogeochem. Cy., 16, 1004, doi:10.1029/2000GB001370, 2002.

Gauci, V., Dise, N., and Blake, S.: Long-term suppression of wetland methane flux following a pulse of simulated acid rain, Geophys. Res. Lett., 32, L12804, doi:10.1029/2005GL022544, 2005.

Gauci, V., Matthews, E., Dise, N., Walter, B., Koch, D., Granberg, G., and Vile, M.: Sulfur pollution suppression of the wetland methane source in the 20th and 21 st centuries, P. Natl. Acad. Sci. USA, 101, 12583-12587, 2004.

Gaudin, A., Buatier, M., Beaufort, D., Petit, S., Grauby, O., and Decarreau, A.: Characterization and origin of $\mathrm{Fe}_{3}^{+}$-montmorillonite in deep-water calcareous sediments (Pacific Ocean, Costa Rica margin), Clays Clay Miner., 53, 452-465, 2005.
Ghio, A. J., Soukup, J. M., Dailey, L. A., Tong, H., Kesic, M. J., Budinger, G. S., and Mutlu, G. K. M.: Wood smoke particle sequesters cell iron to impact a biological effect, Chem. Res. Toxicol., 28, 2104-2111, 2015.

Gläser, G., Wernli, H., Kerkweg, A., and Teubler, F.: The transatlantic dust transport from North Africa to the Americas - Its characteristics and source regions, J. Geophys. Res.-Atmos., 120, 11231-11252, doi:10.1002/2015JD023792, 2015.

Goos, R. J. and Johnson, B. E.: A comparison of three methods for reducing iron-deficiency chlorosis in soybean, Agron. J., 92, 1135-1139, 2000.

Gopakumar, G., Belanzoni, P., and Baerends, E. J.: Hydroxylation catalysis by mononuclear and dinuclear iron oxo catalysts: a methane monooxygenase model system versus the Fenton reagent FeIVO $\left(\mathrm{H}_{2} \mathrm{O}\right) 52^{+}$, Inorgan. Chem., 51, 63-75, 2011.

Graedel, T. E. and Keene, W.: The budget and cycle of Earth's natural chlorine, Pure Appl. Chem., 68, 1689-1697, 1996.

Gupta, D., Kim, H., Park, G., Li, X., Eom, H.-J., and Ro, C.-U.: Hygroscopic properties of $\mathrm{NaCl}$ and $\mathrm{NaNO}_{3}$ mixture particles as reacted inorganic sea-salt aerosol surrogates, Atmos. Chem. Phys., 15, 3379-3393, doi:10.5194/acp-15-3379-2015, 2015.

Haas, S., Weber, N., Berry, A., and Erich, E.: Limestone powder carbon dioxide scrubber as the technology for Carbon Capture and Usage, Cement Int., 3, 34-45, 2014.

Hadley, O. L. and Kirchstetter, T. W.: Black-carbon reduction of snow albedo, Nat. Clim. Change, 2, 437-440, 2012.

Hammer, U. T.: Saline lake ecosystems of the world, Springer Science \& Business Media, Dordrecht, the Netherlands, 1986.

Hammond, C., Forde, M. M., Rahim, A., Hasbi, M., Thetford, A., He, Q., Jenkins, R. L., Dimitratos, N., Lopez-Sanchez, J. A., and Dummer, N. F.: Direct Catalytic Conversion of Methane to Methanol in an Aqueous Medium by using Copper-Promoted FeZSM-5, Angew. Chem. Int. Edn., 51, 5129-5133, 2012.

Hansen, J., Sato, M., Hearty, P., Ruedy, R., Kelley, M., MassonDelmotte, V., Russell, G., Tselioudis, G., Cao, J., Rignot, E., Velicogna, I., Tormey, B., Donovan, B., Kandiano, E., von Schuckmann, K., Kharecha, P., Legrande, A. N., Bauer, M., and Lo, K.-W.: Ice melt, sea level rise and superstorms: evidence from paleoclimate data, climate modeling, and modern observations that $2{ }^{\circ} \mathrm{C}$ global warming could be dangerous, Atmos. Chem. Phys., 16, 3761-3812, doi:10.5194/acp-16-37612016, 2016.

Harrison, D. P.: A method for estimating the cost to sequester carbon dioxide by delivering iron to the ocean, Int. J. Global Warm., 5, 231-254, 2013.

Hauck, J., Köhler, P., Wolf-Gladrow, D., and Völker, C.: Iron fertilisation and century-scale effects of open ocean dissolution of olivine in a simulated $\mathrm{CO}_{2}$ removal experiment, Environ. Res. Lett., 11, 024007, doi:10.1088/1748-9326/11/2/024007, 2016.

Hawkes, J. A., Connelly, D., Gledhill, M., and Achterberg, E. P.: The stabilisation and transportation of dissolved iron from high temperature hydrothermal vent systems, Earth Planet. Sc. Lett., 375, 280-290, 2013.

Hawkings, J. R., Wadham, J. L., Tranter, M., Raiswell, R., Benning, L. G., Statham, P. J., Tedstone, A., Nienow, P., Lee, K., and Telling, J.: Ice sheets as a significant source of highly reactive nanoparticulate iron to the oceans, Nat. Commun., 5, 3929, doi:10.1038/ncomms4929, 2014. 
Herzog, H. J.: Scaling up carbon dioxide capture and storage: From megatons to gigatons, Energy Econ., 33, 597-604, 2011.

Hochmuth, G.: Iron (Fe) nutrition in Plants, IFAS Document SL353, US Department of Agriculture, Extension Service, University of Florida, available at: http://edis.ifas.ufl.edu/pdffiles/SS/SS55500. pdf (last access: 8 January 2017), 2011.

Hoffer, A., Kiss, G., Blazso, M., and Gelencsér, A.: Chemical characterization of humic-like substances (HULIS) formed from a lignin-type precursor in model cloud water, Geophys. Res. Lett., 31, L06115, doi:10.1029/2003GL018962, 2004.

Holm, N. G. and Neubeck, A.: Reduction of nitrogen compounds in oceanic basement and its implications for $\mathrm{HCN}$ formation and abiotic organic synthesis, Geochem. Trans., 10, 1-11, doi:10.1186/1467-4866-10-9, 2009.

Holm, N. G., Oze, C., Mousis, O., Waite, J., and Guilbert-Lepoutre, A.: Serpentinization and the formation of $\mathrm{H}_{2}$ and $\mathrm{CH}_{4}$ on celestial bodies (planets, moons, comets), Astrobiology, 15, 587-600, 2015.

Hoshyaripour, G. A., Hort, M., and Langmann, B.: Ash iron mobilization through physicochemical processing in volcanic eruption plumes: a numerical modeling approach, Atmos. Chem. Phys., 15, 9361-9379, doi:10.5194/acp-15-9361-2015, 2015.

Hossaini, R., Chipperfield, M. P., Saiz-Lopez, A., Fernandez, R., Monks, S., Brauer, P., and Glasow, R.: A global model of tropospheric chlorine chemistry: organic versus inorganic sources and impact on methane oxidation, J. Geophys. Res.-Atmos., 121, 14271-14297, doi:10.1002/2016JD025756, 2016.

Hovland, M., Kuznetsova, T., Rueslåtten, H., Kvamme, B., Johnsen, H. K., Fladmark, G. E., and Hebach, A.: Sub-surface precipitation of salts in supercritical seawater, Basin Res., 18, 221-230, 2006a.

Hovland, M., Rueslåtten, H., Johnsen, H., Kvamme, B., and Kuznetsova, T.: Salt formation associated with sub-surface boiling and supercritical water, Mar. Petrol. Geol., 23, 855-869, 2006b.

Hovland, M., Rueslåtten, H., and Johnsen, H. K.: Buried Hydrothermal Systems: The Potential Role of Supercritical Water, "ScriW", in Various Geological Processes and Occurrences in the Sub-Surface, Am. J. Anal. Chem., 5, 128-139, doi:10.4236/ajac.2014.52016, 2014.

Hu, L., Yvon-Lewis, S. A., Butler, J. H., Lobert, J. M., and King, D. B.: An improved oceanic budget for methyl chloride, J. Geophys. Res.-Oceans, 118, 715-725, 2013.

Hungate, B., Danin, A., Pellerin, N., Stemmler, J., Kjellander, P., Adams, J., and Staley, J.: Characterization of manganeseoxidizing (MnII? MnIV) bacteria from Negev Desert rock varnish: implications in desert varnish formation, Can. J. Microbiol., 33, 939-943, 1987.

Insua, T. L., Spivack, A. J., Graham, D., D’Hondt, S., and Moran, K.: Reconstruction of Pacific Ocean bottom water salinity during the Last Glacial Maximum, Geophys. Res. Lett., 41, 2914-2920, 2014.

Ito, A.: Atmospheric processing of combustion aerosols as a source of bioavailable iron, Environ. Sci. Technol. Lett., 2, 70-75, 2015.

Ito, A. and Shi, Z.: Delivery of anthropogenic bioavailable iron from mineral dust and combustion aerosols to the ocean, Atmos. Chem. Phys., 16, 85-99, doi:10.5194/acp-16-85-2016, 2016.

Ito, T., Nenes, A., Johnson, M., Meskhidze, N., and Deutsch, C.: Acceleration of oxygen decline in the tropical Pacific over the past decades by aerosol pollutants, Nat. Geosci., 9, 443-447, doi:10.1038/ngeo2717, 2016.

Ivarsson, M., Bengtson, S., and Neubeck, A.: The igneous oceanic crust - Earth's largest fungal habitat?, Fungal Ecol., 20, 249-255, 2016.

Jaccard, S. L., Galbraith, E. D., Martínez-García, A., and Anderson, R. F.: Covariation of deep Southern Ocean oxygenation and atmospheric $\mathrm{CO}_{2}$ through the last ice age, Nature, 530, 207-210, 2016.

Jacobson, M. Z.: Control of fossil-fuel particulate black carbon and organic matter, possibly the most effective method of slowing global warming, J. Geophys. Res.-Atmos., 107, ACH 16-11ACH 16-22, 2002.

Jaenicke, R.: Atmospheric aerosols and global climate, J. Aerosol Sci., 11, 577-588, 1980.

Jambeck, J. R., Geyer, R., Wilcox, C., Siegler, T. R., Perryman, M., Andrady, A., Narayan, R., and Law, K. L.: Plastic waste inputs from land into the ocean, Science, 347, 768-771, 2015.

Janecky, D. and Seyfried, W.: Hydrothermal serpentinization of peridotite within the oceanic crust: experimental investigations of mineralogy and major element chemistry, Geochim. Cosmochim. Ac., 50, 1357-1378, 1986.

Jeong, D., Kim, K., and Choi, W.: Accelerated dissolution of iron oxides in ice, Atmos. Chem. Phys., 12, 11125-11133, doi:10.5194/acp-12-11125-2012, 2012.

Jeong, J. and Guerinot, M. L.: Biofortified and bioavailable: the gold standard for plant-based diets, P. Natl. Acad. Sci. USA, 105, 1777-1778, 2008.

Jin, L., Zhang, P., Shao, T., and Zhao, S.: Ferric ion mediated photodecomposition of aqueous perfluorooctane sulfonate (PFOS) under UV irradiation and its mechanism, J. Hazard. Mater., 271, 9-15, 2014.

Johnson, K. S. and Karl, D. M.: Is ocean fertilization credible and creditable?, Science, 296, 467-468, 2002.

Johnson, K. S., Chavez, F. P., and Friederich, G. E.: Continentalshelf sediment as a primary source of iron for coastal phytoplankton, Nature, 398, 697-700, 1999.

Johnson, K. S., Moore, J. K., and Smith, W. O.: A report on the US JGOFS workshop on iron dynamics in the carbon cycle, Tech. rep., Moss Landing, California, http://jgofswww.whoi.edu/ mzweb/iron/iron_rpt.pdf (last access: 8 January 2017), 2002a.

Johnson, K. S., Moore, J. K., and Smith, W. O.: Workshop highlights iron dynamics in ocean carbon cycle, Eos, Transactions American Geophysical Union, 83, 2002b.

Johnson, L. and Eggleston, C.: The photocatalytic actions of desert varnish, University of Wyoming, Wyoming, 2013.

Johnson, M. S. and Meskhidze, N.: Atmospheric dissolved iron deposition to the global oceans: effects of oxalate-promoted $\mathrm{Fe}$ dissolution, photochemical redox cycling, and dust mineralogy, Geosci. Model Dev., 6, 1137-1155, doi:10.5194/gmd-6-11372013, 2013.

Jones, A. C., Haywood, J. M., and Jones, A.: Climatic impacts of stratospheric geoengineering with sulfate, black carbon and titania injection, Atmos. Chem. Phys., 16, 2843-2862, doi:10.5194/acp-16-2843-2016, 2016.

Jorgensen, S. S.: Dissolution kinetics of silicate minerals in aqueous catechol solutions, J. Soil Sci., 27, 183-195, 1976. 
Joughin, I., Smith, B. E., and Medley, B.: Marine ice sheet collapse potentially under way for the Thwaites Glacier Basin, West Antarctica, Science, 344, 735-738, 2014.

Kahan, T. F., Wren, S. N., and Donaldson, D. J.: A Pinch of Salt Is All It Takes: Chemistry at the Frozen Water Surface, Accounts Chem. Res., 47, 1587-1594, 2014.

Kaiho, K., Saito, R., Ito, K., Miyaji, T., Biswas, R., Tian, L., Sano, H., Shi, Z., Takahashi, S., and Tong, J.: Effects of soil erosion and anoxic-euxinic ocean in the Permian-Triassic marine crisis, Heliyon, 2, e00137, doi:10.1016/j.heliyon.2016.e00137, 2016.

Kalvelage, T., Lavik, G., Lam, P., Contreras, S., Arteaga, L., Löscher, C. R., Oschlies, A., Paulmier, A., Stramma, L., and Kuypers, M. M.: Nitrogen cycling driven by organic matter export in the South Pacific oxygen minimum zone, Nat. Geosci., 6, 228-234, 2013.

Kammler, H. K., Mädler, L., and Pratsinis, S. E.: Flame synthesis of nanoparticles, Chem. Eng. Technol., 24, 583-596, 2001.

Kappler, A., Benz, M., Schink, B., and Brune, A.: Electron shuttling via humic acids in microbial iron (III) reduction in a freshwater sediment, FEMS Microbiol. Ecol., 47, 85-92, 2004.

Karydis, V., Kumar, P., Barahona, D., Sokolik, I., and Nenes, A.: Assessing the Impact of Mineral Dust and Adsorption Activation on Cloud Droplet Formation, in: Advances in Meteorology, Climatology and Atmospheric Physics, Springer-Verlag, Berlin, Heidelberg, 515-520, doi:10.1007/978-3-642-29172-2, 2013.

Kasper, M., Sattler, K., Siegmann, K., and Matter, U.: The effect of ferrocene addition on particle formation and burnout in combustion processes, J. Aerosol Sci., 29, S617-S618, 1998.

Kastner, M.: Oceanic minerals: Their origin, nature of their environment, and significance, P. Natl. Acad. Sci. USA, Science, 96, 3380-3387, 1999.

Kawagucci, S., Chiba, H., Ishibashi, J.-i., Yamanaka, T., Toki, T., Muramatsu, Y., Ueno, Y., Makabe, A., Inoue, K., and Yoshida, N.: Hydrothermal fluid geochemistry at the Iheya North field in the mid-Okinawa Trough: Implication for origin of methane in subseafloor fluid circulation systems, Geochem. J., 45, 109-124, 2011.

Kawamura, K., Umemoto, N., Mochida, M., Bertram, T., Howell, S., and Huebert, B.: Water-soluble dicarboxylic acids in the tropospheric aerosols collected over east Asia and western North Pacific by ACE-Asia C-130 aircraft, J. Geophys. Res.-Atmos., 108, 8639, doi:10.1029/2002JD003256, 2003.

Keeling, R. F. and Shertz, S. R.: Seasonal and interannual variations in atmospheric oxygen and implications for the global carbon cycle, Nature, 358, 723-727, 1992.

Keene, W., Khalil, M. A. K., Erickson, D., McCulloch, A., Graedel, T. E., Lobert, J. M., Aucott, M. L., Gong, S. L., Harper, D. B., and Kleiman, G.: Composite global emissions of reactive chlorine from anthropogenic and natural sources: Reactive Chlorine Emissions Inventory, J. Geophys. Res.-Atmos., 104, 8429-8440, 1999.

Kelemen, P. B. and Manning, C. E.: Reevaluating carbon fluxes in subduction zones, what goes down, mostly comes up, P. Natl. Acad. Sci. USA, 112, E3997-E4006, 2015.

Kelemen, P. B. and Matter, J.: In situ carbonation of peridotite for $\mathrm{CO}_{2}$ storage, P. Natl. Acad. Sci. USA, 105, 17295-17300, 2008.

Kelemen, P. B., Matter, J., Streit, E. E., Rudge, J. F., Curry, W. B., and Blusztajn, J.: Rates and mechanisms of mineral carbonation in peridotite: natural processes and recipes for enhanced, in situ
$\mathrm{CO}_{2}$ capture and storage, Annu. Rev. Earth Planet. Sci., 39, 545576, 2011.

Kelley, D. S., Karson, J. A., Früh-Green, G. L., Yoerger, D. R., Shank, T. M., Butterfield, D. A., Hayes, J. M., Schrenk, M. O., Olson, E. J., and Proskurowski, G.: A serpentinite-hosted ecosystem: the Lost City hydrothermal field, Science, 307, 1428-1434, 2005.

Khalil, M. and Rasmussen, R.: Atmospheric methyl chloride, Atmos. Environ., 33, 1305-1321, 1999.

Khalil, M., Moore, R., Harper, D., Lobert, J., Erickson, V. K., and Keene, W.: Natural emissions of chlorine-containing gases: Reactive Chlorine Emissions Inventory, J. Geophys. Res., 104, 8333-8346, doi:10.1029/1998JD100079, 1999.

Kiesgen de Richter, R., Ming, T., and Caillol, S.: Fighting global warming by photocatalytic reduction of $\mathrm{CO}_{2}$ using giant photocatalytic reactors, Renew. Sustain. Energy Rev., 19, 82-106, 2013.

Kim, D., Song, K., and Kaushik, R: Fuel Additives for Particulate Matter/Dust Reduction, Asian J. Chem., 20, 5797-5817, 2008.

Kim, J. R., Santiano, B., Kim, H., and Kan, E.: Heterogeneous oxidation of methylene blue with surface-modified ironamended activated carbon, Am. J. Anal. Chem., 4, 34470, doi:10.4236/ajac.2013.47A016, 2013.

Kim, J.-S. and Park, K.: Atmospheric aging of Asian dust particles during long range transport, Aerosol Sci. Tech., 46, 913-924, 2012.

Kim, K., Choi, W., Hoffmann, M. R., Yoon, H.-I., and Park, B.K.: Photoreductive dissolution of iron oxides trapped in ice and its environmental implications, Environ. Sci. Technol., 44, 41424148, 2010.

Klotz, M. G. and Stein, L. Y.: Nitrifier genomics and evolution of the nitrogen cycle, FEMS Microbiol. Lett., 278, 146-156, 2008.

Klüpfel, L., Keiluweit, M., Kleber, M., and Sander, M.: Redox properties of plant biomass-derived black carbon (biochar), Environ. Sci. Technol., 48, 5601-5611, 2014.

Koch, D. and Del Genio, A. D.: Black carbon semi-direct effects on cloud cover: review and synthesis, Atmos. Chem. Phys., 10, 7685-7696, doi:10.5194/acp-10-7685-2010, 2010.

Köhler, L., Tobón, C., Frumau, K. A., and Bruijnzeel, L. S.: Biomass and water storage dynamics of epiphytes in old-growth and secondary montane cloud forest stands in Costa Rica, Plant Ecol., 193, 171-184, 2007.

Köhler, P., Hartmann, J., and Wolf-Gladrow, D. A.: Geoengineering potential of artificially enhanced silicate weathering of olivine, $\mathrm{P}$. Natl. Acad. Sci. USA, 107, 20228-20233, 2010.

Köhler, P., Abrams, J. F., Völker, C., Hauck, J., and WolfGladrow, D. A.: Geoengineering impact of open ocean dissolution of olivine on atmospheric $\mathrm{CO}_{2}$, surface ocean $\mathrm{pH}$ and marine biology, Environ. Res. Lett., 8, 014009, doi:10.1088/17489326/8/1/014009, 2013.

Köhler, P., Hauck, J., Völker, C., and Wolf-Gladrow, D.: The role of iron during the open ocean dissolution of olivine in a simulated $\mathrm{CO}_{2}$ removal experiment - enhanced weathering, ocean alkalinization, ocean fertilization, Climate Engineering Research Symposium 2015, 7-10 July 2015, Berlin, Germany, 2015.

Konhauser, K. O. and Urrutia, M. M.: Bacterial clay authigenesis: a common biogeochemical process, Chem. Geol., 161, 399-413, 1999. 
Kostka, J. E., Stucki, L. J. W., Nealson, K. H., and Wu, J.: Reduction of structural $\mathrm{Fe}$ (III) in smectite by a pure culture of the $\mathrm{Fe}$ reducing bacterium Shewanella putrifaciens strain MR-1, Clays Clay Miner., 44, 522-529, 1996.

Kraemer, S. M.: Iron oxide dissolution and solubility in the presence of siderophores, Aquat. Sci., 66, 3-18, 2004.

Krastel, S., Bialas, J., and Villwock, A.: Im fragilen Gleichgewicht: Deutsch-Neuseeländisches Forscherteam entdeckt bisher unbekanntes Methanvorkommen bei der Untersuchung von instabilen untermeerischen Hängen, Pressemitteilung 2 Juni 2014 des GEOMAR Helmholz-Zentrum für Ozeanforschung Kiel und Institut für Geowissenschaften der Christian-Albrechts-Universität zu Kiel vom 12 Mai 2014, Kiel, 2014.

Krause, S., Liebetrau, V., Gorb, S., Sánchez-Román, M., McKenzie, J. A., and Treude, T.: Microbial nucleation of Mg-rich dolomite in exopolymeric substances under anoxic modern seawater salinity: New insight into an old enigma, Geology, 40, 587-590, 2012.

Krishnamurthy, A., Moore, J. K., Mahowald, N., Luo, C., Doney, S. C., Lindsay, K., and Zender, C. S.: Impacts of increasing anthropogenic soluble iron and nitrogen deposition on ocean biogeochemistry, Global Biogeochem. Cy., 23, GB3016, doi:10.1029/2008GB003440, 2009.

Kumar, P., Robins, A., Vardoulakis, S., and Britter, R.: A review of the characteristics of nanoparticles in the urban atmosphere and the prospects for developing regulatory controls, Atmos. Environ., 44, 5035-5052, 2010.

Kuo, K. A., Watson, I., and Hunt, H. E.: The SPICE project: an example of geoengineering research, Water and Climate: Policy Implementation Challenges, Proceedings of the 2nd Practical Responses to Climate Change Conference, Engineers Australia, 13 May 2012, Canberra, Australia, 479-485, 2012.

Lackner, M.: Geoengineering for Climate Stabilization, Springer, New York, 2015.

Lam, P. J. and Bishop, J. K.: The continental margin is a key source of iron to the HNLC North Pacific Ocean, Geophys. Res. Lett., 35, L07608, doi:10.1029/2008GL033294, 2008.

Lamy, F., Gersonde, R., Winckler, G., Esper, O., Jaeschke, A., Kuhn, G., Ullermann, J., Martínez-Garcia, A., Lambert, F., and Kilian, R.: Increased dust deposition in the Pacific Southern Ocean during glacial periods, Science, 343, 403-407, 2014.

Lana, A., Bell, T., Simó, R., Vallina, S. M., Ballabrera-Poy, J., Kettle, A., Dachs, J., Bopp, L., Saltzman, E., and Stefels, J.: An updated climatology of surface dimethlysulfide concentrations and emission fluxes in the global ocean, Global Biogeochem. Cy., 25, GB1004, doi:10.1029/2010GB003850, 2011.

Laskin, A., Moffet, R. C., Gilles, M. K., Fast, J. D., Zaveri, R. A., Wang, B., Nigge, P., and Shutthanandan, J.: Tropospheric chemistry of internally mixed sea salt and organic particles: Surprising reactivity of $\mathrm{NaCl}$ with weak organic acids, J. Geophys. Res.Atmos., 117, D15302, doi:10.1029/2012JD017743, 2012.

Latham, J., Bower, K., Choularton, T., Coe, H., Connolly, P., Cooper, G., Craft, T., Foster, J., Gadian, A., Galbraith, L.: Marine cloud brightening, Philos. T. Roy. Soc. Lond. A, 370, 42174262, 2012a.

Latham, J., Parkes, B., Gadian, A., and Salter, S.: Weakening of hurricanes via marine cloud brightening (MCB), Atmos. Sci. Lett., 13, 231-237, 2012b.

Law, K. L., Moreìt-Ferguson, S. E., Goodwin, D. S., Zettler, E. R., DeForce, E., Kukulka, T., and Proskurowski, G.: Distribution of surface plastic debris in the eastern Pacific Ocean from an 11year data set, Environ. Sci. Technol., 48, 4732-4738, 2014.

Lawler, M., Finley, B., Keene, W., Pszenny, A., Read, K., Von Glasow, R., and Saltzman, E.: Pollution-enhanced reactive chlorine chemistry in the eastern tropical Atlantic boundary layer, Geophys. Res. Lett., 36, L08810, doi:10.1029/2008GL036666, 2009.

Le Bras, G. and Platt, U.: A possible mechanism for combined chlorine and bromine catalyzed destruction of tropospheric ozone in the Arctic, Geophys. Res. Lett., 22, 599-602, 1995.

Lenton, A. and Sen Gupta, A.: Carbon credits for oyster farming: fact or fiction?, Fish, 18, 1-30, 2010.

Levin, Z., Teller, A., Ganor, E., and Yin, Y.: On the interactions of mineral dust, sea-salt particles, and clouds: A measurement and modeling study from the Mediterranean Israeli Dust Experiment campaign, J. Geophys. Res.-Atmos., 110, D20202, doi:10.1029/2005JD005810, 2005.

Levine, J. G., Wolff, E. W., Jones, A. E., and Sime, L. C.: The role of atomic chlorine in glacial-interglacial changes in the carbon13 content of atmospheric methane, Geophys. Res. Lett., 38, L04801, doi:10.1029/2010GL046122, 2011.

Li, Q., Sun, H., and Wang, J.: Hydrochemical response of Epikarst Spring to rainfall: implications of nutrition element loss and groundwater pollution, Polish J. Environ. Stud., 19, 441-448, 2010.

Liao, J., Huey, L. G., Liu, Z., Tanner, D. J., Cantrell, C. A., Orlando, J. J., Flocke, F. M., Shepson, P. B., Weinheimer, A. J., and Hall, S. R.: High levels of molecular chlorine in the Arctic atmosphere, Nat. Geosci., 7, 91-94, 2014.

Lim, M., Chiang, K., and Amal, R.: Photochemical synthesis of chlorine gas from iron (III) and chloride solution, J. Photochem. Photobiol. A, 183, 126-132, 2006.

Lima, S. B., Borges, S. M. S., Rangel, M. D. C., and Marchetti, S. G.: Effect of iron content on the catalytic properties of activated carbon-supported magnetite derived from biomass, J. Brazil. Chem. Soc., 24, 344-354, 2013.

Lin, Y. C., Chen, J. P., Ho, T. Y., and Tsai, I.: Atmospheric iron deposition in the northwestern Pacific Ocean and its adjacent marginal seas: the importance of coal burning, Global Biogeochem. Cy., 29, 138-159, 2015.

Lindsay, W. and Schwab, A.: The chemistry of iron in soils and its availability to plants, J. Plant Nutr., 5, 821-840, 1982.

Lipson, D., Miller, K., and Lai, C.: Methane Suppression: The Impacts of Fe (III) and Humic Acids on Net Methane Flux from Arctic Tundra Wetlands in Alaska and Finland, AGU Fall Meeting, abstract \#B32C-02, 9-13 December 2013, San Francisco, California, 2013.

Lipson, D. A., Jha, M., Raab, T. K., and Oechel, W. C.: Reduction of iron (III) and humic substances plays a major role in anaerobic respiration in an Arctic peat soil, J. Geophys. Res.-Biogeo., 115, G00I06, doi:10.1029/2009JG001147, 2010.

Liu, D., Dong, H., Agrawal, A., Singh, R., Zhang, J., and Wang, H.: Inhibitory effect of clay mineral on methanogenesis by Methanosarcina mazei and Methanothermobacter thermautotrophicus, Appl. Clay Sci., 126, 25-32, 2016.

Liu, S., Zhang, L., Liu, Q., and Zou, J.: Fe (III) fertilization mitigating net global warming potential and greenhouse gas intensity in paddy rice-wheat rotation systems in China, Environ. Poll., 164, 73-80, 2012. 
Liu, T. and Dorn, R. I.: Understanding the spatial variability of environmental change in drylands with rock varnish microlaminations, Ann. Assoc. Am. Geogr., 86, 187-212, 1996.

Lobert, J. M., Keene, W. C., Logan, J. A., and Yevich, R.: Global chlorine emissions from biomass burning: Reactive chlorine emissions inventory, J. Geophys. Res.-Atmos., 104, 8373-8389, 1999.

Lopes, C., Kucera, M., and Mix, A. C.: Climate change decouples oceanic primary and export productivity and organic carbon burial, P. Natl. Acad. Sci. USA, 112, 332-335, 2015.

Lovley, D. R. and Blunt-Harris, E. L.: Role of humic-bound iron as an electron transfer agent in dissimilatory Fe (III) reduction, App. Environ. Microbiol., 65, 4252-4254, 1999.

Lovley, D. R., Fraga, J. L., Coates, J. D., and Blunt-Harris, E. L.: Humics as an electron donor for anaerobic respiration, Environ. Microbiol., 1, 89-98, 1999.

Luff, R. and Wallmann, K.: Fluid flow, methane fluxes, carbonate precipitation and biogeochemical turnover in gas hydrate-bearing sediments at Hydrate Ridge, Cascadia Margin: numerical modeling and mass balances, Geochim. Cosmochim. Ac., 67, 34033421, 2003.

Lukowski, A. F., Koss, M., Burden, M. J., Jonides, J., Nelson, C. A., Kaciroti, N., Jimenez, E., and Lozoff, B.: Iron deficiency in infancy and neurocognitive functioning at 19 years: evidence of long-term deficits in executive function and recognition memory, Nutr. Neurosci., 13, 54-70, doi:10.1179/147683010X12611460763689, 2013.

Luna, A., Nascimento, C., and Chiavone-Filho, O.: Photodecomposition of hydrogen peroxide in highly saline aqueous medium, Brazil. J. Chem. Eng., 23, 341-349, 2006.

Luo, C., Mahowald, N., Bond, T., Chuang, P., Artaxo, P., Siefert, R., Chen, Y., and Schauer, J.: Combustion iron distribution and deposition, Global Biogeochem. Cy., 22, GB1012, doi:10.1029/2007GB002964, 2008.

Lyubetskaya, T. and Korenaga, J.: Chemical composition of Earth's primitive mantle and its variance: 1 . Method and results, J. Geophys. Res.-Solid Ea., 112, B03211, doi:10.1029/2005JB004223, 2007.

Machulek Jr., A., Moraes, J. E. F., Okano, L. T., Silvério, C. A., and Quina, F. H.: Photolysis of ferric ions in the presence of sulfate or chloride ions: implications for the photo-Fenton process, Photochem. Photobiol. Sci., 8, 985-991, 2009.

Mackinder, L., Wheeler, G., Schroeder, D., Riebesell, U., and Brownlee, C.: Molecular mechanisms underlying calcification in coccolithophores, Geomicrobiol. J., 27, 585-595, 2010.

Madhu, S., Nagaraju, J., and Sridhar, P.: Evaluation of four stroke diesel engine performance with ferrocene as fuel additive, Int. J. Mag. Eng. Technol. Manage. Res., 2, 2199-2204, 2015.

Maekawa, T., Itoh, S., Sakata, S., Igari, S.-I., and Imai, N.: Pressure and temperature conditions for methane hydrate dissociation in sodium chloride solutions, Geochem. J., 29, 325-329, 1995.

Maher, B. A. and Dennis, P.: Evidence against dust-mediated control of glacial-interglacial changes in atmospheric $\mathrm{CO}_{2}$, Nature, 411, 176-180, 2001.

Maher, B. A., Prospero, J., Mackie, D., Gaiero, D., Hesse, P., and Balkanski, Y.: Global connections between aeolian dust, climate and ocean biogeochemistry at the present day and at the last glacial maximum, Earth-Sci. Rev., 99, 61-97, 2010.
Mahowald, N. M., Baker, A. R., Bergametti, G., Brooks, N., Duce, R. A., Jickells, T. D., Kubilay, N., Prospero, J. M., and Tegen, I.: Atmospheric global dust cycle and iron inputs to the ocean, Global Biogeochem. Cy., 19, GB4025, doi:10.1029/2004GB002402, 2005.

Mahowald, N. M., Engelstaedter, S., Luo, C., Sealy, A., Artaxo, P., Benitez-Nelson, C., Bonnet, S., Chen, Y., Chuang, P. Y., and Cohen, D. D.: Atmospheric Iron Deposition: Global Distribution, Variability, and Human Perturbations, Annu. Rev. Mar. Sci., 1, 245-278, 2009.

Mahowald, N. M., Kloster, S., Engelstaedter, S., Moore, J. K., Mukhopadhyay, S., McConnell, J. R., Albani, S., Doney, S. C., Bhattacharya, A., Curran, M. A. J., Flanner, M. G., Hoffman, F. M., Lawrence, D. M., Lindsay, K., Mayewski, P. A., Neff, J., Rothenberg, D., Thomas, E., Thornton, P. E., and Zender, C. S.: Observed 20th century desert dust variability: impact on climate and biogeochemistry, Atmos. Chem. Phys., 10, 10875-10893, doi:10.5194/acp-10-10875-2010, 2010.

Malvoisin, B., Chopin, C., Brunet, F., and Galvez, M. E.: Lowtemperature wollastonite formed by carbonate reduction: a marker of serpentinite redox conditions, J. Petrol., 53, 159-176, 2012.

Manning, A. C. and Keeling, R. F.: Global oceanic and land biotic carbon sinks from the Scripps atmospheric oxygen flask sampling network, Tellus B, 58, 95-116, 2006.

Martin, J. H.: Glacial-interglacial $\mathrm{CO}_{2}$ change: the Iron hypothesis, Paleoceanography, 5, 1-13, 1990.

Martin, J. H., Coale, K. H., Johnson, K. S., Fitzwater, S. E., Gordon, R. M., Tanner, S. J., Hunter, C. N., Elrod, V. A., Nowicki, J. L., Coley, T. L., Barber, R. T., Lindley, S., Watson, A. J., Van Scoy, K., Law, C. S., Liddicoat, M. I., Ling, R., Stanton, T., Stockel, J., Collins, C., Anderson, A., Bidigare, R., Ondrusek, M., Latasa, M., Millero, F. J., Lee, K., Yao, W., Zhang, J. Z., Friederich, G., Sakamoto, C., Chavez, F., Buck, K., Kolber, Z., Greene, R., Falkowski, P., Chisholm, S. W., Hoge, F., Swift, R., Yungel, J., Turner, S., Nightingale, P., Hatton, A., Liss, P., and Tindale, N. W.: Testing the iron hypothesis in ecosystems of the equatorial Pacific Ocean, Nature, 371, 123-129, 1994.

Martin, P., Loeff, M. R., Cassar, N., Vandromme, P., d'Ovidio, F., Stemmann, L., Rengarajan, R., Soares, M., González, H. E., and Ebersbach, F.: Iron fertilization enhanced net community production but not downward particle flux during the Southern Ocean iron fertilization experiment LOHAFEX, Global Biogeochem. Cy., 27, 871-881, 2013.

Martin, R., Wheeler, J., Ilyinskaya, E., Braban, C., and Oppenheimer, $\mathrm{C} .:$ The uptake of halogen $(\mathrm{HF}, \mathrm{HCl}, \mathrm{HBr}$ and $\mathrm{HI})$ and nitric $\left(\mathrm{HNO}_{3}\right)$ acids into acidic sulphate particles in quiescent volcanic plumes, Chem. Geol., 296, 19-25, 2012.

Martin, W. and Russell, M. J.: On the origin of biochemistry at an alkaline hydrothermal vent, Philos. T. Roy. Soc. Lond. B, 362, 1887-1926, 2007.

Martínez-Garcia, A., Rosell-Melé, A., Jaccard, S. L., Geibert, W., Sigman, D. M., and Haug, G. H.: Southern Ocean dust-climate coupling over the past four million years, Nature, 476, 312-315, 2011.

Martínez-García, A., Sigman, D .M., Ren, H., Anderson, R. F., Straub, M., Hodell, D. A., Jaccard, S. L., Eglinton, T. I., and Haug, G. H.: Iron fertilization of the Subantarctic Ocean during the last ice age, Science, 343, 1347-1350, 2014. 
Matrai, P. and Keller, M.: Total organic sulfur and dimethylsulfoniopropionate in marine phytoplankton: intracellular variations, Mar. Biol., 119, 61-68, 1994.

Matsunaga, K., Ohyama, T., Kuma, K., Kudo, I., and Suzuki, Y.: Photoreduction of manganese dioxide in seawater by organic substances under ultraviolet or sunlight, Water Res., 29, 757759, 1995.

Mayhew, L., Ellison, E., McCollom, T., Trainor, T., and Templeton, A.: Hydrogen generation from low-temperature water-rock reactions, Nat. Geosci., 6, 478-484, 2013.

McCulloch, A., Aucott, M. L., Benkovitz, C. M., Graedel, T. E., Kleiman, G., Midgley, P. M., and Li, Y. F.: Global emissions of hydrogen chloride and chloromethane from coal combustion, incineration and industrial activities: Reactive Chlorine Emissions Inventory, J. Geophys. Res.-Atmos., 104, 8391-8403, 1999.

Medeiros, D. M.: Copper, iron, and selenium dietary deficiencies negatively impact skeletal integrity: A review, Exp. Biol. Med., 241, 1316-1322, doi:10.1177/1535370216648805, 2016.

Meister, P., Gutjahr, M., Frank, M., Bernasconi, S. M., Vasconcelos, C., and McKenzie, J. A.: Dolomite formation within the methanogenic zone induced by tectonically driven fluids in the Peru accretionary prism, Geology, 39, 563-566, 2011.

Mengel, K. and Geurtzen, G.: Iron chlorosis on calcareous soils. Alkaline nutritional condition as the cause for the chlorosis, J. Plant Nutr., 9, 161-173, 1986.

Merinero, R., Lunar, R., Martínez-Frías, J., Somoza, L., and Díazdel-Río, V.: Iron oxyhydroxide and sulphide mineralization in hydrocarbon seep-related carbonate submarine chimneys, Gulf of Cadiz (SW Iberian Peninsula), Mar. Petrol. Geol., 25, 706713, 2008.

Meyer, J. and Riebesell, U.: Reviews and Syntheses: Responses of coccolithophores to ocean acidification: a meta-analysis, Biogeosciences, 12, 1671-1682, doi:10.5194/bg-12-1671-2015, 2015.

Meyer-Oeste, F.-D.: Method for Cooling the Troposphere, Int. Patent CA 2748680 A1, 2010

Meyers, P. A.: Why are the $\delta^{13} \mathrm{C}_{\text {org }}$ values in Phanerozoic black shales more negative than in modern marine organic matter?, Geochem. Geophy. Geosy., 15, 3085-3106, 2014.

Michaud, L. and Renno, N.: The sky's the limit, Mech. Eng., 133, 42-43, 2011.

Miller, K. E., Lai, C.-T., Friedman, E. S., Angenent, L. T., and Lipson, D. A.: Methane suppression by iron and humic acids in soils of the Arctic Coastal Plain, Soil Biol. Biochem., 83, 176-183, 2015

Ming, T.: Solar Chimney Power Plant Generating Technology, Academic Press, Hangzhou, China, p. 246, 2016.

Ming, T., de Richter, R., Liu, W., and Caillol, S.: Fighting global warming by climate engineering: Is the Earth radiation management and the solar radiation management any option for fighting climate change?, Renew. Sustain. Energy Rev., 31, 792-834, 2014.

Misumi, K., Lindsay, K., Moore, J. K., Doney, S. C., Bryan, F. O., Tsumune, D., and Yoshida, Y.: The iron budget in ocean surface waters in the 20th and 21 st centuries: projections by the Community Earth System Model version 1, Biogeosciences, 11, 33-55, doi:10.5194/bg-11-33-2014, 2014.

Mitchell, D. L. and Finnegan, W.: Modification of cirrus clouds to reduce global warming, Environ. Res. Lett., 4, 045102, doi:10.1088/1748-9326/4/4/045102, 2009.
Monico, L., Janssens, K., Hendriks, E., Vanmeert, F., Van der Snickt, G., Cotte, M., Falkenberg, G., Brunetti, B. G., and Miliani, C.: Evidence for Degradation of the Chrome Yellows in Van Gogh's Sunflowers: A Study Using Noninvasive In Situ Methods and Synchrotron-Radiation-Based X-ray Techniques, Angew. Chem., 127, 14129-14133, 2015.

Monnin, C., Chavagnac, V., Boulart, C., Ménez, B., Gérard, M., Gérard, E., Pisapia, C., Quéméneur, M., Erauso, G., Postec, A., Guentas-Dombrowski, L., Payri, C., and Pelletier, B.: Fluid chemistry of the low temperature hyperalkaline hydrothermal system of Prony Bay (New Caledonia), Biogeosciences, 11, 5687-5706, doi:10.5194/bg-11-5687-2014, 2014.

Moore, J. K. and Braucher, O.: Sedimentary and mineral dust sources of dissolved iron to the world ocean, Biogeosciences, 5, 631-656, doi:10.5194/bg-5-631-2008, 2008.

Moore, J. K., Doney, S. C., and Lindsay, K.: Upper ocean ecosystem dynamics and iron cycling in a global threedimensional model, Global Biogeochem. Cy., 18, GB4028, doi:10.1029/2004GB002220, 2004.

Moore, J. K., Lindsay, K., Doney, S. C., Long, M. C., and Misumi, K.: Marine ecosystem dynamics and biogeochemical cycling in the Community Earth System Model [CESM1 (BGC)]: Comparison of the 1990s with the 2090s under the RCP4.5 and RCP8.5 scenarios, J. Climate, 26, 9291-9312, 2013.

Moreno-Castilla, C., Lopez-Ramon, M., and Carrasco-Marín, F.: Changes in surface chemistry of activated carbons by wet oxidation, Carbon 38, 1995-2001, 2000.

Morrissey, J. and Guerinot, M. L.: Iron uptake and transport in plants: the good, the bad, and the ionome, Chem. Rev., 109, 4553-4567, 2009.

Müller, M. N., Barcelos e Ramos, J., Schulz, K. G., Riebesell, U., Kazmierczak, J., Gallo, F., Mackinder, L., Li, Y., Nesterenko, P. N., Trull, T. W., and Hallegraeff, G. M.: Phytoplankton calcification as an effective mechanism to alleviate cellular calcium poisoning, Biogeosciences, 12, 6493-6501, doi:10.5194/bg-126493-2015, 2015.

Müntener, O.: Serpentine and serpentinization: A link between planet formation and life, Geology, 38, 959-960, 2010.

Muscolo, A., Sidari, M., Pizzeghello, D., and Nardi, S.: Effects of humic substances isolated from earthworm faeces, Dyna. Soil Dynam. Plant, 2, 45-52, 2009.

Myriokefalitakis, S., Mihalopoulos, N., Baker, A., and Kanakidou, M.: The anthropogenic influence on Iron deposition over the oceans: a 3-D global modeling, EGU General Assembly Conference Abstracts, 27 April-2 May 2014, Vienna, Austria, p. 8310, 2014.

Myriokefalitakis, S., Daskalakis, N., Mihalopoulos, N., Baker, A. R., Nenes, A., and Kanakidou, M.: Changes in dissolved iron deposition to the oceans driven by human activity: a 3-D global modelling study, Biogeosciences, 12, 3973-3992, doi:10.5194/bg-12-3973-2015, 2015.

Naqvi, S. W. A., Bange, H. W., Farías, L., Monteiro, P. M. S., Scranton, M. I., and Zhang, J.: Marine hypoxia/anoxia as a source of $\mathrm{CH}_{4}$ and $\mathrm{N}_{2} \mathrm{O}$, Biogeosciences, 7, 2159-2190, doi:10.5194/bg7-2159-2010, 2010.

Nayak, B., Das, S. K., and Bhattacharyya, K. K.: Detrital and authigenic (?) baddeleyite $\left(\mathrm{ZrO}_{2}\right)$ in ferromanganese nodules of Central Indian Ocean Basin, Geosci. Front., 2, 571-576, doi:10.1016/j.gsf.2011.08.001, 2011. 
Nedwell, D. B. and Watson, A.: $\mathrm{CH}_{4}$ production, oxidation and emission in a UK ombrotrophic peat bog: influence of $\mathrm{SO}_{4}^{2-}$ from acid rain, Soil Biol. Biochem., 27, 893-903, 1995.

Neubeck, A., Duc, N. T., Hellevang, H., Oze, C., Bastviken, D., Bacsik, Z., and Holm, N. G.: Olivine alteration and $\mathrm{H} 2$ production in carbonate-rich, low temperature aqueous environments, Planet. Space Sci., 96, 51-61, 2014.

Nguyen, T. H. and Ball, W. P.: Absorption and adsorption of hydrophobic organic contaminants to diesel and hexane soot, Environ. Sci. Technol., 40, 2958-2964, 2006.

Nie, W., Ding, A., Wang, T., Kerminen, V.-M., George, C., Xue, L., Wang, W., Zhang, Q., Petäjä, T., and Qi, X.: Polluted dust promotes new particle formation and growth, Scient. Rep., 4, 6634, doi:10.1038/srep06634, 2014.

Nielsen, S. G., Rehkämper, M., Teagle, D. A., Butterfield, D. A., Alt, J. C., and Halliday, A. N.: Hydrothermal fluid fluxes calculated from the isotopic mass balance of thallium in the ocean crust, Earth Planet. Sc. Lett., 251, 120-133, 2006.

Oelkers, E. H., Gislason, S. R., and Matter, J.: Mineral carbonation of $\mathrm{CO}_{2}$, Elements, 4, 333-337, 2008.

Oeste, F. D.: Die $\mathrm{H}_{2} \mathrm{~S}$-Oxidation an aktiver Kohle - ein elektrochemischer Prozess?, Carbon, 15, 225-228, 1977.

Oeste, F. D.: Climate cooling by interaction of artificial loess haze with seasalt haze induced by iron- or titanium-doped ship- and aircraft-fuel, Gemeinschaftstagung DGG und GGW, Schriftenreihe der Deutschen Geologischen Gesellschaft, Geo Leipzig, Leipzig, p. 344, 2004.

Oeste, F. D.: Controlling concentration of active materials necessary for life; air pollution control, US Patents 08/534535, 2009.

Oeste, F. D.: The ISA method (IM), Climate Engineering Research Symposium 2015, Current State and Future Perspectives, Berlin, 2015.

Oeste, F. D. and Ries, E.: IOA, the $\mathrm{CO}_{2}$ - and methane-carbon capturing process: Effective and secure carbon sequestration from troposphere into ocean sediment by flue gas conditioning of coal power plants, 2nd ICEPE 2011 International Conference on Energy Process Engineering, Frankfurt am Main, Book of Extended Abstracts: Efficient carbon capture for coal power plants DECHEMA Gesellschaft für Chemische Techni \& Biotechnologie e.V., Frankfurt am Main, Frankfurt, 207-209, 2011.

Ofner, J., Krüger, H.-U., Grothe, H., Schmitt-Kopplin, P., Whitmore, K., and Zetzsch, C.: Physico-chemical characterization of SOA derived from catechol and guaiacol - a model substance for the aromatic fraction of atmospheric HULIS, Atmos. Chem. Phys., 11, 1-15, doi:10.5194/acp-11-1-2011, 2011.

Oh, S.-Y. and Chiu, P. C.: Graphite-and soot-mediated reduction of 2, 4-dinitrotoluene and hexahydro-1, 3, 5-trinitro-1, 3, 5triazine, Environ. Sci. Technol., 43, 6983-6988, 2009.

Ohman, L.-O., Nordin, A., Sedeh, I. F., and Sjoberg, S.: Equilibrium and Structural Studies of Silicon (IV) and Aluminium (111) in Aqueous Solution. 28. Formation of Soluble Silicic Acid-Ligand Complexes as Studied by Potentiometrie and Solubility Measurements, Acta Chem. Scand., 45, 335-341, 1991.

Ohshima, K. I., Fukamachi, Y., Williams, G. D., Nihashi, S., Roquet, F., Kitade, Y., Tamura, T., Hirano, D., HerraizBorreguero, L., and Field, I.: Antarctic Bottom Water production by intense sea-ice formation in the Cape Darnley polynya, Nat. Geosci., 6, 235-240, 2013.
Okin, G. S., Baker, A. R., Tegen, I., Mahowald, N. M., Dentener, F. J., Duce, R. A., Galloway, J. N., Hunter, K., Kanakidou, M., and Kubilay, N.: Impacts of atmospheric nutrient deposition on marine productivity: Roles of nitrogen, phosphorus, and iron, Global Biogeochem. Cy., 25, GB2022, doi:10.1029/2010GB003858, 2011.

Ola, O. and Maroto-Valer, M. M.: Transition metal oxide based $\mathrm{TiO}_{2}$ nanoparticles for visible light induced $\mathrm{CO}_{2}$ photoreduction, Appl. Catalys. A, 502, 114-121, 2015.

Orcutt, B. N., Sylvan, J. B., Knab, N. J., and Edwards, K. J.: Microbial ecology of the dark ocean above, at, and below the seafloor, Microbiol. Molec. Biol. Rev., 75, 361-422, 2011.

Oster, G. K. and Oster, G.: Photoreduction of Metal Ions by Visible Light, J. Am. Chem. Soc., 81, 5543-5545, 1959.

Osthoff, H. D., Roberts, J. M., Ravishankara, A., Williams, E. J., Lerner, B. M., Sommariva, R., Bates, T. S., Coffman, D., Quinn, P. K., and Dibb, J. E.: High levels of nitryl chloride in the polluted subtropical marine boundary layer, Nat. Geosci., 1, 324$328,2008$.

Otto-Bliesner, B. L., Brady, E. C., and Shields, C.: Late Cretaceous ocean: coupled simulations with the national center for atmospheric research climate system model, J. Geophys. Res.-Atmos., 107, 4019, doi:10.1029/2001JD00821, 2002.

Parekh, P., Follows, M. J., and Boyle, E.: Modeling the global ocean iron cycle, Global Biogeochem. Cy., 18, GB1002, doi:10.1029/2003GB002061, 2004.

Paull, C. K., Ussler, W., Dallimore, S. R., Blasco, S. M., Lorenson, T. D., Melling, H., Medioli, B. E., Nixon, F. M., and McLaughlin, F. A.: Origin of pingo-like features on the Beaufort Sea shelf and their possible relationship to decomposing methane gas hydrates, Geophys. Res. Lett., 34, L01603, doi:10.1029/2006GL027977, 2007.

Pechtl, S. and von Glasow, R.: Reactive chlorine in the marine boundary layer in the outflow of polluted continental air: A model study, Geophys. Res. Lett., 34, L11813, doi:10.1029/2007GL029761, 2007.

Pena, A. L., Segura, E. R., Chan, M. A., and Hoggard, E. P.: Photodegradation of dichloromethane catalyzed by iron (III) chloride on silica gel, Curr. Catalys., 3, 35-38, 2014.

Penner, J. E., Andreae, M., Annegarn, H., Barrie, L., Feichter, J., Hegg, D., Jayaraman, A., Leaitch, R., Murphy, D., and Nganga, J.: Aerosols, their direct and indirect effects, in: Climate Change 2001: The Scientific Basis, Contribution of Working Group I to the Third Assessment Report of the Intergovernmental Panel on Climate Change, Cambridge University Press, Cambridge, 289-348, 2001.

Pérez-Guzmán, L., Bogner, K., and Lower, B.: Earth's Ferrous Wheel, Nat. Educ. Knowl., 3, 32, 2010.

Pérez-Sanz, A. and Lucena, J.: Synthetic iron oxides as sources of $\mathrm{Fe}$ in a hydrophonic culture of sunflower, Iron nutrition in soils and plants, Springer Netherlands, 241-246, doi:10.1007/978-94011-0503-3_3, 1995.

Perry, R. S., Kolb, V. M., Lynne, B. Y., Sephton, M. A., Mcloughlin, N., Engel, M. H., Olendzenski, L., Brasier, M., and Staley Jr., J. T.: How desert varnish forms?, Proc. SPIE 5906, Astrobiology and Planetary Missions, 59060, doi:10.1117/12.626547, 2005.

Philpott, C. C.: Iron uptake in fungi: a system for every source, Biochim. Biophys. Ac., 1763, 636-645, 2006. 
Phrampus, B. J., Hornbach, M. J., Ruppel, C. D., and Hart, P. E.: Widespread gas hydrate instability on the upper US Beaufort margin, J. Geophys. Res.-Solid Ea., 119, 8594-8609, 2014.

Piepenbrock, A., Behrens, S., and Kappler, A.: Comparison of humic substance - and Fe (III)-reducing microbial communities in anoxic aquifers, Geomicrobiol. J., 31, 917-928, 2014.

Pignatello, J. J., Oliveros, E., and MacKay, A.: Advanced oxidation processes for organic contaminant destruction based on the Fenton reaction and related chemistry, Crit. Rev. Environ. Sci. Technol., 36, 1-84, 2006.

Pillar, E. A., Camm, R. C., and Guzman, M. I.: Catechol oxidation by ozone and hydroxyl radicals at the air-water interface, Environ. Sci. Technol., 48, 14352-14360, 2014.

Pinto, I. S., Pacheco, P. H., Coelho, J. V., Lorençon, E., Ardisson, J. D., Fabris, J. D., de Souza, P. P., Krambrock, K. W., Oliveira, L. C., and Pereira, M. C.: Nanostructured $\delta$-FeOOH: an efficient Fenton-like catalyst for the oxidation of organics in water, Appl. Catalys. B, 119, 175-182, 2012.

Platt, U., Allan, W., and Lowe, D.: Hemispheric average $\mathrm{Cl}$ atom concentration from ${ }^{13} \mathrm{C} /{ }^{12} \mathrm{C}$ ratios in atmospheric methane, Atmos. Chem. Phys., 4, 2393-2399, doi:10.5194/acp-4-2393-2004, 2004.

Polgári, M., Hein, J., Németh, T., Pál-Molnár, E., and Vigh, T.: Celadonite and smectite formation in the Úrkút Mn-carbonate ore deposit (Hungary), Sediment. Geol., 294, 157-163, 2013.

Pope, F., Braesicke, P., Grainger, R., Kalberer, M., Watson, I., Davidson, P., and Cox, R.: Stratospheric aerosol particles and solar-radiation management, Nat. Clim. Change, 2, 713-719, 2012.

Postec, A., Quéméneur, M., Méline Bes, N. M., Benaïssa, F., Payri, C., Pelletier, B., Monnin, C., Guentas-Dombrowsky, L., Ollivier, B., and Gérard, E.: Microbial diversity in a submarine carbonate edifice from the serpentinizing hydrothermal system of the Prony Bay (New Caledonia) over a 6-year period, Front. Microbiol., 6, 857, doi:10.3389/fmicb.2015.00857, 2015.

Praetorius, S., Mix, A., Walczak, M., Wolhowe, M., Addison, J., and Prahl, F.: North Pacific deglacial hypoxic events linked to abrupt ocean warming, Nature, 527, 362-366, 2015.

Pratt, K. A., Custard, K. D., Shepson, P. B., Douglas, T. A., Pöhler, D., General, S., Zielcke, J., Simpson, W. R., Platt, U., and Tanner, D. J.: Photochemical production of molecular bromine in Arctic surface snowpacks, Nat. Geosci., 6, 351-356, 2013.

Pufahl, P. and Hiatt, E.: Oxygenation of the Earth's atmosphereocean system: a review of physical and chemical sedimentologic responses, Mar. Petrol. Geol., 32, 1-20, 2012.

Raeisi, E. and Karami, G.: Hydrochemographs of Berghan karst spring as indicators of aquifer characteristics, J. Cave Karst Stud., 59, 112-118, 1997.

Rahmstorf, S.: Thermohaline Ocean Circulation. Encyclopedia of Quaternary Sciences, Postdam Institute for Climate Impact Research, Potsdam, p. 5, Elsevier, Amsterdam, http://www.pik-potsdam.de/ stefan/Publications/Book_ chapters/rahmstorf_eqs_2006.pdf (last access: 8 January 2017), 2006.

Raiswell, R. and Canfield, D. E.: The iron biogeochemical cycle past and present, Geochem. Perspect., 1, 1-2, 2012.

Raiswell, R. and Fisher, Q.: Rates of carbonate cementation associated with sulphate reduction in DSDP/ODP sediments: implica- tions for the formation of concretions, Chem. Geol., 211, 71-85, 2004.

Raiswell, R., Hawkings, J. R., Benning, L. G., Baker, A. R., Death, R., Albani, S., Mahowald, N., Krom, M. D., Poulton, S. W., Wadham, J., and Tranter, M.: Potentially bioavailable iron delivery by iceberg-hosted sediments and atmospheric dust to the polar oceans, Biogeosciences, 13, 3887-3900, doi:10.5194/bg13-3887-2016, 2016.

Raiswell, R., Benning, L. G., Tranter, M., and Tulaczyk, S.: Bioavailable iron in the Southern Ocean: the significance of the iceberg conveyor belt, Geochem. Trans., 9, 9, doi:10.1186/14674866-9-7, 2008.

Rahmstorf, S., Feulner, G., Mann, M. E., Robinson, A., Rutherford, S., and Schaffernicht, E. J.: Exceptional twentieth-century slowdown in Atlantic Ocean overturning circulation, Nat. Clim. Change, 5, 475-480, 2015.

Ramana, M., Ramanathan, V., Feng, Y., Yoon, S., Kim, S., Carmichael, G., and Schauer, J.: Warming influenced by the ratio of black carbon to sulphate and the black-carbon source, Nat. Geosci., 3, 542-545, 2010.

Ramanathan, V. and Carmichael, G.: Global and regional climate changes due to black carbon, Nat. Geosci., 1, 221-227, 2008.

Ramanathan, V., Li, F., Ramana, M., Praveen, P., and Kim, D.: Atmospheric brown clouds: hemispherical and regional variations in long-range transport, absorption, and radiative forcing, J. Geophys. Res., 112, D22S21, doi:10.1029/2006JD008124, 2007.

Rast, W., Calcagno, A., and Williams, W. D.: The Watershed: Water from the Mountains into the Sea, in: Streams And Rivers: Water Flowing Over the Land Surface, Lakes and Reservoirs, vol. 2, edited by: Programme, United Nations Environment Programme, p. 36, http://www.unep.or.jp/ietc/publications/short series/lakereservoirs-2/3.asp (last access: 8 January 2017), 2001.

Read, K. A., Mahajan, A. S., Carpenter, L. J., Evans, M. J., Faria, B. V., Heard, D. E., Hopkins, J. R., Lee, J. D., Moller, S. J., and Lewis, A. C.: Extensive halogen-mediated ozone destruction over the tropical Atlantic Ocean, Nature, 453, 1232-1235, 2008.

Reck, M., Tomasch, J., Deng, Z., Jarek, M., Husemann, P., and Wagner-Döbler, I.: Stool metatranscriptomics: A technical guideline for mRNA stabilisation and isolation, BMC Genomics, 16, 494, doi:10.1186/s12864-015-1694-y,, 2015.

Resing, J. A., Sedwick, P. N., German, C. R., Jenkins, W. J., Moffett, J. W., Sohst, B. M., and Tagliabue, A.: Basin-scale transport of hydrothermal dissolved metals across the South Pacific Ocean, Nature, 523, 200-203, 2015.

Rickard, D. and Luther, G. W.: Kinetics of pyrite formation by the $\mathrm{H}_{2} \mathrm{~S}$ oxidation of iron (II) monosulfide in aqueous solutions between 25 and $125 \mathrm{C}$ : The mechanism, Geochim. Cosmochim. Ac., 61, 135-147, 1997.

Riedel, T. P., Wolfe, G. M., Danas, K. T., Gilman, J. B., Kuster, W. C., Bon, D. M., Vlasenko, A., Li, S.-M., Williams, E. J., Lerner, B. M., Veres, P. R., Roberts, J. M., Holloway, J. S., Lefer, B., Brown, S. S., and Thornton, J. A.: An MCM modeling study of nitryl chloride $\left(\mathrm{ClNO}_{2}\right)$ impacts on oxidation, ozone production and nitrogen oxide partitioning in polluted continental outflow, Atmos. Chem. Phys., 14, 3789-3800, doi:10.5194/acp-14-37892014, 2014.

Righi-Cavallaro, K. O., Roche, K. F., Froehlich, O., and Cavallaro, M. R.: Structure of macroinvertebrate communities in riffles of a 
Neotropical karst stream in the wet and dry seasons, Acta Limnol. Brasil., 22, 306-316, 2010.

Rizzolo, J. A., Barbosa, C. G. G., Borillo, G. C., Godoi, A. F. L., Souza, R. A. F., Andreoli, R. V., Manzi, A. O., Sá, M. O., Alves, E. G., Pöhlker, C., Angelis, I. H., Ditas, F., Saturno, J., MoranZuloaga, D., Rizzo, L. V., Rosário, N. E., Pauliquevis, T., Yamamoto, C. I., Andreae, M. O., Taylor, P. E., and Godoi, R. H. M.: Mineral nutrients in Saharan dust and their potential impact on Amazon rainforest ecology, Atmos. Chem. Phys. Discuss., doi:10.5194/acp-2016-557, in review, 2016.

Roberts, J. A., Bennett, P. C., González, L. A., Macpherson, G., and Milliken, K. L.: Microbial precipitation of dolomite in methanogenic groundwater, Geology, 32, 277-280, 2004.

Roden, E. E. and Edmonds, J.: Phosphate mobilization in iron-rich anaerobic sediments: microbial Fe (III) oxide reduction versus iron-sulfide formation, Arch. Hydrobiol., 139, 347-378, 1997.

Roden, E. E. and Wetzel, R. G.: Organic carbon oxidation and suppression of methane production by microbial Fe (III) oxide reduction in vegetated and unvegetated freshwater wetland sediments, Limnol. Oceanogr., 41, 1733-1748, 1996.

Rombolà, A. D. and Tagliavini, M.: Iron nutrition of fruit tree crops, in: Iron nutrition in plants and rhizospheric microorganisms, Springer Netherlands, 61-83, 2006.

Römer, M., Torres, M., Kasten, S., Kuhn, G., Graham, A. G., Mau, S., Little, C. T., Linse, K., Pape, T., and Geprägs, P.: First evidence of widespread active methane seepage in the Southern Ocean, off the sub-Antarctic island of South Georgia, Earth Planet. Sc. Lett., 403, 166-177, 2014.

Roscoe, H., Kreher, K., and Friess, U.: Ozone loss episodes in the free Antarctic troposphere, suggesting a possible climate feedback, Geophys. Res. Lett., 28, 2911-2914, 2001.

Rose, W. I., Millard, G. A., Mather, T. A., Hunton, D. E., Anderson, B., Oppenheimer, C., Thornton, B. F., Gerlach, T. M., Viggiano, A. A., and Kondo, Y.: Atmospheric chemistry of a 33-34 hour old volcanic cloud from Hekla Volcano (Iceland): Insights from direct sampling and the application of chemical box modeling, J. Geophys. Res.-Atmos., 111, D20206, doi:10.1029/2005JD006872, 2006.

Rosenfeld, D. and Freud, E.: Number of activated CCN as a key property in cloud aerosol interactions or, more on simplicity in complex systems, WCRP First Open Science Conference, Denver, USA, 2011.

Rosenfeld, D., Lohmann, U., Raga, G. B., O’Dowd, C. D., Kulmala, M., Fuzzi, S., Reissell, A., and Andreae, M. O.: Flood or drought: how do aerosols affect precipitation?, Science, 321, 1309-1313, 2008.

Rosenfeld, D., Andreae, M. O., Asmi, A., Chin, M., Leeuw, G., Donovan, D. P., Kahn, R., Kinne, S., Kivekäs, N., and Kulmala, M.: Global observations of aerosol-cloud-precipitation-climate interactions, Rev. Geophys., 52, 750-808, 2014.

Rost, B. and Riebesell, U.: Coccolithophores and the biological pump: responses to environmental changes, Coccolithophores, Springer, Berlin, Heidelberg, 99-125, doi:10.1007/978-3-66206278-4_5, 2004.

Rubasinghege, G., Lentz, R. W., Scherer, M. M., and Grassian, V. H.: Simulated atmospheric processing of iron oxyhydroxide minerals at low $\mathrm{pH}$ : roles of particle size and acid anion in iron dissolution, P. Natl. Acad. Sci. USA, 107, 6628-6633, 2010.
Rumble, D.: Hydrothermal graphitic carbon, Elements, 10, 427433, 2014.

Rustad, D. and Gregory, N.: Photoreduction of gaseous iron (III) chloride with sunlight and other light sources, Inorgan. Nucl. Chem. Lett., 16, 521-524, 1980.

Sadanaga, Y., Hirokawa, J., and Akimoto, H.: Formation of molecular chlorine in dark condition: Heterogeneous reaction of ozone with sea salt in the presence of ferric ion, Geophys. Res. Lett., 28, 4433-4436, 2001.

Saini, R. K., Nile, S. H., and Keum, Y.-S.: Food science and technology for management of iron deficiency in humans: A review, Trends Food Sci. Technol., 53, 13-22, 2016.

Salgado, P., Melin, V., Contreras, D., Moreno, Y., and Mansilla, H. D.: Fenton reaction driven by iron ligands, J. Chil. Chem. Soc., 58, 2096-2101, 2013.

Salter, I., Schiebel, R., Ziveri, P., Movellan, A., Lampitt, R., and Wolff, G. A.: Carbonate counter pump stimulated by natural iron fertilization in the Polar Frontal Zone, Nat. Geosci., 7, 885-889, doi:10.1038/ngeo2285, 2014.

Sander, R.: Compilation of Henry's law constants (version 4.0) for water as solvent, Atmos. Chem. Phys., 15, 4399-4981, doi:10.5194/acp-15-4399-2015, 2015.

Sander, R., Burrows, J., and Kaleschke, L.: Carbonate precipitation in brine - a potential trigger for tropospheric ozone depletion events, Atmos. Chem. Phys., 6, 4653-4658, doi:10.5194/acp-64653-2006, 2006.

Sanhueza, E.: Hydrochloric acid from chlorocarbons: a significant global source of background rain acidity, Tellus B, 53, 122-132, doi:10.1034/j.1600-0889.2001.d01-11.x,, 2001.

Sanna, A., Uibu, M., Caramanna, G., Kuusik, R., and Maroto-Valer, M.: A review of mineral carbonation technologies to sequester $\mathrm{CO}_{2}$, Chem. Soc. Rev., 43, 8049-8080, 2014.

Santachiara, G., Prodi, F., and Belosi, F.: A review of thermo-and diffusio-phoresis in the atmospheric aerosol scavenging process. Part 1: Drop Scavenging, Atmos. Clim. Sci., 2, 148-158, 2012.

Schmidt, C., Vuillemin, R., Le Gall, C., Gaill, F., and Le Bris, N.: Geochemical energy sources for microbial primary production in the environment of hydrothermal vent shrimps, Mar. Chem., 108, 18-31, 2008.

Schmidt, K., Schlosser, C., Atkinson, A., Fielding, S., Venables, H. J., Waluda, C. M., and Achterberg, E. P.: Zooplankton gut passage mobilizes lithogenic iron for ocean productivity, Curr. Biol., 26, 2667-2673, 2016.

Schrag, D. P., Higgins, J. A., Macdonald, F. A., and Johnston, D. T.: Authigenic carbonate and the history of the global carbon cycle, Science, 339, 540-543, 2013.

Schrenk, M. O., Brazelton, W. J., and Lang, S. Q.: Serpentinization, carbon, and deep life, Rev. Mineral. Geochem., 75, 575606, 2013.

Sedwick, P. N., Sholkovitz, E. R., and Church, T. M.: Impact of anthropogenic combustion emissions on the fractional solubility of aerosol iron: Evidence from the Sargasso Sea, Geochem. Geophy. Geosy., 8, Q10Q06, doi:10.1029/2007GC001586, 2007.

Serov, P., Portnov, A., Mienert, J., Semenov, P., and Ilatovskaya, P.: Methane release from pingo-like features across the South Kara Sea shelf, an area of thawing offshore permafrost, J. Geophys. Res.-Ea. Surf., 120, 1515-1529, 2015. 
Shaked, Y. and Lis, H.: Disassembling iron availability to phytoplankton, Front. Microbiol., 3, 123, doi:10.3389/fmicb.2012.00123, 2012.

Shakhova, N., Semiletov, I., and Panteleev, G.: The distribution of methane on the Siberian Arctic shelves: Implications for the marine methane cycle, Geophys. Res. Lett., 32, L09601, doi:10.1029/2005GL022751, 2005.

Shakhova, N., Semiletov, I., Salyuk, A., and Kosmach, D.: Anomalies of methane in the atmosphere over the East Siberian shelf: Is there any sign of methane leakage from shallow shelf hydrates, Geophys. Res. Abstr., 10, A01526, 2008.

Sherwen, T., Evans, M. J., Carpenter, L. J., Schmidt, J. A., and Mickely, L. J.: Halogen chemistry reduces tropospheric O3 radiative forcing, Atmos. Chem. Phys. Discuss., doi:10.5194/acp2016-688, in review, 2016.

Shindell, D., Kuylenstierna, J. C., Vignati, E., van Dingenen, R., Amann, M., Klimont, Z., Anenberg, S. C., Muller, N., JanssensMaenhout, G., and Raes, F.: Simultaneously mitigating near-term climate change and improving human health and food security, Science, 335, 183-189, 2012.

Simon, J. and Klotz, M. G.: Diversity and evolution of bioenergetic systems involved in microbial nitrogen compound transformations, Biochim. Biophys. Ac., 1827, 114-135, 2013.

Simpson, W. R., von Glasow, R., Riedel, K., Anderson, P., Ariya, P., Bottenheim, J., Burrows, J., Carpenter, L. J., Frieß, U., Goodsite, M. E., Heard, D., Hutterli, M., Jacobi, H.-W., Kaleschke, L., Neff, B., Plane, J., Platt, U., Richter, A., Roscoe, H., Sander, R., Shepson, P., Sodeau, J., Steffen, A., Wagner, T., and Wolff, E.: Halogens and their role in polar boundary-layer ozone depletion, Atmos. Chem. Phys., 7, 4375-4418, doi:10.5194/acp-74375-2007, 2007.

Sissmann, O., Brunet, F., Martinez, I., Guyot, F.o., Verlaguet, A., Pinquier, Y., and Daval, D.: Enhanced olivine carbonation within a basalt as compared to single-phase experiments: reevaluating the potential of $\mathrm{CO}_{2}$ mineral sequestration, Environ. Sci. Technol., 48, 5512-5519, 2014.

Sivan, O., Adler, M., Pearson, A., Gelman, F., Bar-Or, I., John, S. G., and Eckert, W.: Geochemical evidence for iron-mediated anaerobic oxidation of methane, Limnol. Oceanogr., 56, 15361544, 2011.

Sivan, O., Antler, G., Turchyn, A. V., Marlow, J. J., and Orphan, V. J.: Iron oxides stimulate sulfate-driven anaerobic methane oxidation in seeps, P. Natl. Acad. Sci. USA, 111, E4139-E4147, 2014.

Sivan, O., Shusta, S., and Valentine, D.: Methanogens rapidly transition from methane production to iron reduction, Geobiology, 14, 190-203, 2016.

Six, K. D., Kloster, S., Ilyina, T., Archer, S. D., Zhang, K., and Maier-Reimer, E.: Global warming amplified by reduced sulphur fluxes as a result of ocean acidification, Nat. Clim. Change, 3, 975-978, 2013.

Skinner, L.: Facing future climate change: is the past relevant?, Philos. T. Roy. Soc. Lond. A, 366, 4627-4645, 2008.

Slomp, C. P., Mort, H. P., Jilbert, T., Reed, D. C., Gustafsson, B. G., and Wolthers, M.: Coupled dynamics of iron and phosphorus in sediments of an oligotrophic coastal basin and the impact of anaerobic oxidation of methane, PLOS ONE, 8, e62386, doi:10.1371/journal.pone.0062386, 2013.
Smetacek, V. and Naqvi, S.: The next generation of iron fertilization experiments in the Southern Ocean, Philos. T. Roy. Soc. Lond. A, 366, 3947-3967, 2008.

Smetacek, V., Klaas, C., Strass, V. H., Assmy, P., Montresor, M., Cisewski, B., Savoye, N., Webb, A., d'Ovidio, F., and Arrieta, J. M.: Deep carbon export from a Southern Ocean iron-fertilized diatom bloom, Nature, 487, 313-319, 2012.

Sokolik, I. N. and Toon, O. B.: Incorporation of mineralogical composition into models of the radiative properties of mineral aerosol from UV to IR wavelengths, J. Geophys. Res., 104, 9423-9444, 1999.

Solomon, E. A., Spivack, A. J., Kastner, M., Torres, M. E., and Robertson, G.: Gas hydrate distribution and carbon sequestration through coupled microbial methanogenesis and silicate weathering in the Krishna-Godavari basin, offshore India, Mar. Petrol. Geol., 58, 233-253, 2014.

Sommariva, R. and von Glasow, R.: Multiphase halogen chemistry in the tropical Atlantic Ocean, Environ. Sci. Technol., 46, 1042910437, 2012.

Song, P., Wang, Y., Pan, J., Xu, W., and Zhuang, L.: Structureactivity relationship in high-performance iron-based electrocatalysts for oxygen reduction reaction, J. Power Sour., 300, 279284, 2015.

Soreghan, G. S., Sur, S., Owens, J. D., Raiswell, R., Heavens, N. G., Natalie, M., and Lyons, T. W.: The potential biological impact of eolian delivery of reactive iron to late Paleozoic icehouse seas, 2014 GSA Annual Meeting in Vancouver, British Columbia, 2014.

Sousa, F. L., Thiergart, T., Landan, G., Nelson-Sathi, S., Pereira, I. A., Allen, J. F., Lane, N., and Martin, W. F.: Early bioenergetic evolution, Philos. T. Roy. Soc. Lond. B, 368, 20130088, doi:10.1098/rstb.2013.0088, 2013.

Southworth, B. A. and Voelker, B. M.: Hydroxyl radical production via the photo-Fenton reaction in the presence of fulvic acid, Environ. Sci. Technol., 37, 1130-1136, 2003.

Spolaor, A., Vallelonga, P., Cozzi, G., Gabrieli, J., Varin, C., Kehrwald, N., Zennaro, P., Boutron, C., and Barbante, C.: Iron speciation in aerosol dust influences iron bioavailability over glacial-interglacial timescales, Geophys. Res. Lett., 40, 1618 1623, 2013.

Storelvmo, T., Kristjansson, J., Muri, H., Pfeffer, M., Barahona, D., and Nenes, A.: Cirrus cloud seeding has potential to cool climate, Geophys. Res. Lett., 40, 178-182, 2013.

Stramma, L., Schmidtko, S., Levin, L. A., and Johnson, G. C.: Ocean oxygen minima expansions and their biological impacts, Deep-Sea Res. Pt. I, 57, 587-595, 2010.

Straub, K. L., Kappler, A., and Schink, B.: Enrichment and isolation of ferric-iron-and humic-acid-reducing bacteria, Meth. Enzymol., 397, 58-77, 2005.

Studebaker, M. L., Huffman, E., Wolfe, A., and Nabors, L.: Oxygen-containing groups on the surface of carbon black, Indust. Eng. Chem., 48, 162-166, 1956.

Suess, E., Torres, M., Bohrmann, G., Collier, R., Greinert, J., Linke, P., Rehder, G., Trehu, A., Wallmann, K., and Winckler, G.: Gas hydrate destabilization: enhanced dewatering, benthic material turnover and large methane plumes at the Cascadia convergent margin, Earth Planet. Sc. Lett., 170, 1-15, 1999.

Sullivan, R. C., Guazzotti, S. A., Sodeman, D. A., Tang, Y., Carmichael, G. R., and Prather, K. A.: Mineral dust is a sink 
for chlorine in the marine boundary layer, Atmos. Environ., 41, 7166-7179, 2007.

Sun, X. and Turchyn, A. V.: Significant contribution of authigenic carbonate to marine carbon burial, Nat. Geosci., 7, 201-204, 2014.

Sur, S., Owens, J. D., Soreghan, G. S., Lyons, T. W., Raiswell, R., Heavens, N. G., and Mahowald, N. M.: Extreme eolian delivery of reactive iron to late Paleozoic icehouse seas, Geology, 43, 1099-1102, 2015.

Swanson, K. A.: The effect of dissolved catechol on the dissolution of amorphous silica in seawater, Pennsylvania State University, Pennsylvania, 1988.

Sylvan, J. B., Toner, B. M., and Edwards, K. J.: Life and death of deep-sea vents: bacterial diversity and ecosystem succession on inactive hydrothermal sulfides, mBio, 3, e00279-11, doi:10.1128/mBio.00279-11, 2012.

Tagliabue, A. and Dutkiewicz, S.: Iron Model Intercomparison Project (FeMIP), Working Group proposal submitted to SCOR April 2016, available at: http://www.scor-int. org/AnnualMeetings/2016GM/FeMIP.pdf (last access: 8 January 2017), 2016.

Tagliabue, A., Aumont, O., DeAth, R., Dunne, J. P., Dutkiewicz, S., Galbraith, E., Misumi, K., Moore, J. K., Ridgwell, A., and Sherman, E.: How well do global ocean biogeochemistry models simulate dissolved iron distributions?, Global Biogeochem. Cy., 30, 149-174, doi:10.1002/2015GB005289, 2015.

Takashima, R., Nishi, H., Huber, B. T., and Leckie, E. M.: Greenhouse world and the Mesozoic Ocean, Oceanogr. Soc., 19, 8292, 2006.

Taylor, L. L., Quirk, J., Thorley, R. M., Kharecha, P. A., Hansen, J., Ridgwell, A., Lomas, M. R., Banwart, S. A., and Beerling, D. J.: Enhanced weathering strategies for stabilizing climate and averting ocean acidification, Nat. Clim. Change, 6, 402-406, doi:10.1038/nclimate288, 2016.

Teh, Y. A., Dubinsky, E. A., Silver, W. L., and Carlson, C. M.: Suppression of methanogenesis by dissimilatory Fe (III)-reducing bacteria in tropical rain forest soils: Implications for ecosystem methane flux, Global Change Biol., 14, 413-422, 2008.

Teixeira, A. P. C., Tristão, J. C., Araujo, M. H., Oliveira, L. C., Moura, F. C., Ardisson, J. D., Amorim, C. C., and Lago, R. M.: Iron: a versatile element to produce materials for environmental applications, J. Brazil. Chem. Soc., 23, 1579-1593, 2012.

Thakur, R. S., Chaudhary, R., and Singh, C.: Influence of pH on photocatalytic reduction, adsorption, and deposition of metal ions: speciation modeling, Desalinat. Water Treat., 56, 13351363, 2015.

Tréguer, P. and Pondaven, P.: Global change: silica control of carbon dioxide, Nature, 406, 358-359, 2000.

Tribovillard, N., Du Châtelet, E. A., Gay, A., Barbecot, F., Sansjofre, P., and Potdevin, J.-L.: Geochemistry of cold seepageimpacted sediments: Per-ascensum or per-descensum trace metal enrichment?, Chem. Geol., 340, 1-12, 2013.

Turner, D. R. and Hunter, K. A.: The biogeochemistry of iron in seawater, Wiley, Chichester, 2001.

Ünüsan, N.: The Importance of Iron on Preschool Children and Effect on Cognitive Development, Eğitim Bilimleri Dergisi, 17, 87-98, 2013.
Van Bodegom, P. M., Scholten, J. C., and Stams, A. J.: Direct inhibition of methanogenesis by ferric iron, FEMS Microbiol. Ecol., 49, 261-268, 2004.

van Helmond, N. A. G. M., Sluijs, A., Sinninghe Damsté, J. S., Reichart, G.-J., Voigt, S., Erbacher, J., Pross, J., and Brinkhuis, H.: Freshwater discharge controlled deposition of CenomanianTuronian black shales on the NW European epicontinental shelf (Wunstorf, northern Germany), Clim. Past, 11, 495-508, doi:10.5194/cp-11-495-2015, 2015.

van Kessel, M. A., Speth, D. R., Albertsen, M., Nielsen, P. H., den Camp, H. J. O., Kartal, B., Jetten, M. S., and Lücker, S.: Complete nitrification by a single microorganism, Nature, 528, 555-559, doi:10.1038/nature16459, 2015.

van Sebille, E., Wilcox, C., Lebreton, L., Maximenko, N., Hardesty, B. D., van Franeker, J. A., Eriksen, M., Siegel, D., Galgani, F., and Law, K. L.: A global inventory of small floating plastic debris, Environ. Res. Lett., 10, 124006, doi:10.1088/17489326/10/12/124006, 2015.

Vione, D., Maurino, V., Minero, C., and Pelizzetti, E.: The atmospheric chemistry of hydrogen peroxide: A review, Annali di Chimica-Roma, 93, 477-486, 2003.

von Glasow, R.: Modeling the gas and aqueous phase chemistry of the marine boundary layer, Universität Mainz, Mainz, Germany, available at: http://archimed.uni-mainz.de/pub/2001/0018/diss. pdf (last access: 8 January 2017), 2000.

von Glasow, R. and Sander, R.: Variation of sea salt aerosol pH with relative humidity, Geophys. Res. Lett., 28, 247-250, 2001.

Vorhies, J. S. and Gaines, R. R.: Microbial dissolution of clay minerals as a source of iron and silica in marine sediments, Nat. Geosci., 2, 221-225, doi:10.1038/ngeo441, 2009.

Voss, M., Bange, H. W., Dippner, J. W., Middelburg, J. J., Montoya, J. P., and Ward, B.: The marine nitrogen cycle: recent discoveries, uncertainties and the potential relevance of climate change, Philos. T. Roy. Soc. B, 368, 20130121, doi:10.1098/rstb.2013.0121, 2013.

Vu, A. T., Nguyen, N. C., and Leadbetter, J. R.: Iron reduction in the metal-rich guts of wood-feeding termites, Geobiology, 2, 239247, 2004.

Wagner Mackenzie, B., Waite, D. W., and Taylor, M. W.: Evaluating variation in human gut microbiota profiles due to DNA extraction method and inter-subject differences, Front. Microbiol., 6, 1-11, doi:10.3389/fmicb.2015.00130, 2015.

Wallmann, K., Aloisi, G., Haeckel, M., Tishchenko, P., Pavlova, G., Greinert, J., Kutterolf, S., and Eisenhauer, A.: Silicate weathering in anoxic marine sediments, Geochim. Cosmochim. Ac., 72, 2895-2918, 2008.

Wang, B., O’Brien, R. E., Kelly, S. T., Shilling, J. E., Moffet, R. C., Gilles, M. K., and Laskin, A.: Reactivity of liquid and semisolid secondary organic carbon with chloride and nitrate in atmospheric aerosols, J. Phys. Chem. A, 119, 4498-4508, 2014a.

Wang, L., Yao, Y., Zhang, Z., Sun, L., Lu, W., Chen, W., and Chen, H.: Activated carbon fibers as an excellent partner of Fenton catalyst for dyes decolorization by combination of adsorption and oxidation, Chem. Eng. J., 251, 348-354, 2014b.

Wang, P., Grover, S., and Pruppacher, H.: On the effect of electric charges on the scavenging of aerosol particles by clouds and small raindrops, J. Atmos. Sci., 35, 1735-1743, 1978.

Wang, R., Balkanski, Y., Bopp, L., Aumont, O., Boucher, O., Ciais, P., Gehlen, M., Peñuelas, J., Ethé, C., and Hauglustaine, D.: In- 
fluence of anthropogenic aerosol deposition on the relationship between oceanic productivity and warming, Geophys. Res. Lett., 42, 10745-10754, doi:10.1002/2015GL066753, 2015a.

Wang, R., Balkanski, Y., Boucher, O., Bopp, L., Chappell, A., Ciais, P., Hauglustaine, D., Peñuelas, J., and Tao, S.: Sources, transport and deposition of iron in the global atmosphere, Atmos. Chem. Phys., 15, 6247-6270, doi:10.5194/acp-15-6247-2015, 2015 b.

Wang, S. H., Hsu, N. C., Tsay, S. C., Lin, N. H., Sayer, A. M., Huang, S. J., and Lau, W. K.: Can Asian dust trigger phytoplankton blooms in the oligotrophic northern South China Sea?, Geophys. Res. Lett., 39, L05811, doi:10.1029/2011GL050415, 2012.

Wang, W., Lai, D. Y., Li, S., Kim, P. J., Zeng, C., Li, P., and Liang, Y.: Steel slag amendment reduces methane emission and increases rice productivity in subtropical paddy fields in China, Wetlands Ecol. Manage., 22, 683-691, 2014.

Wang, X., Ouyang, Z., Zhuo, S., Zhang, M., Zheng, G., and Wang, Y.: Serpentinization, abiogenic organic compounds, and deep life, Sci. China Earth Sci., 57, 878-887, 2014.

Wang, Y., Lee, K.-H., Lin, Y., Levy, M., and Zhang, R.: Distinct effects of anthropogenic aerosols on tropical cyclones, Nat. Clim. Change, 4, 368-373, 2014.

Watson, A. and Nedwell, D. B.: Methane production and emission from peat: the influence of anions (sulphate, nitrate) from acid rain, Atmos. Environ., 32, 3239-3245, 1998.

Watson, A. J., Vallis, G. K., and Nikurashin, M.: Southern Ocean buoyancy forcing of ocean ventilation and glacial atmospheric $\mathrm{CO}_{2}$, Nat. Geosci., 8, 861-864, doi:10.1038/ngeo2538, 2015.

Wayne, R. P., Poulet, G., Biggs, P., Burrows, J., Cox, R., Crutzen, P., Hayman, G., Jenkin, M., Le Bras, G., and Moortgat, G.: Halogen oxides: Radicals, sources and reservoirs in the laboratory and in the atmosphere, Atmos. Environ., 29, 2677-2881, 1995.

Weber, T., Cram, J. A., Leung, S. W., DeVries, T., and Deutsch, C.: Deep ocean nutrients imply large latitudinal variation in particle transfer efficiency, P. Natl. Acad. Sci. USA, 113, 8606-8611, doi:10.1073/pnas.1604414113, 2016.

Wei, Y., Shohag, M., Yang, X., and Yibin, Z.: Effects of foliar iron application on iron concentration in polished rice grain and its bioavailability, J. Agr. Food Chem., 60, 11433-11439, 2012.

Weiser, V., Eisenreich, N., Roth, E., and Pfeil, A.: Mechanisms of Soot Reduction in Diesel Pool Fire by Ferrocene, 3rd european combustion meeting, ECM 2007, 11-13 April 2007, Crete, Greece, http://www.stfinechem.com/wp-content/uploads/ 2015/10/1316500124.pdf (last access: 8 January 2017), 2007.

Weller, C., Tilgner, A., Bräuer, P., and Herrmann, H.: Modeling the Impact of Iron-Carboxylate Photochemistry on Radical Budget and Carboxylate Degradation in Cloud Droplets and Particles, Environ. Sci. Technol., 48, 5652-5659, 2014.

WHO: Micronutrient deficiencies: iron deficiency anemia, WHO, Geneva, available at: http://www.who.int/nutrition/topics/ida/ en/, see also http://www.who.int/nutrition/publications/en/ ida_assessment_prevention_control.pdf (last access; 8 January 2017), 2013.

WHO, FAO, and UNICEF: Recommendations on wheat and maize flour fortification meeting report: Interim consensus statement, Interim Consensus Statement, Genova, available at: http://www.who.int/nutrition/publications/micronutrients/ wheat_maize_fort.pdf (last access; 8 January 2017), 2009.
Willey, J. D., Kieber, R. J., Seaton, P. J., and Miller, C.: Rainwater as a source of Fe (II)-stabilizing ligands to seawater, Limnol. Oceanogr., 53, 1678-1684, 2008.

Williams, J., de Reus, M., Krejci, R., Fischer, H., and Ström, J.: Application of the variability-size relationship to atmospheric aerosol studies: estimating aerosol lifetimes and ages, Atmos. Chem. Phys., 2, 133-145, doi:10.5194/acp-2-133-2002, 2002.

Williamson, P., Wallace, D. W., Law, C. S., Boyd, P. W., Collos, Y., Croot, P., Denman, K., Riebesell, U., Takeda, S., and Vivian, C.: Ocean fertilization for geoengineering: a review of effectiveness, environmental impacts and emerging governance, Proc. Saf. Environ. Protect., 90, 475-488, 2012.

Wittmer, J. and Zetzsch, C.: Photochemical activation of chlorine by iron-oxide aerosol, J. Atmos. Chem., doi:10.1007/s10874-0169336-6, in press, 2016.

Wittmer, J., Bleicher, S., Ofner, J., and Zetzsch, C.: Iron (III)induced activation of chloride from artificial sea-salt aerosol, Environ. Chem., 12, 461-475, $2015 \mathrm{a}$.

Wittmer, J., Bleicher, S., and Zetzsch, C.: Iron (III)-Induced Activation of Chloride and Bromide from Modeled Salt Pans, J. Phys. Chem. A, 119, 4373-4385, 2015 b.

Wittmer, J., Bleicher, S., and Zetzsch, C.: Report on the Photochemical Induced Halogen Activation of Fe-containing Aerosols, J. Climatol. Weather Forecast., 4, 1000169, doi:10.4172/23322594.1000169, 2016.

Worman, S. L., Pratson, L. F., Karson, J., and Klein, E.: Global rate and distribution of $\mathrm{H}_{2}$ gas produced by serpentinization within oceanic lithosphere, Geophys. Res. Lett., 43, 6435-6443, doi:10.1002/2016GL069066, 2016.

Wren, S. N. and Donaldson, D. J.: How does deposition of gas phase species affect $\mathrm{pH}$ at frozen salty interfaces?, Atmos. Chem. Phys., 12, 10065-10073, doi:10.5194/acp-12-10065-2012, 2012.

Wu, Y.-H., Liao, L., Wang, C.-S., Ma, W.-L., Meng, F.-X., Wu, M., and $\mathrm{Xu}, \mathrm{X}$.-W.: A comparison of microbial communities in deepsea polymetallic nodules and the surrounding sediments in the Pacific Ocean, Deep-Sea Res. Pt. I, 79, 40-49, 2013.

Xu, H.-Q., Hu, J., Wang, D., Li, Z., Zhang, Q., Luo, Y., Yu, S.H., and Jiang, H.-L.: Visible-Light Photoreduction of $\mathrm{CO}_{2}$ in a Metal-Organic Framework: Boosting Electron-Hole Separation via Electron Trap States, J. Am. Chem. Soc., 137, 13440-13443, 2015.

Yamamoto, A., Yamanaka, Y., Oka, A., and Abe-Ouchi, A.: Ocean oxygen depletion due to decomposition of submarine methane hydrate, Geophys. Res. Lett., 41, 5075-5083, 2014.

Yehuda, S., Rabinovitz, S., Carasso, R. L., and Mostofsky, D. I.: Long-lasting cognitive, physiological and hematological effects in rehabilitated, early dietary iron-deficiency adult rats, and improvement by treatment with a mixture of essential fatty acids, Nutr. Neurosci., 11, 167-171, doi:10.1179/147683008X301568, 2008.

Yokouchi, Y., Noijiri, Y., Barrie, L., Toom-Sauntry, D., Machida, T., Inuzuka, Y., Akimoto, H., Li, H.-J., Fujinuma, Y., and Aoki, S.: A strong source of methyl chloride to the atmosphere from tropical coastal land, Nature, 403, 295-298, 2000.

Yoshizawa, K., Shiota, Y., Yumura, T., and Yamabe, T.: Direct methane-methanol and benzene-phenol conversions on Fe-ZSM5 zeolite: Theoretical predictions on the reaction pathways and energetics, J. Phys. Chem. B, 104, 734-740, 2000. 
Young, C. J., Washenfelder, R. A., Edwards, P. M., Parrish, D. D., Gilman, J. B., Kuster, W. C., Mielke, L. H., Osthoff, H. D., Tsai, C., Pikelnaya, O., Stutz, J., Veres, P. R., Roberts, J. M., Griffith, S., Dusanter, S., Stevens, P. S., Flynn, J., Grossberg, N., Lefer, B., Holloway, J. S., Peischl, J., Ryerson, T. B., Atlas, E. L., Blake, D. R., and Brown, S. S.: Chlorine as a primary radical: evaluation of methods to understand its role in initiation of oxidative cycles, Atmos. Chem. Phys., 14, 3427-3440, doi:10.5194/acp-14-34272014, 2014.

Yu, H., Chin, M., Bian, H., Yuan, T., Prospero, J. M., Omar, A. H., Remer, L. A., Winker, D. M., Yang, Y., and Zhang, Y.: Quantification of trans-Atlantic dust transport from seven-year (20072013) record of CALIPSO lidar measurements, Remote Sens. Environ., 159, 232-249, 2015a.

Yu, H., Chin, M., Yuan, T., Bian, H., Remer, L. A., Prospero, J. M., Omar, A., Winker, D., Yang, Y., and Zhang, Y.: The fertilizing role of African dust in the Amazon rainforest: A first multiyear assessment based on data from Cloud-Aerosol Lidar and Infrared Pathfinder Satellite Observations, Geophys. Res. Lett., 42, 19841991, 2015b.

Zamaraev, K. I.: Catalytic science and technology for environmental issues, Catalys. Today, 35, 3-13, 1997.

Zamaraev, K. I., Khramov, M. I., and Parmon, V. N.: Possible impact of heterogeneous photocatalysis on the global chemistry of the Earth's atmosphere, Catalys. Rev., 36, 617-644, 1994.

Zhang, H., McFarquhar, G. M., Cotton, W. R., and Deng, Y.: Direct and indirect impacts of Saharan dust acting as cloud condensation nuclei on tropical cyclone eyewall development, Geophys. Res. Lett., 36, L06802, doi:10.1029/2009GL037276, 2009.

Zhang, L., Keller, J., and Yuan, Z.: Inhibition of sulfate-reducing and methanogenic activities of anaerobic sewer biofilms by ferric iron dosing, Water Res., 43, 4123-4132, 2009.

Zhang, L., Derlon, N., Keller, J., and Yuan, Z.: Dynamic response of sulfate-reducing and methanogenic activities of anaerobic sewer biofilms to ferric dosing, J. Environ. Eng., 138, 510-517, 2012.

Zhang, X. L., Wu, G. J., Zhang, C. L., Xu, T. L., and Zhou, Q. Q.: What is the real role of iron oxides in the optical properties of dust aerosols?, Atmos. Chem. Phys., 15, 12159-12177, doi:10.5194/acp-15-12159-2015, 2015.
Zhang, Y., Shi, R., Rezaul, K. M., Zhang, F., and Zou, C.: Iron and zinc concentrations in grain and flour of winter wheat as affected by foliar application, J. Agr. Food Chem., 58, 1226812274, 2010.

Zhang, Z., Moore, J. C., Huisingh, D., and Zhao, Y.: Review of geoengineering approaches to mitigating climate change, J. Clean. Product., 103, 898-907, doi:10.1016/j.jclepro.2014.09.076, 2015.

Zhao, M.-Y., Zheng, Y.-F., and Zhao, Y.-Y.: Seeking a geochemical identifier for authigenic carbonate, Nat. Commun., 7, 10885, doi:10.1038/ncomms10885, 2016.

Zhou, S., Xu, J., Yang, G., and Zhuang, L.: Methanogenesis affected by the co-occurrence of iron (III) oxides and humic substances, FEMS Microbiol. Ecol., 88, 107-120, 2014.

Zhou, X., Zhang, Y., Wang, C., Wu, X., Yang, Y., Zheng, B., Wu, H., Guo, S., and Zhang, J.: Photo-Fenton reaction of graphene oxide: a new strategy to prepare graphene quantum dots for DNA cleavage, Acs Nano, 6, 6592-6599, 2012.

Zhu, X., Prospero, J. M., Savoie, D. L., Millero, F. J., Zika, R. G., and Saltzman, E. S.: Photoreduction of iron (III) in marine mineral aerosol solutions, J. Geophys. Res.-Atmos., 98, 9039-9046, 1993.

Ziegler, M., Diz, P., Hall, I. R., and Zahn, R.: Millennial-scale changes in atmospheric $\mathrm{CO}_{2}$ levels linked to the Southern Ocean carbon isotope gradient and dust flux, Nat. Geosci., 6, 457-461, 2013.

Zijlstra, H.: 3. Early diagenesis of chalk, in: The sedimentology of chalk, Springer-Verlag, Berlin, doi:10.1007/978-3-540-49153-8, 1995.

Zuberi, B., Johnson, K. S., Aleks, G. K., Molina, L. T., Molina, M. J., and Laskin, A.: Hydrophilic properties of aged soot, Geophys. Res. Lett., 32, L01807, doi:10.1029/2004GL021496, 2005.

Zuo, Y. and Zhang, F.:Soil and crop management strategies to prevent iron deficiency in crops, Plant Soil, 339, 83-95, 2011. 